\title{
AL-MASĀLIK WA-L-MAMĀLIK(II). CONSTRUYENDO UNA NUEVA IMAGEN DEL MUNDO: RUTEROS, GEOGRAFÍA Y CARTOGRAFÍA AL SERVICIO DE LA CAUSA ŠI'I $\bar{I}$
}

\author{
Francisco Franco-Sánchez \\ Universidad de Alicante
}

\section{RESUMEN}

Se han recogido informaciones acerca de la adscripción religiosa e ideología de los principales autores de los tratados geográficos que llevan por título Kitāb al-Masālik wa-l-mamālik $(K M M)$-y obras relacionadas-, centrándonos en la mentalidad y creencias de sus autores. Se presentan como ši ì considerado como esencial a la hora de la caracterización de sus obras. El objetivo principal de este estudio es reevaluar estas obras del $K M M$ (y alguna otra conexa) como una nueva geografía: elaborada desde una perspectiva $s^{\zeta} \bar{i} \bar{\imath}$, de origen persa, y propia del imperio 'abbāsì, definida en su esencia por la oposición al legado helenístico en la geografía las ciencias y la astronomía ptolemaica, cuyo rechazo va creciendo en Oriente entre los siglos IV y X. Muchos de estos autores presentan como no islámicas estas "ciencias de los antiguos", y este tipo de obras de $K M M$ (en especial las que se han presentado como pertenecientes a la "escuela de al-Baljī») serán el resultado de una propuesta intelectual acorde a los presupuestos de la šía. Palabras Clave: Al-Masālik wa-l-mamālik, geografía árabe medieval, cartografía árabe medieval, šì $a$, imperio 'abbāsì.

\section{AL-MASÄLIK WA-L-MAMÄLIK(II). BUILDING A NEW WORLD VIEW: ROUTE GUIDES, GEOGRAPHY AND CARTOGRAPHY AT THE SERVICE OF THE ŠI' 'I CAUSE}

\section{Abstract}

The study presents informations about the religious affiliation and ideology of the main authors of geographical treaties entitled Kitāb al-Masālik wa-l-mamälik $(K M M)$-as well as of other related works. Most of them are presented as ši $\bar{\imath} \bar{\imath}$, a subject so far hardly pointed out and formerly considered as non-relevant to the characterization of these works. The aim of this study is to re-evaluate them as a new geography from a š́ ${ }^{\prime} \bar{i}$ perspective of Persian origin, and proper to the 'abbāsi empire. Such new geography can be defined: by its opposition to the Hellenistic legacy in geography, the sciences, and the Ptolemaic astronomy, gradually contested in the East between the $4^{\text {th }}$ H. $/ 10^{\text {th }}$ C.e. centuries. Many of these authors present these «sciences of the ancients» as non-Islamic, and this type of works of $K M M$ (especially those presented as belonging to the «school of al-Baljī») result from an intellectual proposal akin to šía ideology.

Keywords: Al-Masālik wa-l-mamālik, medieval Arabic geography, medieval Arabic cartography, šìa, Abbasid empire.

DOI: https://doi.org/10.25145/j.cemyr.2018.26.05

Cuadernos del CEMrR, 26; septiembre 2018, pp. 111-170; ISSN: e-2530-8378 


\section{INTRODUCCIÓN ${ }^{1}$}

Los tratados geográficos que llevan por título Kitäb al-Masālik wa-l-mamālik ("Tratado sobre los caminos y los reinos», que abreviaremos como $K M M$, para una mayor eficacia expositiva), así como algún otro relacionado con ellos, han sido presentados como una serie de obras geográficas escritas en Oriente por autores en su mayor parte de origen persa, elaboradas en el entorno 'abbāsĩ a lo largo de los siglos IX y x. Sobre este tipo de obras se ha escrito una bibliografía inmensa, en árabe y en lenguas europeas, pero entendemos que, a pesar de ello, la panorámica resultante es heterogénea y ofrece escasa precisión. De ahí que hace tiempo tuviéramos el objetivo de investigar sobre este tema tan viejo y conocido, aplicando nuevos criterios para el análisis de estas obras geográficas.

En una monografía anterior ya expusimos la relevancia de la cartografía y de la particular visión del mundo y del Occidente musulmán que muestran los mapas de la conocida como "escuela de al-Baljī»" tema íntimamente incardinado con la estructura y fines de este conjunto de obras.

En un estudio monográfico precedente replanteamos sobre nuevos criterios el comúnmente conocido como género geográfico árabe medieval de al-Masālik wa-lmamälik. En el mismo replanteamos la cuestión a base de centrarnos en un nuevo análisis de las obras, para poner el énfasis en aspectos hasta la fecha no considerados. Para ello nos centramos en el análisis de su título (por su cualidad de etiqueta identificadora): hallamos hasta 15 obras que lo llevan (tal cual, o con variantes) y se apuntó cuál es la estructura expositiva básica y grupos en que diferenciar esta clase de ruteros y de tratados de geografía humana ${ }^{3}$.

Nuestro objetivo consiste en cambiar la consideración de una serie de características de estos tratados, hasta la fecha no vistas como relevantes para, de este modo, llegar a nuevas conclusiones acerca de la esencia y motivaciones que determinaron la elaboración de estas obras. Es sabido que fueron obras generadas en el

${ }^{1}$ Este trabajo se ha desarrollado en el marco de Proyecto de Investigación Autobiografía y cartografía como proyecciones identitarias en el islam clásico, Ref. FFI2014-58636-P, concedido por la Secretaría de Estado de Investigación, Desarrollo e Innovación del MINECO.

${ }^{2}$ F. Franco-SÁnchez, «El occidente musulmán en los mapas del Mediterráneo de la «escuela de al-Baljī (s. Iv H./x J.C.)», en A.I. Planet y F. Ramos (eds.), Relaciones hispano-marroquies: una vecindad en construcción, Madrid, Ediciones del Oriente y del Mediterráneo, 2005, pp. 35-62. Sobre la cartografía de la «escuela de al-Baljī» hemos de remitir a G.R. TiвbeTs, «The Balkhī School of Geographers", en J.B. Harley y D. Woodward (eds.), The History of Cartography. Volume Two. Book One. Cartography in the Traditional Islamic and South Asian Societies, Chicago-Londres, The University of Chicago Press, vol. II/1, pp. 108-136, así como al resumen y bibliografía complementaria que hicimos en el referido artículo sobre «El occidente musulmán».

${ }^{3}$ F. Franco-SÁnchez, "Al-Masālik wa-l-mamālik: Precisiones acerca del título de estas obras de la literatura geográfica árabe medieval y conclusiones acerca de su estructura expositiva». Philologia Hispalensis, vol. 31/2 (2017), pp. 37-66. 
centro y sede del poder 'abbāsì y que en general tenían como objetivo construir una nueva geografía coherente con el ámbito cultural y religioso musulmán ${ }^{4}$.

En el presente trabajo vamos a realizar un replanteamiento similar del género -y obras relacionadas-, centrándonos ahora en la mentalidad y creencias de sus autores, tema seńalado hasta la fecha, pero con escaso énfasis a la hora de comprobar cómo ha influido esto en sus obras. Ya André Miquel y los autores de sus biografías ${ }^{5}$ en las $E I^{1}$ y $E I^{2}$ resaltaron el carácter persa y $\check{s}^{\prime} \bar{\imath}^{-6}$ de casi todos, pero entendemos que este aspecto necesita ser recontextualizado en consonancia con las circunstancias políticas que vivió cada autor. El objetivo principal de este estudio es reevaluar estas obras del $K M M$ (y alguna otra conexa) como una geografía elaborada desde una sutil perspectiva $s_{\bar{i}} \bar{i}$, presentada como una geografía nueva, de origen persa, propia del imperio 'abbāsī, y definida en su esencia por la oposición al legado helenístico de la geografía y la astronomía ptolemaica (que muchos de estos autores presentan como no islámica). Para llegar a esta conclusión nos detendremos en la revisión detallada de cada una de las biografías de los autores más antiguos de las obras tituladas como $K M M$, así como de otros que, participando de la misma -o similar- ideología, titularon sus tratados geográficos con títulos diferentes.

${ }^{4}$ A esta geografía de los siglos IX y x le ha dedicado A. Miquel cuatro volúmenes indispensables: La géographie humaine du monde musulman jusqu'au milieu du 11e. siècle. Géographie et géographie humaine dans la littérature arabe des origines à 1050. París-La Haya, ed. Mouton \& École Pratique des Hautes Études, Tome 1, 1967, 426 pp; La géographie humaine du monde musulman jusqu'au milieu du 11e. siècle. Géographie arabe et représentation du monde: la terre et l'étranger. París-La Haya, Mouton \& École Pratique des Hautes Études, Tome 2, 1975, 705 pp; La géographie humaine du monde musulman jusqu'au milieu du 11e. siècle. Le milieu naturel. París-La Haya, Mouton \& École Pratique des Hautes Études, Tome 3, 1980, 543 pp; La géographie humaine du monde musulman jusqu'au milieu du 11e. siècle. Les travaux et les jours. París, École Pratique des Hautes Études et Sciences Sociales, Tome 4, 1988, 387 pp. En los tomos I y II estudia autores y obras, y en los otros dos desmenuza y analiza el contenido de estas y otras muchas obras geográficas.

${ }^{5} E I^{1}$ y $E I^{2}$ como acrónimos alusivos a $E I^{1}$ M.Th. Houtsma et al. (eds.), The Encyclopedia of Islam: A Dictionary of the Geography, Ethnography and Biography of the Muhammadan Peoples. Leiden/Londres, E.J. Brill/Luzac, 1913-1938. 4 tomos y 5 suplementos (Reimpr Leiden/New York/ Köln, E.J. Brill, 1993, 8 vols. +1 Suppl.). EI ${ }^{2}$ P.J. Bearman; Th. Bianquis; C.E. Bosworth; E. Donzel; W.P. Heinrichs et al. (eds.), en francés: Encyclopédie de l'Islam, nouvelle èdition, Leiden, E.J. Brill, 1960-2005. 12 vols. En inglés: The Encyclopaedia of Islam. 2nd ed. Leiden, E.J. Brill, 19602005, 12 vols.

${ }^{6} \mathrm{La}$ RAE recomienda la castellanización de este término árabe como «chií», así como "chiismo» para referirse a la rama del islam que la sunna bautizó como šša (aunque ellos prefieran la denominación de 'alīes). Usaremos el término árabe, por ser más corriente en este ámbito de estudio que su castellanización. 


\section{UNAS OBRAS GEOGRÁFICAS ESCRITAS POR AUTORES ŠI'I'IES Y EN AMBIENTES ŠI'I'IES}

Se presenta como apéndice al final de este artículo un resumen tabulado de los datos sobre las obras, autores, sus cronologías y otras particularidades tanto de los tratados titulados explícitamente como $K M M$ como de otras obras relacionadas temática y/o cronológicamente con ellos. Son datos enunciados en un estudio precedente ${ }^{7}$, que se exponen aquí organizados y tabulados.

Este resumen se ha estructurado en forma de cuadro para mayor claridad. Con una simple ojeada se pueden ver los datos de mayor relevancia que se relacionan con la composición, origen y peculiaridades de cada una de las 20 obras enunciadas. Siendo un cuadro esquemático, no hemos añadido el aparato bibliográfico de apoyo para sustentar las afirmaciones que se hacen, o que se ponen en boca de determinados investigadores citados, puesto que podrán hallarse en nuestro anterior trabajo citado. Solo los nuevos datos añadidos se documentan con notas.

Este cuadro-apéndice es, por tanto, punto de partida y un apoyo esquemático para la exposición que vamos a desarrollar en este segundo estudio dedicado a las obras de $K M M$ y a otros tratados geográficos contemporáneos emparentados con ellas.

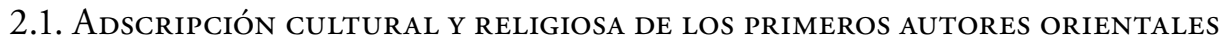 DE GEOGRAFÍA: EL KMM COMO ITINERARIOS RUTEROS Y GUÍAS DEL SERVICIO DE CORREOS EN ORIENTE}

Desde la Edad Media, hay común coincidencia en que un primer grupo de autores elaboraron una serie de obras, que titularon como $K M M$, unos ruteros enriquecidos con muchos datos geográficos, y con finalidades claramente administrativas. Lo curioso es que ya estas primeras obras fueron escritas por autores š̉̇ ìes y con finalidades específicas. Algunos datos de sus biografías nos proporcionan informaciones de sumo interés.

2.1.1. Según algunas referencias, fue un persa de nombre Abū Ŷa’far Aḥmad al-Jarrāz (m. 258/872) quien habría escrito el más antiguo y primer tratado titulado con el título de Kitāb al-masālik wa-l-mamālik ${ }^{8}$, obra perdida de la que se desconocen otros datos.

7 Ver F. FranCo-SÁNCHEZ, «Al-Masālik wa-l-mamālik».

8 «Unos autores afirman que fue Abū Ŷa'far Aḥmad Ibn al-Hāriñ Ibn al-Mubārak al-Jarrāz (m. 258/872) quien compuso el primer KMM. Según cuenta al-Marzubān̄̄-tomándolo de al-Kāni'-, dice que murió en $\underline{d} \bar{u}-l-h i \hat{y} \hat{y} \hat{y} a$ del año $258 / 872$. Era un especialista en relatos sagrados y fue reputado poeta y cliente (mawlà) de al-Manșūr. Se alojaba en la puerta de Kūfa, y allí fue enterrado. Algunos dicen que murió un año después», según relato de AL-MARZUBĀNī, Kitāb al-Muqtabis, apud. YāQūT al-Ḥamāwī, ed. ár. Iḥsān 'ABвĀs, Mu'ŷam al-'udabā'. Beirut, Dār al-Garb al-Islāmī, vol. I, p. 228. 
2.1.2. En cambio, sí que sabemos que Ŷa’far Ibn Aḥmad al-Marwazī (m. 274/887) en al-Ahwaz (Irán) escribió un $K M M$ que circuló en Bagdad'; por lo poco que sabemos de él, perece ser que su primera finalidad era la del utilitarismo administrativo, puesto que en el mismo se dice que se recogían minuciosamente los itinerarios utilizados por los antiguos servicios de correos omeyas, con la finalidad de servir de guía para tal fin.

2.1.3. Aḥmad Ibn Ṭayyib al-Sarajsī, murió en $286 / 899$ condenado por el califa 'abbāsì al-Mu’taḍid (gobierna 279-289/892-902). Sobre las circunstancias de su vida, Yāqūt aporta una versión diferente a otros autores, que dicen que el califa le confió un secreto y éste lo reveló, lo cual fue la causa de su condena y ejecución. Escribió que

la razón de su ejecución fue que invitó a al-Mu'tạ̣id a la escuela (madhab) de los filósofos y a abandonar el islam, por eso le mató. Y cuando le ejecutó le dijo: «Tú nos enseñaste que los sabios (hukamà) dicen 'los reyes no deben enfadarse y si se enfadan no deben perdonar' y si no fuera por tu enseñanza te hubiera soltado por tus antiguos servicios, pero elige la manera de tu ejecución». Eligió comer la carne y beber vino viejo hasta emborracharse, y luego fue desmembrado y le dejaron desangrarse hasta morir. Ordenó esto al-Mu'taḍid y se aplicó, pensando Aḥmad que cuando dejara de fluir su sangre moriría inmediatamente, sin pena. Y fue al revés ${ }^{10}$.

En el contexto de finales del s. III/Ix la pugna contra la filosofía de origen griego y los filósofos derivará en persecución en todo el imperio. Entre éstos, al-Kindī despunta como una notable personalidad. Las fuentes reiteran que entre los muchos discípulos del gran filósofo al-Kindī (ca. 178-261 / ca. 794-874) son citados al-Sarajsī y al-Baljī. En este motivo encontramos el sentido adecuado para entender la anterior noticia de Yāqūt, que viene a decir que era un filósofo que había participado en la formación del califa abasí al-Mu’taḍid, pero que era un mal musulmán, ya que, aun cercano a la muerte, decide tomar vino, e incluso toma una decisión errónea respecto al modo de morir ejecutado ${ }^{11}$.

9 Buena parte de los autores afirman que fue el primer autor de quien se dice que escribió una obra titulada como Kitāb al-masālik wa-l-mamālik, obra inconclusa y perdida, no conservada; tras su muerte sus libros fueron llevados a Bagdad para ser vendidos en 274/887, según IBN AL-NADĪM, apud. YĀQūT al-Ḥamāwī, Mu'ŷam al-'udabā', II, p. 776. Según Muḥammad 'Imād al-Dīn al-Iṣfahān̄̄, «Ŷa'far Ibn Aḥmad al-Marwazī, conocido por Abū l-'Abbās, era originario de al-Ahwāz, en Irán, y se

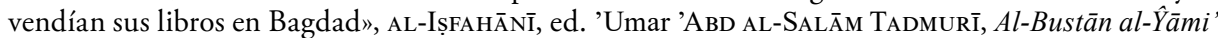
li-Ŷami' tawārīj ahl al-zamān. Beirut, al-Maktabat al-'Așrīya, 2002, p. 199.

${ }^{10}$ YĀQūT al-Ḧamāwī, Mu'ŷam al-'udabā', vol. I, pp. 287-289.

${ }^{11}$ A este respecto, esta noticia transmitida por Yāqūt encierra una ironía implícita: el médico y filósofo al-Kindī (m. 261/874) fue el primer gran filósofo de la medicina árabe. Al-Kindī concibe la gradualidad del efecto de los fármacos, afirmando que, en la elaboración de los compuestos, a un aumento geométrico de la cantidad de los componentes ha de corresponder un aumento aritmético de sus efectos. De este modo, de poco le sirvió el vino ingerido por al-Sarajsī para atenuar el tormento hasta llegar a la muerte, puesto que Yāqūt afirma que no perdió la conciencia del dolor en sus últimos momentos. Sugiere claramente que el vino no actuó como un medicamento al uso, pues no es fármaco, sino bebida embriagante. 
Es curioso que, aunque fuera perseguido por ser filósofo, varios autores han transmitido noticia de su rechazo hacia la astrología y la astronomía. Por el estudio de Franz Rosenthal sobre su personalidad, sabemos de su vasta producción en temas relacionados con las "ciencias de los antiguos" griegos $^{12}$, en especial en filosofía, y en su tesis doctoral G. de Vaulx d'Arcy aporta una relación de obras de al-Sarajsī en la que se añade un "Libro de introducción a la astronomía», junto con otros de aritmética, música, lógica gramatical, varios de temas filosóficos, etc. ${ }^{13}$.

2.1.4. El tercer tratado conocido de $K M M$, el primero preservado (aunque solo parcialmente), es el escrito por 'Ubayd Allāh Ibn 'Abd Allāh (o Ibn Aḥmad) Ibn Jurradāḍbih (m. 272/885 o 300/912), personalidad de quien tenemos más datos biográficos. Este historiador y geógrafo del s. III era de origen persa (era de Jurasān), de familia y religión zoroastriana (zarādištīya), luego se convirtió en musulmán al servir a los visires barmakíes. Hay discrepancias sobre las fechas de su nacimiento y muerte: se cita el 205/820 o el 211/826. Inmigró de joven y creció en Bagdad, en donde comenzó su esmerada educación con su propio padre, y escogió el arte y la música de mano del músico más famoso de su época, Isḥāq al-Mawsīlī. En la época del califa al-Watīiq bi-1lāh (227-232/842-847) desempeñó el cargo del Șāhib al-Barīd wa-l-jabar entre 227/842 y 232/846-7. Al parecer su trabajo le llevó a ampliar su conocimiento sobre el estado de los caminos y de las provincias, en relación con el pago del impuesto obligatorio (jarāŷy), recogiendo también características geográficas y administrativas del Irán y de las regiones musulmanas y no musulmanas. La razón de compilar este libro fue su cercanía al califa 'abbāsī al-Mu'tamid (255-279/869-892), pues asistía a sus sesiones literarias (maŷallis). Ibn al-Nadìm enumera ocho títulos de obras de su autoría ${ }^{14}$, entre los que solo destacaremos un Kitāb al-anwā', tratado astronó-

12 F. Rosenthal, Ahmad b. at-Tayyib as-Sarahsī. A Scholar and a Littérateur of the Ninth Century. New Haven, CONN., American Oriental Society, 1943.

${ }^{13}$ G. de VAulX D’Arcy, Les Épîtres des Frères en Pureté (Rasā’il Ihwān aṣ-ṣafā) une pensée de la totalité. Établissement de la paternité historique et commentaire philosophique de l'ouvrage, tesis doctoral defendida el 19 noviembre de 2016 en la Université Paris-Sorbonne (École Doctorale v), dirigida por M. Marwan Rashed, pp. 107-109. Esta enunciación de obras es uno de los argumentos de base para, tras su comparación (p. 108) con los temas de algunas epístolas de los Ijwān al-Ṣafāa', sostener que al-Sarajsì habría participado de modo preferente en la autoría de las Rasă’ $i l$.

${ }_{14}$ Ibn al-Nadīm enumera las siguientes: «Adab al-samā' 'Tratado sobre la etiqueta y la audición musical', YYamharat ansab al furs wa-l-nawāqil 'Libro sobre genealogías de los persas y los pueblos deportados', Kitāb al-Masālik wa-l-mamālik, Kitāb al-tabīj 'Tratado de cocina', Kitāb al-šarāb 'Libro de las bebidas', Al-Lahu wa-l-malāh $\overline{~ ' T r a t a d o ~ s o b r e ~ e l ~ l a u ́ d ~ y ~ l o s ~ i n s t r u m e n t o s ~ m u s i c a l e s ', ~ K i t a ̄ b ~}$ al-nudamā' wa-l-ŷlas $\bar{a}$ ', Kitāb al-anwā' 'Libro sobre el ascenso de las estrellas y las constelaciones'. Otras fuentes le atribuyen otros dos libros que son Al-Kabīr fīl-ta'rīj y unas 'historias' (wa-Ajbār Ibn Jurradaḍbih)", apud. ed. ár., trad. fr., M.J. de Goeje, Kitâb al-Masâlik wa'l-Mamâlik (Liber Viarum et Regnorum) auctori Abu'l Kâsim Obaidalla ibn Abdallah Ibn Khordâdhbeh et excerpta e Kitâb alKharâdj auctori Kodâma ibn Dja' far, quae cum versione gallica edidit, indicibus et Glosario instruixit M.J. de Goeje. Leiden, E.J. Brill (BGA vi), 1889, p. xx de su «Introducción». De todas estas obras se conservan solo dos libros: KMM y su tratado musical Mujtậr min al-Lahu wa-l-malāhī. 
mico no conservado ${ }^{15}$. Al-Jațīb al-Bagdādī solo enuncia cinco de estas obras ${ }^{16}$, sin citar esta última.

En su $K M M$ también incluyó informaciones no estrictamente geográficas, sino de literatura, cocina u otras lecturas recogidas, motivo que le granjeó severas críticas por otros autores, comenzando por el propio al-Mas'ūìi, quien definió su baja opinión sobre el $K M M$ del siguiente modo: «Es bueno en lo que toca a rutas y distancias, pero sin información sobre los gobernantes y sus territorios y, en consecuencia, solo es útil para los correos» ${ }^{17}$. Por idéntico motivo Abū l-Farāŷ al-Ișfahānī también tenía una baja opinión de esta obra, que recogió Yāqūt al-Hamawīi ${ }^{18}$.

2.1.5. Relacionado con la obra anterior hemos de mencionar el Kitāb al-masālik de al-Ŷayhānī. Sobre la personalidad de este autor ya indicamos que Ch. Pellat explicó la heterogeneidad de noticias sobre él, aparentemente irreconciliables, concluyendo que el Kitāb al-Masālik era una obra familiar en la que habrían intervenido tres miem-

15 Podemos suponer que este perdido Kitāb al-anwā' habría tenido contenidos similares al de idéntico título escrito por su contemporáneo Ibn Qutayba (213-276/828-889), éste sí conservado y editado por M. Hamidullah; Ch. Pellat, Kitāb al-anwāa'. Hyderabad, 1375/1934. El resumen del contenido de tratado de Ibn Qutayba sería: introducción corta. Descripción detallada de las veintiocho casas grandes lunares (pp. 4-88), que contiene mucha información de otras estrellas adyacentes y constelaciones. Seguido de tradiciones meteorológicas acerca de ellos (pp. 88-94). Le siguen las tradiciones meteorológicas relacionadas con ellas (pp. 88-94). Sigue otro saber astrometeorológico (pp. 94-120), principalmente sobre las estaciones y eventos en la vida de los beduinos. Luego, se proporciona información astronómica sobre los doce signos zodiacales (p. 120); sobre los polos (p. 122); sobre la Vía Láctea (p. 123); sobre las esferas celestes (p. 124); sobre los planetas (p. 126); el sol y la luna (p. 138); sobre los ascendentes, colocaciones y amaneceres (pp. 141, 142, 143), y sobre estrellas fijas famosas (las que no están incluidas en el pasaje de las mansiones lunares, pp. 145-158). Trata luego de los fenómenos meteorológicos: vientos, lluvia, nubes, relámpagos y truenos, y de la predicción de la lluvia. Finalmente, con diferentes formas, trata de explicar algunas constelaciones (p. 182) y el uso de las estrellas para la orientación (al-ihtidā', p. 186), P. Kunitzsch, «Ibn Qutayba», Dictionary of Scientific Biography. Nueva York, Charles Scribner's Sons, vol. 11 (1981), pp. 246-247.

16 «Escribió tanto el KMM como otras obras, tales como Kitāb al-nudamā' wa-l-ŷlasā, Al-Lahu wa-l-malāhī, Kitāb al-tabj 'Libro de cocina', Kitāa al-šarāb 'Libro de las bebidas'”, AL-JAț̣̄B AL-BAGDĀDĪ, Tārīj Bagdad wa- $\underline{d} u y \bar{u} l u-h u$, ed. Mușțafà 'Abd al-Qādir 'AțțĀ. Beirut, Dār al-Kutub al-'Ilmīya, 1417/1996.7, vol. 17, p. 10.

${ }_{17}$ Al-Mas'ūdī, Kitāb murūŷy ad- $\underline{d} a h a b$, ed. ár., trad. fr. Ch. Pellat, Mas'ūdī. Les Prairies d'or. Beirut, Publications de l'Université Libanaise, 1962-1965, vol. I, p. 241. C.E. Bosworth, «Ebn Kordāḍbeh (or Korradāḍbeh), Abu'l-Qāsem 'obayd-Allāh b. 'Abd-Allāh», Encyclopæedia Iranica. Londres, 1982, vol. viII, pp. 37-38. En línea: http://www.iranicaonline.org/articles/ebn-kordadbeh [consultado: 03/05/2018].

${ }^{18}$ Yāqūt recoge que «su abuelo era zoroastriano, que se convirtió al islam por presión de los visires barmakíes. Se encargó [de la Jefatura] del Correo y de la Inteligencia (tawallà al-barìd $w a-l-j a b \bar{a} r$ ) en la provincia (nawāhi) de al-Ŷabal. Era un confidente y amigo de al-Mu'tamid (256279/870-92) y le contaba noticias y relatos literarios ( $a d a b)$. Incluyó en sus escritos "maravillas" y noticias verdaderamente raras, hasta que dijeron algunos, al copiar su obra 'tal como lo dijo (kad̄a za'ama) Ibn Jurradāḍbih y si fuera mentira, sería su responsabilidad'. Cuando Abū l-Farāŷ al-Ișfahānī recogía algo de él en su obra, lo menospreciaba diciendo 'no comprueba lo que recoge en sus escritos (inna-hu qalīl al-tașhịh li-mā yarwīhi wa-yudaminu-hu kutubu-hu)'», YĀQūT al-Ḥamāwī, Mu'ŷam al-'udabä', vol. IV, p. 1573 . 
bros de este linaje, quienes habrían realizado una autoría continuada ${ }^{19}$; el tercero la habría concluido en los años inmediatamente posteriores a 330/941-2.

Este $K M[\mathrm{M}]$ no ha perdurado, pero debió de completar la obra homónima de Ibn Jurradādbih, con el cual se confunde en numerosas ocasiones.

Añade al-Muqaddasī que al-Ŷayhānī había reunido e interrogado a los viajeros venidos del extranjero para informarse acerca de sus estados, sus recursos, sus vías de comunicación, la altura de los astros y la posición que toma su sombra. Completa afirmando que esto tenía como finalidad llegar a conquistar estos países y conocer sus recursos; seguidamente le reprocha el que habiendo desarrollado la geografía física de los países descritos, hubiera olvidado datos de importancia ${ }^{20}$. Gardīzī informa que al-Ŷayhānī escribió misivas a sus corresponsales, que residían en zonas que iban desde Bizancio a China, y de ellos habría obtenido todo tipo de datos por escrito $^{21}$. Está claro que el acopio de datos reunidos en ambas obras se debe a que sus dos autores estaban en una posición administrativa de privilegio para conseguir datos geográficos valiosos.

De hecho Ibn Hawqal afirma que desde el inicio de sus viajes, allá por 331/943, y durante muchos años, llevará como guías los tratados de Ibn Jurradādbih, al-Ŷayhānī y de Qudāma Ibn Ŷa'far ${ }^{22}$, pero él lamenta haber poseído los dos primeros, pues «han acaparado su espíritu», mientras que no les muestra ningún aprecio. La explicación posiblemente se deba a que sus dos autores habían estado cercanos e imbuidos por el entorno de los filósofos, que tanto odiaban los šs' '̀es (a mediados del s. x). En este sentido, otro autor šš̀ $’$ como al-Muqaddasī califica a al-Abū 'Abd Allāh al-Ŷayhānī de filósofo y astrólogo, colocándole las dos etiquetas del repudio.

2.1.6. Aunque no titulara su obra como KMM, al-Ya'qūbī (m. 284/897) es autor de un Kitāb al-buldān, obra conservada incompleta pero etiquetada de otro modo, que parece ser tuvo alguna cartografía, hoy también perdida. Se trata de una obra geográfica creada en el mismo entorno y con finalidades similares a las apuntadas, motivo por el que, sin pertenecer por título al género, debe ser considerada como directamente emparentada con el grupo de los $K M M$. A. Miquel alaba su arrojo personal y deseo de sostener un «racionalismo pegado a la tierra», un repudio de un adab "de gabinete» como sistema cultural exclusivo ${ }^{23}$. Pero sobre unas asentadas convic-

19 Ch. Pellat, «Al-Djayhānī», $E I^{2}$, 2004, vol. xII, Supplement, p. 265.

${ }^{20} B G A$ ini, pp. 3-4 (esto es, ed. ár. de la obra de Ibn ḤaWQal de M.J. de Goeje, Bibliotheca Geographorum Arabicorum. Pars Tertia. Descriptio Imperii Moslemici auctore Al-Mokaddasi. Leiden, E.J. Brill, 1877, pp. 3-4).

${ }^{21}$ Opus cit., nota 19.

22 Ibn HawqaL, ed. ár. J.H. Kramers, Opvs Geographicvm auctore Ibn Hawkal (Abū l-Kāsim Ibn Hawkal al-Nașībī). Secundum textum et imagenes Codicis Constantinopolitani conservati in Bibliotheca antiqui Palatii núm. 3346 cui titulus est "Liber Imaginis Terrae». Leiden, E.J. Brill, 1938, p. 329. Trad. fr. J.H. Kramers; G. Wiet, Ibn Hawqal. Configuration de la Terre (Kitāb Șūrat al-Arụ). Beirut-París, Maisonneuve et Larose / Comission Internationale pour la Traduction des Chefs-Oeuvre, 1964, p. 322.

${ }^{23}$ A. Miquel, La géographie humaine, t. I, p. 287. 
ciones šš '̄es, estos viajes por el Oriente conocido ${ }^{24}$ afirma A. Miquel que estaríamos tentados de interpretarlos como los realizados por los $d u^{\prime} a \bar{t}$ (misioneros o agentes, sing. $\left.d a^{\prime} \bar{\imath}\right) \bar{s} \grave{s}^{\prime} \bar{\imath} e s$, cuyos viajes estaban en buena parte destinados a extender sus propias convicciones religiosas, en calidad de misioneros. Miquel afirma que al-Ya'qūbī está «en las antípodas de este tipo de aventurero turbulento y ya picaresco que se encarna en un Ibn Hawqal o un al-Muqaddasi $\rangle^{25}$; opina que sus viajes parecen haber sido los de un gran administrador y, aparte, en la época en que él escribe, la propa-

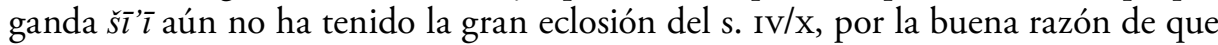
la ruptura, a pesar de sangrientos enfrentamientos, aún no se ha consumado entre los šs'îes y el califato 'abbāsì (siempre tan hábil para mantener vivas ciertas esperanzas del partido de los 'alies). En su opinión, su autor, aun siendo šs' '̄i no había pertenecido al grupo de los misioneros militantes políticamente activos. Pero esto no indica que estas creencias no influyeran en alguna medida en la concepción de su obra, profundamente influida por concepciones persas.

Como una primera conclusión, los autores de este grupo oriental inicial de $K M M$ poseen una serie de aspectos en común y algunas divergencias:

- Apenas nada sabemos de al-Jarrāz (m. 258/872) y al-Marwazī (m. 274/887), pero este último y al-Ya'qūbī (m. 284/897) eran šš̀ies. Al-Sarajsī (m. 286/899) sabemos que frecuentó ambientes jāriŷ̀̃es y quizás fue también filo-šlı $\bar{l}$; tenemos datos de que al-Sarajsī vivió en la corte del califa al-Mu'taḍid, en un ambiente de relativa liberalidad. En cambio, en la obra de al-Ya'qūbī, las creencias šš '̀es se muestran claramente: en su hostilidad hacia los omeyas y en su atracción por la figura de 'Alī; utiliza fuentes š̉ı' ies (procedentes del sexto imām, Ŷa'far al-Ṣādiq). En contraste, Ibn Jurradāḍbih (m. ca. 300/912) es de familia zoroastriana, converso al islam (sin más detalles), y los alŶayhānī (desp. 330/941-2) fueron visires sāmānies (un imperio sunnī iraní que gobernó desde 819 a 999).

- Todos ellos hacen una serie de obras con la finalidad de reunir en una guía lo que necesitan saber los altos representantes de la administración: Al-Marwazī elabora un rutero en que recogen los itinerarios del servicio de correos omeyas, un manual para uso de funcionarios. Al-Sarajsī vive en la propia corte 'abbāsī, en la que desempeñó algunos cargos oficiales (vigilancia de la hisba los lunes, reparto de las herencias los martes y mercado de los esclavos el miércoles), de modo que tuvo acceso fácil a la información que habrá de reflejar en su desaparecido $K M M$. Ibn Jurradāḍbih, jefe del Servicio de Correos y de Inteligencia durante muchos ańos en dos provincias del imperio y luego en la capital, está en la mejor de las posiciones para escribir un rutero de gran calidad, como así hará; pero al final, su falta de rigor y su anhelo por enriquecer la seca estructura del rutero con informaciones

\footnotetext{
${ }_{24}$ Viajes que se desarrollaron por Armenia, Jurasán, India, Palestina y el Magreb.
}

25 A. Miquel, La géographie humaine, t. I, p. 288. 
diversas, en ocasiones leyendas, harán que éste no sea muy apreciado en diversos ámbitos intelectuales. Esta falta de sistematicidad parece que fue suplida en la continuación de esta obra que hicieran los tres al-Ŷayhānī: estos visires sāmānies, desde su posición de gobernantes, aprovecharán sus recursos para obtener informaciones procedentes de todo el mundo conocido y al alcance de sus informadores. Es una pena que no nos haya perdurado esta obra. Al-Ya’qūbī, por su parte, también trabajó en la administración, como secretario al servicio de los Țāhiríes; en base a esta posición con seguridad obtuvo muchos datos administrativos, pero su innovación consistió en no conformarse con ello, puesto que al-Ya'qubī fue un viajero que conoció las regiones de Armenia, Ādarbaŷān, India y del Magreb, de modo que en sus obras aprovecha estas informaciones geográficas, históricas y estadísticas obtenidas personalmente, con lo que abre un nuevo camino a la obtención de datos. Aun así, más que una obra puramente geográfica se la ha calificado como obra de adab.

- Son cercanos al ámbito sociocultural de los filósofos: Al-Sarajsī es quien más se destaca en este aspecto, hasta el punto que Yāqūt justifica su ejecución en "que invitó a [l califa] al-Mu'taḍid a la escuela (mad hab) de los filósofos», siendo discípulo directo de al-Kindī. Ibn Jurradādbih estudió el arte y la música, ambas «ciencias de los antiguos», pero, sobre todo, escribió un tratado sobre música y otro sobre astronomía. Al-Ya'qūbī es quien no cuadraría bien en este marco, dado que ya está muy imbuido por un šš $\bar{l} s m o$ militante (aunque aún no tan radicalizado como medio siglo después).

2.2. LOS AUTORES DE LA ESCUELA ORIGINAL ORIENTAL DE KMM: UN NÚCLEO Šİ $\bar{l}$, AUNQUE HETEROGÉNEO EN EL TIEMPO Y ADSCRIPCIÓN DE GRUPO RELIGIOSO 2.2.1. La extraordinaria personalidad de Abū Zaydal-Baljī (ha. 236-322/ha. 850-934)

Es curioso cómo los otros autores posteriores de su «escuela» han venido a eclipsar la figura del autor epónimo del grupo, Abū Zayd Aḥmad Ibn Sahl al-Baljī. Su nisba lo ubica como originario de Balj, en Persia. El motivo por el que se le ha prestado poca atención quizás sea porque su Kitāb șuwar al-aqālīm (también conocida por Taqwìm al-buldān) no se ha conservado en cuanto a obra independiente. Es el iniciador con su obra, pero sobre todo con su personalidad y pensamiento (que trasciende mucho más allá de la geografía), de una cadena reconocida de geógrafos. Es clarificadora la biografía que le dedica Yāqūt al-Ḥamawī (575-626/11791229) a Abū Zayd al-Baljīi:

Yāqūt afirma que ha leído escrito de su propia letra de Abū Sahl Aḥmad Ibn 'Ubayd Allāh Ibn Aḥmad, que era cliente (mawlà) del califa (amīr al-mu'minīn) [de ese momento] y que éste había escrito un libro con información sobre Abū Zayd al-Baljī, Abū-l-Qāsim al-Ka’bī al-Baljī y Abū-l-Ḥasan Šahīd al-Baljī. Y dice: «He resumido lo que he mencionado en la biografía de estos tres». 
Dice [Abū Sahl Aḥmad en las noticias sobre Abū Zayd al-Baljī]: «Nació en el pueblo llamado Šāmistyān, en el rustāq del río Garbankī, de los doce ríos de Balj, y su padre era de Saŷziyān. Era maestro de nińos y eso lo mencionó Abū Muhammad al-Ḥasan al-Wazīrī, quien tiene un libro sobre las noticias de Abū Zayd al-Baljī y oí que enseñaba a los niños de este pueblo de Šāmistyān, me refiero a su padre. Amaba Abū Zayd a su pueblo, por ser su origen de allí, y tenía nostalgia de él. Y por eso, cuando tuvo una mejor situación, [allí] construyó sus fincas, y la cuidó [la región]; desde hacía poco tiempo estaban estas fincas en manos de sus nietos y familiares, hasta que desaparecieron con los hechos [luctuosos] que acontecieron en Balj. Oí que el príncipe Aḥmad Ibn Sahl Ibn Hāšim, que gobernaba Balj, tenía a su servicio a Abū-l-Qāsim 'Abd Allāh al-Ka'bī y a Abū Zayd, y les tenía aprecio [...]. Era Abū Zayd, como describe al-Ḥasan al-Wazīrī (quien le había visto y le conocía personalmente): 'alto, delgado, hombre de pocas palabras y hombre de respeto'.

Y lo describió Abū 'Alī Aḥmad al-Munīrī al-Ziyādī en una carta con malas intenciones dirigida Abū Zayd, y éste le respondió con una respuesta que le minusvaloraba, destacando que su fortuna en las ciencias era escasa y sus opiniones no eran ciertas. Sigue al-Wazīrī: 'Cuando era joven fue a Iraq en pos de la ciencia, [estando] de la mano de los grandes sabios. Se dirigió caminando con los peregrinos y permaneció ocho años en Iraq, saliendo de allí y conociendo otros países cercanos, encontrándose con los grandes eruditos. Fue discípulo de al-Kindī, aprovechando mucho sus conocimientos. Profundizó en la filosofía y atacó los secretos de la astronomía y la astrología. Investigó los principios de la religión de la šarīa y y esto lo llevó a tener dudas, a veces buscaba al imām y otras veces se entregaba a las ciencias de la astronomía y la astrología, y luego, como Allāh le destinó para estar entre los salvados, no lo dejó perdido en la oscuridad de los condenados. Le señaló los buenos caminos y por eso permaneció firme en la religión y en el camino recto, con una visión verdadera'. Dijo al-Wazīrī: 'Era un buen creyente y por eso negaba la ciencia de la astrología y sus efectos, afirmaba lo contrario [que ella]. Fue mencionado en la presencia del imām Abū Bakr Aḥmad al-Bazzār, el muftí de Balj, y éste elogió a alBaljī afirmando que era un hombre de buena creencia y no se le puede acusar de las opiniones filosóficas que le injustamente se le adjudicaban. Y no se ha encontrado en sus libros ninguna palabra que manchara su creencia'.

Tiene obras tituladas: Kitāb aqsām al-'ulūm 'Tratado sobre clasificación de las ciencias', Kitāb šarā'i' al-adyān, Kitāb al-siyāsat al-kabīr y Kitāb al-siyāsat al-șagīr, Kitāb Kamāl al-Dīn, Fạ̣l șinā'at al-Kitāba, Kitāb masālih al-abdān wa-l-anfus, Ijtiyarāt al-sayr, Kitāb asmā' Allāh wa-sifātu-hu, Kitāb șinā'at al-š̉’ r, Kitāa faḍ̄lat al-ajbār, Kitāb asmā' wa-l-kunà wa-l-alqāb, Kitāb asāmīd al-ašy $\bar{a}$ ', Kitāb al-nahw. Todas ellas se han perdido ${ }^{26}$.

Al-Ṣafadī (m. 763/1362) aporta las mismas 14 obras que Yāqūt y añade otras 20 más, entre las que se destacan un tratado sobre el ajedrez, dos obras más de filosofía, una de astronomía, y de $a d a b$ o formación del político ${ }^{27}$. El mismo al-Șafadī

26 YĀQūT al-Ḥamawī, Mu'ŷam al-'udabā', vol. I, pp. 275-279.

${ }^{27}$ Al-Sūrat wa-l-mușawwar, Hudūd al-falsafa, Mã yașihhu min ahkām al-nuŷùm, al-Radd 'alà 'abadat al-awțān, Aqsām 'ulūm al-falsafa, al-Qarābīn wa-l-ḍabā' ih, 'Ismat al-anbiyā', al-Samā' wa-l-

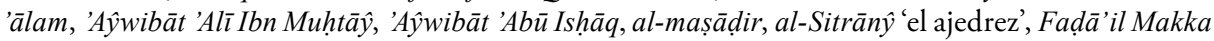


escribe otra biografía de Abū Zayd al-Balj̄ị, que traducimos íntegra por las nuevas informaciones que incorpora:

Era alto, delgado, moreno, de ojos caídos, con los párpados inferiores oscuros, y su cara picada de viruela. Era hombre de pocas palabras, respetuoso y con personalidad. Entró en Irāq y aprendió de sus sabios, viajó luego por muchos países y aprendió luego mucho con el mismo al-Kindī, en especial filosofía, estuvo contra la ciencia de la astrología y la astronomía. Destacó en medicina, y también investigó los principios de la religión, hablando bien de él el imām Abū Bakr Aḥmad Ibn Muḥammad al-Bazzār, imán y muftí de Balj, afirmando que era recto en su madhab, de buena creencia, y no era conocido por lo que la gente le acusaba a causa de sus conocimientos filosóficos. No encontraron nada en sus libros que pudiera cuestionar la doctrina o la creencia mayoritaria. Viajó a Irāq para encontrarse con el imām, pues su

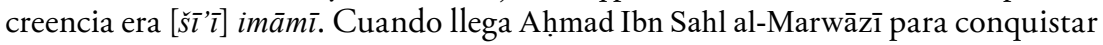
Balj le insistió para que fuera su ministro y se negó, por lo cual tomó a Abū l-Qāsim al-Qāệ̄ de ministro y a Abū Zayd de secretario. Le daba apuros diferenciar entre los șahabā' y entre árabes y no árabes (persas y demás). Fue una persona que tenía conocimiento de todas las ciencias, de los antiguos y los contemporáneos, y que escogía en sus obras el camino de los filósofos, pero se parecía más a los literatos. Fue primeramente maestro de enseñanza infantil (coránica), luego ascendió con su saber. Según Ibn al-Nadīm fue acusado de ilhāad, ateísmo, por dividir las ciencias según un modelo aristotélico ${ }^{28}$.

Finalmente, la biografía que le dedica al-'Asqalānī (m. 852/1449) recoge otra información complementaria sobre al-Balj̄î, referida por

Abū-l-Qāsim al-Baljī, quien atestigua que Abū Zayd al-Baljī fue acusado injustamente de ateísmo, pero afirmó que era monoteísta y mu'tazilī, afirmando que estudiaron juntos y que le conocía mejor que nadie. Estudió con él la lógica (al-mantiq). Le critica al-Fajr al-Rāzī diciendo que Abū Ḥayyān al-Tawhīdī habló muy bien de él, pero afirma que negó hadices ciertos sobre los nombres de Allāh, por lo cual llega a despreciar a los sabios de la šarì'. [Al-'Asqalān̄i recoge que] Según Yāqūt su viaje se prolongó durante ocho años; afirma que aprendió la filosofía de al-Kindī, y que era de doctrina ši '’i imāmiñ, pero que luego la abandonó. Vivió desde ha. 236/850 y murió en $322 / 934$, con más de ochenta años ${ }^{29}$.

Las tres biografías son suficientemente explícitas, siendo la más rica y fiable la de Yāqūt al-Hamawī. Abū Zayd al-Baljī es presentado como una personalidad

\footnotetext{
'Excelencias de La Meca', Sifat al-umām 'Descripción de las naciones', Faḍl al-mulk 'Elogio del poder', al-Mujtașar fīl-luga 'Compendio sobre la lengua', Adab al-șultān wa-l-ra' ìya 'Formación del sultán y de los súbditos', Faḍā'il Balj 'Excelencias de Balj', Tafșìr al-fātiha wa-l-hurūf 'Comentario de la fätiha y de las letras -al principio de las azoras del Corán-', Rusūm al-Kutub. Al-ȘAfaḍī, ed. ár. Aḥmad

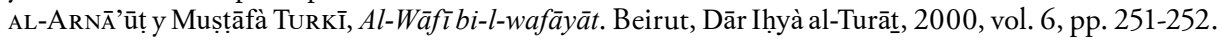
${ }_{28}$ Ibidem, pp. 251-254.

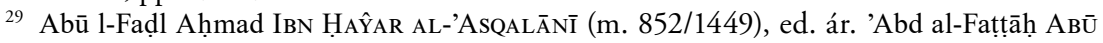
GudDA, Lisān al-mīzān. Beirut-Damasco, Dār al-Bǎšāàir, 2002, vol. I, p. 479.
} 
tan extraordinaria para su época que fue objeto de al menos dos libros biográficos, desgraciadamente perdidos.

Como colofón solo apuntaremos que fue un prolífico polígrafo, a quien se adjudican 34 títulos de obras, aunque ninguna de ellas haya pervivido. Su fama residió más en el ámbito de su personalidad como filósofo y autor de obras filosóficas. A causa de ello se dudaba de su ortodoxia religiosa, motivo por el cual tanto Yāqūt como al-Safạ̣ī se vieron obligados a reiterar la virtud y sinceridad de su creencia, que se define como šs̆' ìmāmì. Hubo quien le tachó hasta de ateísmo, pero siempre encontró otras personalidades que sacaron la cara por él.

También se afirma que fue médico, y astrónomo, aunque rechazaba la astrología. Tiene además obras sobre $a d a b$, formación del príncipe, de literatura diversa, así como de religión. Es lógico, por tanto, que en el ámbito de la geografía destacara escasamente; se puede creer que la suya fue una obra de gabinete, compuesta en base a otras anteriores, a tenor de lo que sobre ésta escribiera su discípulo y amigo al-Iștajrī.

Hay un aspecto que apenas es resaltado por sus biógrafos, y es que fue un funcionario al servicio del poder. Yāqūt afirma que «el príncipe Aḥmad Ibn Sahl Ibn Hāšim, que gobernaba Balj, tenía a su servicio a [...] y a Abū Zayd, y les tenía aprecio», y al-Safadī precisa que desempeñó el cargo de secretario del príncipe de Balj Aḥmad Ibn Sahl al-Marwāzī. Como es evidente, esto le situaría en un ambiente de corte palatina, en el cual tendría tiempo para desarrollar estos saberes y para escribir. En este sentido, como tal funcionario de la corte, también podría habérsele incluido en el anterior grupo de geógrafos $(\$ 2.1$.), pero su perfil y su personalidad lo alejan de ellos y lo sitúan como el primero de una nueva línea de geógrafos. Es curioso cómo hasta este momento apenas se ha hablado de geografía, y sí de cómo entender el mundo, siguiendo las pautas de los antiguos griegos y romanos.

\subsubsection{Los continuadores de al-Balji: la «escuela de al-Balji» o «escuela del Atlas del Islam»}

2.2.2.1. Se puede decir que el inicio de esta escuela está en la silsila que Ibrāhīm al-Iștajrī al-Fāris̄ī al-Karjī (m. después 340/951) refiere en el prólogo como la justificación para escribir su $K M M$. Afirma que quiso ampliar y enmendar la obra de al-Baljī para convertirla en lo que consideraba que debía ser obra geográfica de este carácter. En consecuencia, al-Iștajrī copia el Kitāb șuwar al-aqālīm de al-Baljī y lo fusiona con su propia obra, de modo que la obra de al-Baljī no es posible reconocerla en el $K M M$ resultante (que habría sido compuesto a finales del s. IV/X).

André Miquel resalta de al-Iștajrī que es un personaje sin pasado, sin familia, del cual lo ignoramos todo, salvo que viajó a través del Oriente conocido ${ }^{30}$. Por

${ }^{30}$ Es difícil hacer seguimiento de estos viajes, puesto que hay que deducirlos de ciertas anotaciones que hace el autor en su propia obra. Así sabemos que al-Iștajrī viajó por la parte oriental del islam: Egipto, Siria, la península Arábiga, Iraq, Irán, Jurāsān, Juzistān, Daylam y Transoxiana, y es discutido si también por el Sind. A. Miquel, La géographie humaine, t. I, p. 292-293; 299 n. 1. 
su nisba se nos indica que su gentilicio proviene de Iștajr, la antigua Persépolis. A diferencia de al-Baljī, no se han encontrado otras noticias suyas escritas por ningún coetáneo, y lo que sabemos se ha extraído del análisis de su $K M M$.

Apunta Brockelmann que la primera redacción de su $K M M$ es posible que se realizara en lengua persa ${ }^{31}$, y A. Miquel reitera que no oculta su apego a la historia y a las tradiciones persas, lo cual se emparenta con un interés muy claro por el šl’ ismo; carácter atenuado por la objetividad del autor (por ejemplo, al hablar del mālikismo del Magreb, del jāriŷismo ibādī o de los omeyas de al-Andalus). Pero hallamos simpatías evidentes en otros lugares de la obra: cuando habla del mu'tazilismo de Abū 'Alī al-Ŷubbā'î y de la influencia de su hijo Abū Hāšim sobre el šš' ismo de los medios büyies; por la atención que les dedica a las posibilidades y dificultades del fạtimismo en el Magreb, y en especial a la larga exposición sobre el qarmațismo a través de dos de sus grandes figuras: Ḥallāŷ y Abū Sa'īd al-Ŷannabī. Esto hizo que algún autor coetáneo lo viera como un dā' qármața (con lo cual Miquel no está del todo de acuerdo) ${ }^{32}$.

2.2.2.2. La silsila continúa con quien luego será su discípulo, Ibn Ḥawqal al-Nașībī, que tuvo una formación como mu'tazilī y luego derivó hacia el š̉̇ ismo.

En su Kitāb șürat al-arḍ (también conocido por KMM) refiere Ibn Hawqal cómo siendo joven tuvo un encuentro personal con un al-Iștāijrī anciano ${ }^{33}$. Tal diálogo se produjo probablemente sobre el 340/951-2, en el Sind -según el contexto-, o en Bagdad, más probablemente. En la conversación discuten sobre la cartografía que al-Ișțajrī incluye en su obra. Como resultado, Ibn Ḥawqal le comunica al maestro que va a ser él quien perfeccione y corrija su obra: «Hice mejoras en más de un lugar y quise publicarla bajo su nombre. Pero juzgué oportuno no dejar más que el mío en la autoría de la obra ${ }^{34}$. En este sentido, A. Miquel señala la dificultad de separar qué corresponde a al-Iștajiñ y qué a Ibn Ḥawqal en la obra resultante ${ }^{35}$.

31 C. Brockelmann, Geschichte der Arabischen Litteratur (GAL), Leiden, E.J. Brill, 19371942, Suppl. t. I, p. 408. Ibidem, p. 293.

32 A. Miquel, La géographie humaine, t. I, p. 293 n. 41.

33 En ella discuten sobre la cartografía de al-Iștajrīi: Ibn Hawqal encuentra errores en el mapa del Sind que coinciden en el del Fārs, al-Iștajrī aprueba el dibujo que hiciera Ibn Ḥawqal del Ādarbayŷān y de la Alta Mesopotamia, pero discrepa del dibujo que Ibn Ḥawqal hizo respecto a los mapas de Egipto y del Magreb. Tal reunión se produjo probablemente sobre el 340/951-2 (C. VAN Arendonk, «Ibn Ḥawḳal, Abū l-Kāāsm (Muhammad)». EI ${ }^{1}$, vol. III, 1979, p. 83) en un lugar que no está claro: en el Sind (según el contexto del relato) o en Bagdad (como es lo más probable) (IBN HịawQAL, Trad. fr. J.H. Kramers; G. Wiet, Ibn Hawqal. Configuration de la Terre, p. 322).

${ }^{34}$ Ibn Hawqal, trad. fr. J.H. Kramers; G. WIEt, Ibn Hawqal. Configuration de la Terre, p. 322. A. Miquel, «Ibn Ḥawḳal, Abū l-Kāsim Muḥammad b. 'Alī al-Nāṣībī», EI², vol. III, 1971, p. 233.

35 Apunta A. Miquel que, de hecho, se decidirá incluso por cambiar el título original de $K M M$ por el nuevo de Kitāb șūrat al-arḍ. El estudio de las aportaciones reales de Ibn Hawqal es un trabajo que está aún por hacer: «Constato que Ibn Ḥawqal tiene precisamente el cuidado de afirmar la parte original de esta personalidad mediante el empleo del 'yo' [primera persona singular], bastante frecuentemente sustituido por el 'nosotros' [primera persona plural], el cual, empleado por al-Iștajrī, hubiera sido más de rigor en una obra común», A. Miquel, La géographie humaine, t. I, p. 303, n. 6. 
Ibn Ḥawqal era originario de Nașībīn (Alta Mesopotamia/ al-Ŷazīra), en donde creció y pasó su adolescencia. Según cuenta el propio Ibn Hawqal, partirá de Bagdad en 331/943 con la finalidad de conocer otras gentes y pueblos y hacer negocios comerciales. Esta larga serie de viajes que le llevará por todo el mundo se prolongará durante 31 ańos de peregrinar, hasta 362/973, última fecha atestiguada para sus viajes por todo el mundo ${ }^{36}$. Ibn Ḥawqal, al igual que al-Muqaddasī, no podrá evitar el convertir esas operaciones comerciales en una actividad política en favor de la šlı sión: mientras que R. Dozy, R. Bruchswig y M. Canard ${ }^{37}$ piensan que sí fue un $d \bar{a} ’ \bar{\imath}$ šl’ $\bar{l}$, con argumentos más o menos coincidentes, É. Lévi-Provençal y I. Krachkovky creen que no, y, por su lado, A. Miquel busca mantenerse en una relativa equidistancia que acaba siendo favorable a esta posibilidad ${ }^{38}$.

Escribió que Ibn Ḥawqal, si no fue un agente al servicio de los fạtimies, al menos sí fue un simpatizante declarado. Pero, a pesar de simpatizar con ellos, no se muerde la lengua y critica las equivocaciones cometidas por esta dinastía en la administración de Egipto $^{39}$; esto lo demuestra claramente al escribir el capítulo sobre el Magreb, pues expresa sus votos por el éxito de las empresas de los fạtimíes ${ }^{40}$; A. Miquel interpreta que este hecho no se circunscribe solo a esa forma de šš ismo, «en realidad, me parece que Ibn Hawqal estaba, como muchos otros escritores de su tiempo, tentado por lo que se podría denominar el complejo doctrinal mu'tazilo-šš ’̄ en líneas generales bastante amplio y finalmente menos definible por lo que reivindica que por lo que excluye, a saber, las formas exacerbadas del järiŷismo y del sunnismo» ${ }^{41}$.

Este pensamiento, en pleno siglo décimo, calificado como el «siglo ismà 'îl del Islam», está más comprometido en la lucha política y la propaganda anti-áabbāsì. En este punto es significativo que, además de Hallāŷ y las figuras enumeradas por al-Ișțajrī del movimiento qármața, Ibn Ḥawqal añade la figura de al-Šalmaganī, antiguo imāmī, cercano al fătimismo, que en seguida se convirtió en el cabeza de una šš $a$ extremista y rebelde, siendo finalmente ejecutado por el califato. A. Miquel acaba concluyendo: «El šs̆ ’ismo de Ibn Hawqal me parece representativo de un movimiento

36 Desde el 7 ramadān 331/15 mayo 943, en que parte de Iraq, pasa por África del Norte, al-Andalus, Ghana, Egipto, altas tierras de Adarbayŷān y Armenia, e Iraq. En el año 358/969 está en Juwārizm, después cruza Mesopotamia, luego su país natal hasta Susiana; en 362/973 está en Sicilia, siendo ésta la última fecha que aporta. Hay otros viajes para los que no se tiene fecha, como a Nubia. A. Miquel, La géographie humaine, t. I, p. 299, n. 1 y 3.

${ }^{37}$ M. Canard, "L'impérialisme des fātimides et leur propagande». Annales de l'Institut d'Études Orientales de la Faculté des Lettres d'Alger, n. vi, 1942-1947, pp. 156-193.

${ }^{38}$ Resumen de las opiniones en A. Miquel, La géographie humaine, t. I, p. 300 y n. 2, 259-260.

39 Ibn Hawqal ed. ár. J.H. Kramers, Opvs Geographicvm, p. 153; trad. fr. J.H. Kramers; G. Wiet, Ibn Hawqal. Configuration de la Terre, p. 150.

${ }^{40}$ Ibn Hawqal ed. ár. J.H. Kramers, Opvs Geographicvm, p. 79. Felicitaciones por los éxitos pasados (pp. 71-72), interés por la extensión del poder fātimī hacia el este (hacia el Jurasán, p. 310), hacia la península Arábiga (pp. 24, 27).

${ }^{41}$ A. Miquel, La géographie humaine, t. I, pp. 300-301. 
doctrinalmente muy amplio y culturalmente muy abierto", manifestando incluso simpatías por los zoroastrianos. Pero reconoce que la suya es la figura de

un nuevo personaje: el comerciante misionero, imbuido de una sólida instrucción y de un no menos sólido sentido de los negocios, es el tipo ideal de estos propagandistas šš'ies $(d u ' a \bar{t})$ que recorren el islam del s. IV/x y, al azar de sus viajes y de sus transacciones, se entretienen, discuten y predican un islam multi-confesional, reivindicando el justo lugar en este conjunto para la descendencia y la filosofía 'alies, con una preferencia marcada, aunque natural y no exclusiva por los fătimīes, cuya aventura marca verdaderamente el primer gran éxito del šš ’ísmo en sus tentativas de implantación temporal ${ }^{42}$.

Ibn Ḥawqal trabajó veinte años en la composición del texto y los mapas de su Kitāb șūrat al-ard, lo cual supone un importante trabajo de acumulación, primero, y de sintetización, después. La huella de sus creencias está patente en su obra, tanto que es ella la que nos va dando pistas para entender el pensamiento de su autor.

Esta interminable serie de viajes, así como su fe šš $\bar{l}$, ha inclinado a verle como un $d \bar{a} \hat{l} \bar{s} s \bar{l} \hat{l}$, , tema sobre el cual ha habido controversia. Está claro que es una circunstancia esencial en su vida, de modo que no es posible negar que en diversa

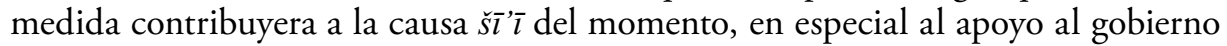
fătimī tunecino primero y egipcio finalmente.

2.2.2.3. Muḥammad Ibn Aḥmad Ibn Abī Bakr al-Bannā’ al-Šāmī al-Muqaddasī es el tercer geógrafo miembro de esta «escuela de al-Baljī». Es curioso que, originario de Jerusalén, haya querido conservar como elemento diferenciador esta nisba, que remite a tiempos pasados ${ }^{43}$. Sobre su biografía hay muy escasos datos más, salvo lo poco que trasluce de su Kitāb ahsan at-taqāsìm fì ma'rifat al-aqālìm «La mejor de las clasificaciones, [tratado] para el conocimiento de los climas [las regiones]». Escribe que su abuelo paterno Abū Bakr era conocido como al-Bannā', pues había participado en la construcción para Ibn Ṭūlūn de las defensas marítimas de la ciudad de Acre $(\mathrm{Akka})^{44}$. Nace hacia el 334/945 en un medio acomodado, con abundante servidumbre, en el que recibe la mejor educación. Entre los 36 nombres y oficios con que se define, destacamos los de recitador del Corán (muqrī), jurisconsulto (faqīh), $s \underline{u} f \bar{l}$, hombre santo y siervo de Dios (wālī wa-'ābid), asceta (zāhid), peregrino (sayyāhh), copista (warrāq), encuadernador (muŷallid), mercader, recitador (mudakkir), imām,

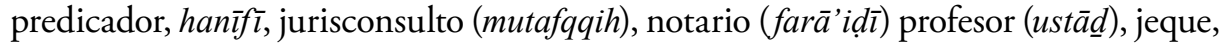
sabio (dānišūmand), estudioso (nišāstah), conductor $(r a \bar{a} k i b)$ y finalmente «mensa-

${ }^{42}$ Ibidem, pp. 300-302.

43 Al-Muqaddasī escribe que es un «nombre que remite alegremente a épocas lejanas», y así lo expresa tanto en el prefacio, como en la conclusión de su Aḥsan al-taqāsìm, mostrando su preferencia por él, en vez del más común de al-Maqdisī, ed. ár. $B G A$ III, pp. 1, 49.

${ }^{44}$ Ibidem, pp. 162-163, 357, 367. 
jero» (rasū $l)$ «y todo ello en los diversos países en los que he vivido y en los muchos lugares que he visitado» ${ }^{45}$.

Pasa sus primeros 20 años en Jerusalén, para luego salir e iniciar una interminable serie de viajes, que le llevarán desde los confines de la India musulmana a Armenia, riberas del Nilo y Asia Central. En el Mediterráneo llega a conocer Sicilia, pero el Magreb lo conoce solo indirectamente, y al-Andalus reconoce no haberlo visitado jamás ${ }^{46}$. Sí parece conocer Siŷistān, pero no el Sind. Lo cierto es que pasa su vida en el camino, y André Miquel se cuestiona el porqué de la larga serie de viajes que recoge en su estudio. De la enunciación de los 36 nombres que hace en la autopresentación en su obra, A. Miquel le adjudica el rol de un aventurero, bastante elocuente y cultivado como para hablar a las gentes del lugar, un pícaro que vive la

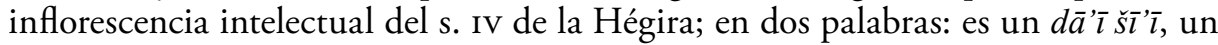
misionero que extiende sus ideas entre las masas urbanas y las rábitas, mezquitas y demás lugares de reunión religiosa. Todo ello se ha de poner en relación con el gran movimiento del ismailismo que por entonces florece.

No puede negarse el carácter militante del šš ísmo de al-Muqaddasī, y él mismo reconoce que debido a ello entró en prisión, fue tratado de hereje y de espía y estuvo a poco de ser linchado ${ }^{47}$. Está claro que tuvo una dedicación tanto de comerciante como de predicador allí donde sus viajes le llevaron. A. Miquel ve claras sus opiniones en política: al-Muqaddasī apenas dedica atención a la Bagdad būyzu, que ha traicionado la causa 'alì, y la presenta como una ciudad en la que el destino está consumado, en beneficio de El Cairo fățimī, nueva sede de la gloria del califato. Con este punto de vista, se comprende, pues, que no haga una descripción positiva del Daylam y de quienes salieron del mismo: los visires būyies, gobernantes šììes, pero también traidores, puesto que políticamente eran duodecimanos y, sobre todo, eran los protectores del califato 'abbāsī (por tanto, enemigos del progreso del califato fățimī por el este $)^{48}$. No deja de criticar también la actitud de los omeyas hacia

45 «Yo he estudiado el fiqh y el adab, practicado el ascetismo y la devoción, enseñado el fiqh y el $a d a b$, pronunciado la juṭa en el púlpito, hecho la llamada a la oración desde los minaretes, hecho de imām en las mezquitas, recitado en las aljamas, frecuentado las escuelas, invocado a Dios en las reuniones, tomado la palabra en las sesiones (maŷālis), compartido la harīsa con los șūfīes, la

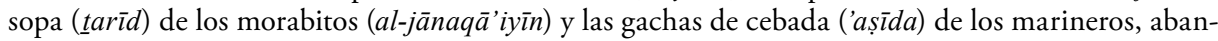
donado en las mezquitas en la noche, viajado en las soledades, vagado por los desiertos, practicado frecuente y sinceramente la abstinencia, y después comido abiertamente los alimentos prohibidos (harām), adquirido la amabilidad de los devotos de la montańa del Líbano e intimado con los gobernantes, poseído esclavos y después cargado los cestos sobre mi cabeza. En algunas ocasiones he estado cerca del ser ahogado, y nuestras caravanas han sido asaltadas en el camino. He servido a los cadíes y a los grandes, dirigido la palabra a los sultanes y a los visires, hecho amistades en el camino con los libertinos, vendido productos en el mercado, conocido las prisiones, o las acusaciones de espionaje», su presentación autobiográfica puede encontrarse en AL-MUQADDASĪ, Aḥsan al-taqāsìm, $B G A$ III, pp. 43-45, y este texto traducido en la p. 44.

46 Ibidem, pp. 222-3 sobre al-Andalus y sobre Sicilia p. 211. Ver sobre sus viajes A. MiQueL, La géographie humaine, t. I, p. 314 n. 5, 315.

${ }_{47}$ Al-MuQdiddasī, Ahsan al-taqāsìm, pp. 44, 126, 256, 399.

48 A. Miquel, La géographie humaine, t. I, pp. 316-317. 
los š̉ '̄es ${ }^{49}$. Es cuando menos curiosa su actitud respecto a los sāmāníes del Jurasán, dinstía sunnī y estimada por al-Muqaddasī, lo cual se explica por la hostilidad abierta de los sāmānies hacia los būyies; así, una provincia que se escapa a la autoridad de los büyíes debería ser una de las provincias que acabarían siendo fieles (a sus enemigos, los fātimīes) ${ }^{50}$.

Al-Muqaddasī es un autor claramente implicado en la propaganda šs $’ \bar{l}$, siendo evidente su carácter pro-fătimì. Esto no le presenta como un fanático, y ello se deduce de los juicios de valor que va dando a lo largo de las descripciones de lugares y personas. A. Miquel lo entiende del modo siguiente: «Sobre un fondo de šs 'îsmo entendido en sentido amplio, las preferencias de al-Muqaddasī, al menos en el sentido político, han tomado poco a poco, la proporción de las victorias fätimieses, la forma de una simpatía cada vez más clara hacia el lugar del nuevo califato cairota, el ismailismo triunfante de Egipto, fijando las aspiraciones de un šl' '̌smo necesitado de un éxito temporal». Pero, en lo doctrinal, el autor es comprensivo con todos los que se escapan de la obediencia fạtimì y la rechazan, como los sāmāníes. Esta actitud es definida como eclecticismo que desborda los límites del islam: así, cristianos, zoroastrianos y judíos también reciben numerosas menciones en esta obra y en el seno del islam, la objetividad del autor le impone hacer notar en cada provincia las escuelas jurídicas musulmanas existentes ${ }^{51}$, además de los diversos grupos de š̉ '̌ies, jārîȳes, mu'tazilīes, ẓāhirīes, y las diversas variedades del sunnismo. Pero su interés por lo humano no se queda en ello: «El š̉i ’̌smo de al-Muqaddasī se acomoda así mostrando estrecha relación con el misticismo, por un lado, y con la teología dogmática (kaläm), por otro: su interés se manifiesta por los șüfies que él ha conocido en sus cenobios (jānaqāt), y por los mu'tazilies, de donde no nos extrañará que subraye

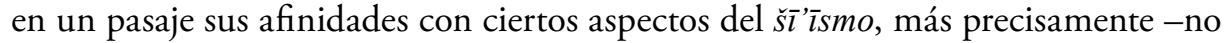
es por azar-con el fätimismo» ${ }^{52}$.

Si él escoge entre los 36 nombres de la autodefinición inicial de su obra el hanīf $\bar{\imath}$, no nos ha de extrañar que hallemos huella en diversos lugares de su obra de su fascinación hacia la persona de Abū Ḥanīfa, quien se apoya en la palabra de 'Alī y es reivindicado por al-Muqaddasī como el gran mediador, como el punto de encuentro doctrinal para un islam ecléctico y alejado de toda intransigencia ${ }^{53}$.

49 En un lugar critica la actitud de los omeyas hacia los 'alies, y en otro lugar elogia las cualidades "profanas» de los omeyas de al-Andalus, AL-MuQADDAs̄i, Ahsan al-taqāaīm, pp. 293 y 233.

50 A. Miquel, La géographie humaine, t. I, pp. 317-319

51 El estudio de las diferentes escuelas jurídicas (madāanhib) que Ibn Ḥawqal y al-Muqaddasī refieren en el Magreb fue realizado por A. CARMONA GonZÁLEZ, «Las corrientes doctrinales del Occidente musulmán vistas por geógrafos orientales del siglo X", en Actas del II Coloquio Hispano-Marroqui de Ciencias Históricas "Cultura, Ciencia y Sociedad", Granada, 6-11 noviembre 1989, Madrid, ICMA/Al-Andalus'92, 1992, pp. 107-114.

52 A. Miquel, La géographie humaine, t. I, p. 320.

53 Al-Muqaddasī presenta a Abū Hanīfa como el imām que da una unidad al sistema, exalta su rol de mediador y éste aparece como el símbolo de un sincretismo que se define fundamentalmente por el repudio de todo exceso de uno u otro bando (pp. 374, 392, 403). En las fronteras de un sunnismo y de un $\breve{s} \grave{\imath}\urcorner \bar{s}$ smo moderados hay lugar para toda una familia espiritual que se reconoce 
En esta detallada e inteligente presentación de A. Miquel quizás haya que resaltar que su cerrada defensa del poder e ideología fạtimī cairota le aleja de este

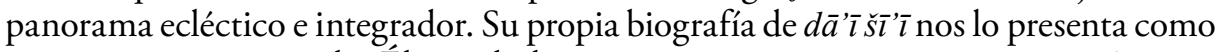
un misionero interesado. Él, sin duda, muestra que conoce mejor que ningún otro de los autores que estudiamos las diferencias entre las diversas escuelas jurídicas y los grupos del islam, así como demuestra tener una formación de primer orden; religiosa, literaria o de arquitectura, siendo el gran apasionado del viaje.

Es el primero que en vez del dār al-islam, «sede del islam» (concepto religioso), prefiere hablar de la mamlakat al-islām, el «imperio del islam», como un término técnico, reciclando la antigua etiqueta de iqlìm para ahora denominar a una gran región, definida tanto por su poder político como por sus pueblos y costumbres. El objetivo de este estudio no es definir todas las novedades que introducen este grupo de autores de la «escuela de al-Baljī» en sus obras geográficas o en su cartografía asociada a ellas. Simplemente apuntamos que ellos iniciarán una nueva geografía y llevarán a cabo el desarrollo de la misma en sus tratados, comúnmente etiquetados como $K M M$.

\subsection{LOS AUTORES OCCIDENTALES QUE TITULARON SUS OBRAS COMO KMM: TARDÍOS ECOS DE CARÁCTER GEOGRÁFICO-HISTÓRICO}

2.3.1. Al-Ḥasan Ibn Aḥmad al-Muhallabī al-'Azīzì (m. 380/990) es un autor singular dentro de los autores de $K M M$, por varios motivos: era de origen magrebí, šl $\bar{\imath} \mathrm{y}$ escribió un KMM conocido como Kitāb al-'Azizz $\bar{l}^{54}$, por haber sido elaborado y dedicado para el califa fățimī Abū Manșūr Nizār al-'Azìz bi-llāh (gob. 365-386/975-996). Obra hoy perdida, de ella solo han quedado algunos fragmentos que copiaron Yāqūt (55 menciones) y Abū l-Fidā' (135 alusiones) en las suyas respectivas; ambos consideraban a al-Muhallabī un gran geógrafo.

Poco sabemos de él, más allá de que era originario de Túnez y que viajó para hacer acopio de datos personales para su KMM. Como tal geógrafo parece conocer muy bien Egipto, Siria e Iraq, mientras que el resto de su obra parece que ha sido recogida de otras anteriores, en especial de la de Ibn Hawqal (aunque sin citarlo). Es obligado establecer un paralelo entre ambos, ya que los dos están interesados por la

en la aceptación conjugada de la legitimidad de los tres primeros califas y del rol privilegiado de 'Alī (p. 399), del mismo modo que hay lugar para la condena, en el terreno teológico, de los excesos de

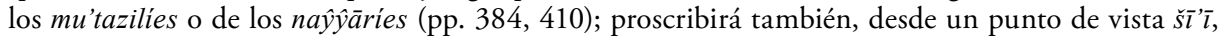
los excesos en la devoción hacia 'Alī (pp. 128, 395). En cuanto al sunnismo, hay rechazo también del afecto excesivo hacia el omeya Mu'âwiya (pp. 365, 384), del exceso de apego a los hadices (pp. 41, 365, 367, 415, 439, 469, 481, 1), de la intransigencia de los mālikies (p. 236), crítica a los hanbalies por su sumisión al poder (p. 152), por sus prácticas (p. 388), por sus tendencias antropomorfistas (p. 126), etc. Ver A. Miquel, La géographie humaine, t. I, p. 321 y notas 5, 6, 8 y 9.

54 'Umar Ibn Ahmad al-'Uqaylū, IBN AL-'ADĪM (588-660/1193-1262): Bugyat at-talab fī ta'rīj Halab, ed. ár. Suhayl Zakkār. Damasco-Beirut, Dār al-Fiqr, vol. I, p. 348. Ver Ch. Pellat: «Al-Muhallabī, Abū l-Ḥusayn al-Hasan b. Aḥmad», $E I^{2}$, vol. viI (1993), p. 360. 
dinastía fătimī y por el África sudanesa. Lo evidencia el que esté dedicada la obra al califa al-'Azīz, pero además hallamos una clara prevención hacia la dinastía omeya de Damasco ${ }^{55}$. Entre las características diferenciales de este $K M M$ está el que de sus membra disjecta se adivina una gran obra, que presentaría una geografía mundial. Por Abū-l-Fidā' y Yāqūt sabemos que su compilación desbordó las fronteras del mundo islámico conocido, llegando a describirse zonas de Asia y del océano Índico ${ }^{56}$.

Por otro lado, los detalles de geografía física son abundantes y la geografía administrativa parece haber sido reflejada con mucho más cuidado que en las obras de Ibn Ḥawqal o al-Muqaddasī, las anotaciones de distancias e itinerarios o la fijación de los lugares parece fue cuidadosamente consignada (por lo cual lo copiaron Yāqūt y Abū-l-Fidā); anota para cada lugar su indicación precisa de longitud y latitud, así como su pertenencia al clima (iqlim) que le corresponde, entendido en el sentido que le daba al término la geografía griega ${ }^{57}$.

Con ello, la obra de al-Muhallabī es más que una geografía exclusivamente del mundo islámico, es más heredera de los tratados de geografía administrativa $(\$ 2.1$.$) propiamente pertenecientes a la cadena (silsila) de la «escuela de al-Baljī».$ A pesar de su evidente carácter $\breve{s} \mathfrak{l}\urcorner \bar{l}$, las dos características citadas la alejan de este núcleo central que se puso como objetivo elaborar una nueva imagen del mundo.

En opinión de A. Miquel, si lo comparamos con Ibn Hawqal o al-Muqaddasī, al-Muhallabī parece menos novato, más sabio, como un geógrafo clásico, de quien poco más podemos aventurar. Su conclusión es que la obra de al-Muhallabī se puede explicar teniendo en cuenta el espíritu de El Cairo fătimì que la vio nacer: para el nuevo califato, que aspiraba a sustituir a los califatos de Córdoba y de Bagdad, se trataba de afirmar, entre otras manifestaciones de esta voluntad de poder, que se había hecho cargo de los valores culturales hasta ahora asumidos por Iraq ${ }^{58}$.

También encontramos que el $K M M$ de al-Muhallabī es una obra geográfica tardía, de la segunda mitad del s. $\mathrm{x}$, y ya en Oriente se han escrito antes otras obras que han marcado el camino a seguir. En el caso de este $K M M$ su innovación fue el

55 A. Miquel, La géographie humaine, t. I, p. 310, n. 5.

56 Así, de un total de 76 citas en que Abū l-Fidā' le menciona (sin contar las citas de distancias), copia de esta obra la descripción de la ruta marítima de China, Awdagust, el canal de Constantinopla, Tíbet, India, Socotra y Kalah. Yāqūt recogerá tres descripciones suyas del África sudanesa. Ibid, p. 310, notas 1,6 y 5 .

${ }_{57}$ Los itinerarios aparecen igualmente en cuanto ruteros necesarios para delimitar los límites de cada entidad provincial en torno a la cual se distribuyen. La estructura de sus descripciones geográficas incluye descripción de las ciudades, con breve apunte sobre sus tradiciones y su historia, monumentos y lugares santos, etnografía y producciones, lo cual podemos saber siguiendo su rastro en la obra de Yāqūt, ibid, pp. 311-312, n. 6.

58 «La obra de al-Muhallabī -y tantas otras que no conoceremos jamás- se inscribía, pues, en el mismo contexto que los ataques militares, la propaganda política, las embajadas o las grandes obras públicas de El Cairo. A falta de otra certidumbre, al menos podemos pensar que en materia de $a d a b$, las normas en vigor en la corte fătimī eran muy novedosas: no se trataba, en verdad, más que de recoger la herencia de un Oriente políticamente decadente, pero en el cual los valores continuaban siendo tenidos como la regla de oro", ibidem, p. 312. 
enumerar los territorios conocidos más allá del mundo islámico, usando patrones que ya utilizaron los autores de la «escuela de al-Baljī».

\subsubsection{En el cuadro-apéndice final han quedado reflejados algunos datos esenciales referidos a otros tratados coetáneos y posteriores etiquetados como $\mathrm{KMM}^{59}$}

2.3.2.1. El perdido $K M M$ de al-Warrāq (292-363/904-973) se escribió casi a la par que el homónimo de al-Muhallabī. Lo escribió un erudito que parece originario de Cairuán, que allí se formó y luego había huido de los fatimíes de Túnez. Ibn Hazm afirma que el propio califa andalusí al-Hakam II le hizo el encargo personal a al-Warrāq de componer un «libro voluminoso sobre los caminos y reinos del Norte de África ${ }^{60}$. Por la escasa información que tenemos de este $K M M$, el haber sido un encargo del califa, que deseaba conocer los caminos y reinos del Magreb, escrito por quien había vivido allí y tenía información de primera mano sobre la región, nos remite a esos tratados iniciales del género, elaborados como acopio de información al servicio de los gobernantes (enunciados en $\$ 2.1$.). En plena guerra contra los fațimiés norteafricanos, era lógico que el poder califal ordenara hacer acopio de información referente a la realidad social y política, para conocer y actuar del modo más adecuado en un Magreb que se había convertido en el escenario militar de una guerra religiosa. Al igual que estos tratados iniciales que, escritos en el Bagdad 'abbāsiz, se centraban en describir el Próximo Oriente, éste, escrito en la Córdoba omeya, parece que fue un tratado exhaustivo centrado en el Magreb; en el mismo, sobre la base de la información geográfica, habrían sido incluidos además abundantes datos de historia y etnología.

2.3.2.2. Esta obra ha perdurado en buena medida a través de los textos que incluyera Abū 'Ubayd al-Bakrī (432-487/1040-1094) en su propio KMM. En 24 ocasiones reconoce que toma el texto de al-Warrāq, pero silencia su origen en muchas otras que le copia. Sabiendo que al-Bakrī no había viajado por el Magreb, la pro-

59 Los datos esenciales acerca de autores y obras, así como la bibliografía sobre todos ellos, se pueden encontrar desarrollados en F. FranCo-SÁNCHEZ, "Al-Masālik wa-l-mamālik», del $§ 8$ en adelante.

${ }^{60}$ Ibn 'I haber resumido esta información extraída del Kitāb al-Masālik wa-l-Mamālik de Muhammad Ibn Yūsuf al-Qarāwī (por al-Qayrawānī), IBN 'Id̄̄̄RĪ, ed. ár. R.P. Dozy, Histoire de l'Afrique et de l'Espagne intitulée al-Bayano'l-mogrib par Ibn Adhari (de Maroc), des fragments de la Chronique d'Arîb (de Cordue). Leiden, E.J. Brill, 1848-1851, vol. I, p. 241; nueva ed. ár. de G.S. Colin; É. Lévi-ProvenÇAL, Histoire de l'Afrique du Nord et de l'Espagne Musulmane intitulée Kitāb Al-Bayān Al-Mughrib par Ibn 'In̄hāà Al-Marrākushī et fragments de la Chronique de 'Arīb. Tome Premier. Histoire de l'Afrique du Nord de la Conquête au XIe. Siècle. Leiden, E J. Brill, vol. I, 1948, vol. I, p. 232. Ḥusayn Mu’NIs, "Al-Ŷugrāfĩya wa-l-ŷugrāfīyūn fī-1-Andalus min al-bidāya ilà l-Hiŷāāì. Revista del Instituto de Estudios Islámicos en Madrid, vols. viI-VIII (1959-1960), pp. 199-359. R. PockLIngton, "Al-Warrāq, Muhammad», Biblioteca de al-Andalus $[B A]$, dirección y edición Jorge Lirola Delgado. Almería, Fundación Ibn Tufayl de Estudios Árabes, 2004-2012, vol. 7, pp. 614-615. 
cedencia de la rica información que recoge sobre esta región, casi con toda seguridad, habría sido copiada del $K M M$ de al-Warrāq. Al-Bakrī lo elabora en al-Andalus, en la corte de al-Mu'tasim, en Almería (puerto mediterráneo y también cruce de caminos marítimos más allá de este mar), y se está escribiendo en el 460/1068, durante el período de los reinos de taifas ${ }^{61}$. Han perdurado varias partes de la obra, pero se han perdido otras importantes ${ }^{62}$. A diferencia del de al-Warrāq, este tratado tiene una finalidad diferente, y encierra la ambición de ser una cosmografía mundial.

En este eco tardío de los $K M M$ orientales, sobre la base de un rutero se añade todo tipo de informaciones, no solo de geografía física y humana, sino también de historia política y economía de las regiones descritas. Con ello la estructura original de rutero evoluciona para pasar a convertirse en una obra mixta geográfica e histórica, de mayor complejidad que sus precedentes homónimos orientales.

2.3.2.3. El Kitāb tarșī’ al-ajbār de Aḥmad al-’Udùī (393-478/1003-1085) es una obra cuyos fragmentos conservados apenas arrojan una idea general acerca de su estructura, que sería la de una geografía de carácter global: las primeras hojas sueltas que conforman el unicum que ha perdurado nos informan acerca del texto conservado: se inicia con unos seis folios casi ilegibles que -según parece- tratan de Egipto (tres folios), Siria (2 ff.) e Irán (1 f.) y luego viene el cuerpo esencial de la obra, conformado por el largo fragmento sobre al-Andalus ( $42 \mathrm{ff}$. $)^{63}$. Según parece, también fue compuesta en la corte de al-Mu’tasim de Almería, y se habría concluido en el 472/1079-80.

${ }^{61}$ Ver la ed. ár. de los fragmentos conservados por Adrien P. Van Leeuwen; André Ferré, Kitāb al-masālik wa-l-mamālik li-Abī 'Ubayd al-Bakrī. Qarțây (Túnez), Dār al-'Arabīya li-l-Kitāb / Bayt al-Ḥikma, 1992, 2 vols. Reimpresión: [Beirut], Dār al-Garb al-Islāmī, 1992, 2 vols. Évariste LÉvi-ProvençAL, "Abū 'Ubayd al-Bakrī», $E I^{2}$, vol. I, 1960, pp. 159-161. Ḥ. Mu'NIS, "Al-Ŷugrāfīya wa-1-ŷugrāfĩyūn», pp. 199-359. J. Lirola Delgado, «Al-Bakrī, Abū 'Ubayd», Biblioteca de al-Andalus $[B A]$, dirección y edición Jorge Lirola Delgado. Almería, Fundación Ibn Tufayl de Estudios Árabes, 2004-2012, vol. 1, pp. 154-160.

${ }^{62}$ No se ha conservado la introducción, con lo cual desconocemos cuáles fueron las motivaciones, posible dedicatoria u objetivos de al-Bakrī al escribirla. Tampoco la recogieron o resumieron otros autores posteriores, de lo cual deducimos que no encontraron en ella nada relevante. Luego habla de las historias de los profetas, de los antiguos árabes; descripción de los edificios religiosos míticos de los pueblos antiguos. Comienza la parte de geografía física con la descripción de los ríos, mares e islas. Luego se refiere a la división griega del mundo en siete aqālīm o climas (pero no la utiliza, puesto que organiza su obra de modo diverso). Descripción del mundo conocido: desde la India y China en dirección a Occidente, siguiendo básicamente un mismo esquema expositivo (introducción histórica, descripción geográfica, información sobre su población, la economía local y enumeración de los itinerarios de la región). La última parte de la obra se ocupa de describir la parte occidental de Europa; en ella incluye la descripción de al-Andalus y de algunas de sus ciudades. J. Lirola, «Al-Bakrī», p. 157.

${ }^{63}$ Estos seis folios iniciales no fueron incluidos por al-Ahwānī en su edición del texto conservado, que solo recogió los 42 folios referidos a al-Andalus, como indica el título de la edición: 'Abd al-'Azīz AL-AhwĀNīi, Aḥmad Ibn 'Umar Ibn Anas al-'Uḍrī. Nuṣūṣ 'an al-Andalus. Fragmentos geográfico-históricos de Al-Masālik ilà ğamī' al-Mamālik. Madrid, Instituto Egipcio de Estudios Islámicos de Madrid, 1965. 228 pp. Sobre la historia de las páginas conservadas de este manuscrito y de su edición ver F. Franco-SÁNCHEZ, «El tratado de Teodomiro en su contexto histórico y paleográ- 
2.3.2.4. El último a incluir en este grupo sería al-Šarīf al-Idrīsī ( ha. 493-571 / ha. 1099-1175-6), como autor de un Kităb [Uns] Al-Muhaŷ wa-rawd al-furaŷy (también titulado por otros autores como $K M M$, y rebautizado -el manuscrito de Estambulpor K. Miller como "pequeño Idrīsī»). Es una obra desconcertante en el panorama de la geografía árabe, pues la podemos calificar como un auténtico rutero al estilo del Itinerario de Antonino romano ${ }^{64}$. Según F. Sezgin, el «pequeño Idrīsī» habría sido compuesto en Sicilia para el emperador Guillermo I (1154-1166), probablemente hacia el final de la vida del autor ${ }^{65}$. Respecto a la fecha de su composición, Annliese Nef ha afirmado que, según una de las copias manuscritas, el Uns al-muhaŷ parece haber sido concluido en 588/1192, lo que indicaría que al-Idrīsī se habría quedado en Sicilia trabajando tras la muerte de Roger II (lo cual coincide con algunas de las pocas noticias que poseemos sobre él). Para la fecha de su muerte, afirma que no sabe de dónde se ha extendido la fecha del 1164-1165, y propone la de 571/1175-117666.

Es como si al-Idrīsī en la corte siciliana hubiera tenido a mano este u otro rutero romano, y se hubiera propuesto actualizarlo, articulando un rutero ya no solo del imperio islámico (ya muy fragmentado por entonces), sino de todo el mundo conocido. Aprovechó para incluirle una cartografía añadida, asunto que, una vez realizada la cartografía de la Nuzhat al-muštāq, no debió ser demasiado complicado

fico», eHumanista/IVITRA, n. 5 (2014), $\$ 4$, pp. 325-327 <Enlace al volumen de la revista y al artículo http://www.ehumanista.ucsb.edu/ivitra/volumes/5> [Consultado: 02/05/2018].

${ }^{64}$ En 1984 Fuat SezGin publicó dos manuscritos como edición facsimilar del Uns al-muhây wa-rawd al-furây, en la obra Al-Idrīsī (d. ca. 560/1165). Uns al-muhaj wa-rawd al-furaj. The Entertainment of Hearts, and Meadows of Contemplation. Frankfurt am Main, Institut History Arabic-Islamic Science (Series C-7), 1984, 570 pp. En base a esta edición fotostática de F. Sezgin, ha realizado la fijación del texto árabe, traduciéndolo al español, con estudio: Jassīm Abid Mizal [Alubudi]: Al-Idrīsī. Los caminos de al-Andalus en el siglo XII según Uns al-Muhây wa-rawd al-furâŷ. Madrid, CSIC, 1989, 425 pp.

${ }^{65}$ Con esta afirmación Fuat Sezgin corrige el explicit de la obra, y opina que ésta habría sido compuesta en 555/1160 o 558/1163 (dado que el autor murió en 560/1165). Intentando dar una explicación a la fecha del explicit, J.A. Mizal otorga verosimilitud a la fecha del 588/1192 para la conclusión de la obra, al suponer que el manuscrito conservado sería una copia de una primera versión original; esta copia habría sido realizada por un torpe, inculto y descuidado amanuense, lo cual explicaría los errores e imprecisiones de todo tipo que contiene. Para ello, interpreta el ustu'mila «se usó, fue utilizado» del explicit en pasiva, y no como ista'mala "utilizó, usó», según la ed. y trad. esp. de J.A. Mizal, pp. 27-28. Con posterioridad, R. Rubinacci ha publicado la traducción italiana integral de la introducción a la obra en cuestión, que considera de utilidad, por aportar elementos de juicio sobre el problema de su origen; al final de su razonamiento llega a la misma constatación que había inducido a J.H. Kramers a considerar al Uns al-muhay como un compendio de la Nuzha reelaborado en el s. VII/XIII, con la introducción de algunos datos de importancia del Kitāb al-Badī' de Ibn Sa'īd; habría sido redactado por un compilador del cual se desconoce el nombre. R. RubiNaCci, «Intorno al cosidetto Piccolo Idrîsî», en B. Scarcia Amoretti y L. Rostagno (eds.), Yâdnâma: in memoria di Alessandro Bausani, vol. II: Storia della Scienza-Linguistica-Letteratura, Roma, Bardi Editori / Università di Roma «La Sapienza» («Studi Orientali», vol. x), vol. II (1991), pp. 88-96.

${ }^{66}$ Annliese Nef, "Al-Idrīsī: un complément d'enquête biographique», en H. Bresc y E. Tixier du Mesnil (dirs.), Géographes et voyageurs au Moyen Âge, París, Presses Universitaires de Paris Ouest, 2010, pp. 63-64. 
(a pesar de lo cual, ambas cartografías difieren bastante en los detalles, quizás porque lo que nos ha llegado es una deficiente copia). El resultado es una obra geográfica que parece cerrar el círculo del $K M M$ : ruteros que se van enriqueciendo en datos de todo tipo, para acabar en una obra final que supone la vuelta a su escueta estructura expositiva inicial, con mapas añadidos.

Todos los autores reseñados tienen en común que son occidentales (pues escriben en Córdoba, Almería o Sicilia), son sunnies y sus obras fueron ofrecidas a los dos soberanos para los que trabajaban (al servicio del califa omeya al-Hakam II, la primera, y al soberano Gillermo II de Sicilia, en el caso de al-Idrīsī). Ahora bien, sus obras tienen objetivos diferentes (al-Warrāq elabora un tratado que es un acopio de información para un uso político-administrativo, mientras que al-Idrīsī elabora un rutero con una cartografía añadida).

En los casos de al-Bakrī y al-'Uḍrī, sus $K M M$ son dos cosmografías con ambición global, cuya finalidad habría sido la de servir como acta notarial que registra por escrito la realidad de un mundo que (al menos en al-Andalus, donde ellos escribían) se hallaba sumido en un cambio continuo, y no para mejor. Por ello el registrar cómo fue esa realidad en el anterior siglo $\mathrm{x}$ adquiría el sentido de la fijación de un pasado cercano, en el que el califato omeya andalusí era la gran casa de seguridad política y doctrinal (en donde todos ellos se sentían amparados), lo cual es evidente en el caso de la obra de al-'Ud dos suponen el contrapunto doctrinal al origen oriental y šs̀ '̄ de los primeros $K M M$ y sus obras son el resultado de la desviación occidental y sunnī del género. Estos dos, en base al corpus de los anteriores $K M M$, elaboran unas obras más detalladas, más trufadas de datos históricos, etnológicos, administrativos y económicos.

2.3.2.5. Este tipo de obras geográficas surge en Oriente, en Bagdad, como una innovación de carácter ššl’ pero un epígono final, al-'Umarī (700-749/1301-1349) devuelve el género a Oriente, aunque con carácter sunnī. Sus enciclopédicos Masālik al-abșār fì mamālik al-amșār son la referencia obligada en lo que concierne a la administración durante el período mameluco. Esta monumental obra supone la evolución final hacia un tipo de tratado puramente enciclopédico, en el cual lo geográfico ya ha quedado diluido entre una multitud de saberes e historias diversos, sin que lo geográfico tampoco sirva como eje o criterio para la ordenación del contenido.

2.3.2.6. Los posteriores libros que hemos recogido solo utilizan ese título tan famoso con el fin de dotar a sus obras de una etiqueta famosa y reconocida. Ésta sigue siendo garantía de clasicidad para unos tratados ya de carácter bien alejado de lo geográfico o lo histórico. 


\section{LOS PRIMEROS TRATADOS GEOGRÁFICOS ÁRABES: LA PRIMERA GEOGRAFÍA ELABORADA EN LA ÉPOCA 'ABBĀSI (SS. IX-X)}

Cada uno de los $K M M$ ha de ser ubicado en el momento de la historia de la geografía que le corresponde ${ }^{67}$, mientras que, como conjunto, estos tratados han de ser ubicados en el período cultural en que se compusieron. Del cruce de las dos caracterizaciones (la individual geográfica y la colectiva cultural) se deducirán algunas conclusiones acerca del origen y sentido de estos $K M M$.

Antes de volver sobre este grupo de obras, se hace necesario sintetizar algunos datos sobre las obras geográficas y la cartografía precedentes.

\subsection{LA PRIMERA GEOGRAFía Y CARTOGRAFÍA ÁRABE: HERENCIA INDIA Y GRECO- HELENÍSTICA}

3.1.1. Durante el califato omeya oriental (41-132/661-750) tuvo lugar la segunda expansión del islam, ampliándose las fronteras del imperio hasta Francia, por el oeste, y el Sind, en el este. Es momento de expansión, reorganización militar y administrativa y edificación de un nuevo imperio, lo cual se hace apoyándose en el antiguo funcionariado de las regiones conquistadas y aprovechando en gran medida las anteriores estructuras administrativas de los nuevos países anexionados. Durante esos primeros ańos el Estado islámico es una superestructura religiosa y administrativa que se va imponiendo progresivamente, aunque bastante rápido.

En el apartado cultural vamos a encontrar una pervivencia de los saberes del pasado preislámico, denominados genéricamente "las ciencias de los antiguos», mientras que se van articulando de modo progresivo y rápido la esencia y la estructura de lo que luego se conocerán como las «ciencias de la religión" " ${ }^{6}$, estableciéndose de este modo un binomio conceptual que sirvió para clasificar los saberes a lo largo del período clásico.

3.1.2. Bajo el gobierno del califa abasí Abū Ŷa’far al-Manșūr (136-158/754-775), el fundador de Bagdad, se produce un notable desarrollo de las ciencias matemáticas, astronomía y geografía. En este período se producirán una serie de fenómenos con-

67 Ver F. Franco-SÁnchez, «Al-Masālik wa-l-mamālik», $\$ 3.1$ y 4 .

${ }^{68}$ Las 'ulüm al-awā'il o 'ciencias de los antiguos', heredadas de culturas extranjeras -indoirania y, sobre todo, griega - «lo que incluye el conjunto de las ciencias exactas y físico-naturales, medicina, cierto tipo de ingeniería mecánica ('ilm al-hiyal), además, claro está de la filosofía», frente a las 'ulūm ad-dīn o 'ciencias de la religión [islámica]', relativas a la religión y a la tradición lingüísticoliteraria propia, fueron un binomio conceptual que buscaba una clara oposición maniquea entre los saberes religiosos (o que eran útiles para la religión) y aquéllos que, heredados y útiles en el pasado, no lo eran a efectos religiosos. J. Vernet, «La ciencia en el islam y Occidente», en Estudios sobre Historia de la Ciencia Medieval, Barcelona-Bellaterra, Universidades Central y Autónoma de Barcelona, 1979, p. 21. J. SAmsó, Las ciencias de los antiguos en al-Andalus. Madrid, Mapfre, 1992, pp. 15-16. 
vergentes que darán como resultado un gran crecimiento de los conocimientos geográficos. Entre las influencias externas, hay una clara (sobre todo en cuanto a conocimientos geográficos y astronómicos), la que procede de la India ${ }^{69}$. La influencia india se manifestó más sobre la astronomía que sobre la propia geografía (por más que entre los persas ya era conocida la astronomía india); de este modo se tradujeron al árabe importantes obras indias ${ }^{70}$, siendo su influencia esencial para la astronomía, y también la geografía astronómica derivada.

3.1.3. En el califato de al-Ma'mūn (197-218/813-833) se acrecentó el gusto por las obras del saber helenístico, de modo que se acentuó la labor traductora al árabe de las mismas. Serán las parcelas relacionadas con el saber helenístico las más directamente afectadas por esta labor traductora.

Las primeras obras geográficas de las que tenemos noticia son las emparentadas con la geografía astronómica y la astronomía, y son herederas directas del pasado griego y helenístico. Se hallan vinculadas directamente con una astronomía aplicada a la representación cartográfica, y hay toda una cartografía que es heredera de la de Marino de Tiro, Eratóstenes, pero sobre todo de la cartografía de Ptolomeo. Se trata de una línea de geografía que se conoce como científica, en cuanto a heredera y continuadora de un pasado helenístico traducido y divulgado en la corte 'abbāsī, por el conocido grupo de traductores encuadrados en el Bayt al-Hikma o 'casa de la Sabiduría'.

Se conoce como tal al grupo de sabios que se concentró en la corte para desarrollar, bajo su mecenazgo, esa labor científica de traducción y de estudio ${ }^{71}$. Las aportaciones de este grupo de científicos se verán en todos los campos de la ciencia árabe, habiendo un antes y un después de esta iniciativa colegiada, de la que conocemos algunos integrantes, aunque su labor sea adjudicada al conjunto y puesta, generalmente, bajo el nombre de su mecenas (como ejemplo se puede aducir la Șürat al-Ma'mūnìya o 'Mapamundi de al-Ma'mūn'). La labor de traducción fue una de sus ocupaciones preferentes, siendo la continuadora y aceleradora de este flujo de traspaso al árabe de las más importantes obras de la antigüedad; los traductores, gene-

69 S. MaQbul Ahmad, «Djughnrāfiyā», $E I^{2}$, vol. II (1965), pp. 590-602.

${ }^{70}$ Como el Sūrya-siddhānta, un tratado de astronomía oriental que habría llegado a la corte (a través de Gundisapur) en 156/772, o la traducción por AL-FAZĀRī del Sind-Hind, el sistema de astronomía de la India. Otra obra sánscrita traducida es el Āryabht'īya (árabe Arŷabhad) de ĀrryabhaŤa de Kusumaputra (hoy Patna, 476-550 J.C.), y el Khandakhāyaka de Brahmagupta (598-670 J.C.), escrito en 665. Algunas concepciones geográficas de Āryabhata se harán famosas entre la geografía árabe.

${ }^{71}$ Sobre el paso y la traducción del saber antiguo a la ciencia islámica, en general geografía matemática o astronómica: Ḥ. 'Abbās 'AțīTū MaḥmŪD; Ḥassān Ḥallāe, Al-'ulūm 'inda l-'arab. Beirut, Dār al-Nahḍa al-'Arabīya, 1990, 496 pp. Más concretamente sobre la 'Casa de la Sabiduría', sus integrantes y el entorno científico en que desarrollaron sus aportaciones tratan el excelente estudio de J. Aḥmad 'Aț̣̂' Allā̄H, Bayt al-Hikma fī 'aṣr al-'Abbāsīyīn. El Cairo, Dār al-Fikr al-'Arabī, 1989, 518 pp. y el de Myriam SAlama-CARR, La traduction à l'époque abbaside: l'école de Hunayn Ibn Ishāa et son importance pour la traduction. París, Didier Érudition (Coll. «Traductologie», núm. 6), 1990, 122 pp., aunque éste más centrado en la medicina y la astronomía. 
ralmente arameos, muchos de ellos no musulmanes, conocían el griego, el siríaco y la lengua del nuevo imperio islámico, el árabe, y vertieron la mayoría de las obras al árabe por intermediación de versiones en siríaco $^{72}$. Entre ellas se cuentan las obras geográficas de Marino de Tiro y de Ptolomeo ${ }^{73}$. Del primero tenemos indicios porque así lo apuntaron algunos autores, pero tenemos constancia que en época 'abbāsi se tradujo en varias ocasiones la obra de Ptolomeo ${ }^{74}$ :

1. Es famosa la traducción al árabe realizada por el persa Muḥammad Ibn Mūsà alJwārizmī (m. ha. 232/847), traducción a la que incorporó los datos contemporáneos y procedentes de los conocimientos adquiridos por los árabes. Él mismo afirma haber traducido esta obra, que sabemos que contenía cartografía, aunque ésta no haya perdurado.

2. El persa al-Mas'ūdī (nacido en Bagdad y fallecido en El Cairo, 303-355/915956) se sirvió también de esta obra, así como de su mapamundi ${ }^{75}$. Se piensa que no contenía mapas.

3. En sus tratados, Tāabit Ibn Qurra (m. 288/901) también incluyó una parte de la obra de Ptolomeo, conteniendo unos mapas que no se han preservado ${ }^{76}$.

4. Al-Hamdānī (280-334 / 893-945) hizo una traducción parcial en la introducción a su obra Sifa Ŷazirat al-'Arab, 'Descripción de la península Arábiga' ${ }^{77}$. Es un resumen,

${ }^{72}$ Ha defendido que el Bayt al Ḥikma de Bagdad fue una biblioteca, pero no un centro de traducciones Françoise Micheau, «Les institutions scientifiques dans le Proche Orient médiéval», en Histoire des sciences arabes. 3. Technologie, alchimie et sciences de la vie, Sous la direction de Roshdi Rashed, París, Éditions du Seuil, vol. 3 (1997), pp. 233254.

73 J. Vernet, La cultura hispano árabe en Oriente y Occidente. Barcelona, Ariel, 1978, pp. 19, 92. Sobre las traducciones realizadas en Bagdad, de Ptolomeo y del legado científico griego, es un buen estado de la cuestión el realizado por George SALIBA, "Arabic Science and the Greek Legacy», en From Baghdad to Barcelona. De Bagdad a Barcelona. Estudios sobre Historia de las Ciencias Exactas en el Mundo Islámico en honor del prof. Juan Vernet, Barcelona, Universitat de Barcelona/CSIC, 1996, pp. 19-37.

${ }^{74}$ Sobre la traducción al árabe de la obra de Claudio Ptolomeo se ha escrito largamente. Fue estudiado el texto por C.A. Nallino, Al-Huwārizmī e il suo rifacimento della Geografia di Tolomeo. Roma, Accademia dei Lincei (Memoria della Reale Accademia dei Lincei, serie v, vol. II, 1), 1894. También han insistido en la influencia ptolemaica en la cartografía árabe Hans von MžıK, «Ptolemaeus und die Karten des arabischen Geographen. Vortrag gehalten in der Fachsitzung der KK geographischen Gesellshchaft in Wien", Mitteilungen der KK, vol. LVIII (1915), pp. 152-176, y Ch. ANAGNOSTAKIs, The Arabic Version of Ptolemy's Planisphaerium. New Haven, Conn., Yale University Press, 1984, 323 pp.; el propio Mžik y otros investigadores han insistido en estudios mucho más particulares, como H. von MžıK, «Osteuropa nach der arabischen Bearbeitung der Geografikà Huphêgêsis des Klaudios Ptolemaios von Mohammed Ibn Mūsa al Khuwārizmī», Wiener Zeitung Fûr die Kunde des Morgenlandes, vol. XLIII (1936), pp. 161-193. Un punto de vista discrepante lo ha planteado Husayn MU'NIS, "Las traducciones del texto y los mapas de la Geografía de Ptolomeo», en La Traducción y la critica Literaria. Actas de las Jornadas de Hispanismo Árabe, Madrid, ICMA, 1990, pp. 303-306.

${ }^{75}$ Ch. Pellat, «Al-Mas'ūdī», $E I^{2}$, vol. vi (1991), pp. 784-789.

${ }^{76}$ Régis Morelon, «Tābit b. Qurra and Arab Astronomy in the 9 th. Century», Arabic Sciences and Philosophy. A Historical Journal, vol. 4, núm. 1 (1994), pp. 111-140. Julio SAMsó, Las ciencias de los antiguos en al-Andalus. Madrid, Mapfre, 1992, p. 263.

77 Ed. ár. de D.H. Müller, Al-Hamdānī. Sifat Ŷazìrat al-'Arab. Leiden, 1884-1891, vol. I. O. LöfGren, «Al-Hamdānī», $E I^{2}$, vol. III (1971), pp. 126-128. 
pero es más claro que la traducción realizada por al-Jwārizmī. Tampoco aparecen mapas porque la copia que utilizó al-Hamdānī es obra de un copista tardío que no tenía ni idea de la importancia de los mapas de Ptolomeo. Hasta el momento poseemos solamente el texto, pero no mapas ${ }^{78}$.

Éstas son las noticias que poseemos de al menos cuatro traducciones que se realizaron de la geografía tolemaica antes de finales del s. $\mathrm{x}^{79}$. Las cuatro versiones son realizadas en el entorno bagdadí, en círculos cercanos al poder 'abbāsì.

Fueron igualmente traducidas al árabe otras obras de Ptolomeo, como el Almagesto (al-Maŷisțī, conocido solo por su versión árabe), un Kitāb al-anwāa' ("Tratado sobre los eventos astronómicos») o el Tetrabiblon (al-Maqālāt al-arba'a). Igualmente hay que citar en ese caudal en transferencia al mundo árabe la Geografía de Marino de Tiro ( $h a .70-130)$-también consultada por al-Mas'ūdī-, traduciéndose además el Timeo (en árabe: Timā'uss) de Platón, la Meteorología (en árabe Al-Âtāar al-'ulwīya), el De Caelo (Al-Samā' wa-l-'ālam) y la Metafísica (árabe Mā ba'd al-țabī'a) de Aristóteles ${ }^{80}$.

\subsection{LA INFORMACIÓN GEOGRÁFICA EN TRATADOS DE ADAB: APUNTES GEOGRÁFICOS PARA LAS ÉLITES CULTAS BAGDADÍES}

Respecto al origen y la primera geografía árabe, A. Miquel lo retrotrae a las primeras obras de $a d a b^{81}$. Argumentó que las primeras obras que incluyen temas geográficos surgen del $a d a b$ como género dentro de una literatura árabe en formación. Difícilmente traducible adab «literatura», o «bagaje cultural» en sentido más amplio, para A. Miquel remite a "cultura básica» (culture moyenne, "cultura media»), que abarcaría temas e influencias propios y extranjeros. Dicho de otro modo, el adab ha de ser entendido como el indispensable bagaje cultural necesario para toda persona que quisiera ser considerada culta, con elevada formación y educación refinada en el Bagdad de los ss. Ix y x. Para la formación de estos adīb surgirán recopilaciones culturales diversas, en las que hallaremos una parte en que se habla de geografía.

Los dos representantes de esta época son los grandes escritores al-Ŷăhịiz ( $h a$. 160-255/776-868) e Ibn Qutayba (213-276/828-889), los cuales, aunque separados

78 H. MU'NIS, «Las traducciones del texto y los mapas», p. 305.

79 Por lo que hace referencia a la transmisión de la tradición científica griega al mundo islámico, cabe destacar las importantes obras de F. Rosenthal, The Classical Heritage in Islam. Berkeley, California U.P., 1975, y D.L. O'Leary, How Greek Science passed to the Arabs. Londres, 1949, reimpr. Londres-Boston, Henley, 1979.

${ }^{80}$ J. Vernet, La cultura hispanoárabe en Oriente y Occidente, pp. 143-144. Como guía general, especialmente para éste, pero también para el resto de la geografía, ya se ha apuntado la obra de G. SARTON, Introduction to the History of Science. Baltimore, Carnegie Institution of Washington, 1927-1948, 3 vols. en 5 tomos.

${ }^{81}$ El origen de la relación entre adab y geografía ha sido expuesto largamente por A. MiQUEL, La géographie humaine, t. I, cap. II, pp. 35-68. 
por cerca de medio siglo, representan una misma tendencia compiladora, aunque de signo opuesto: uno supone la apertura filosófica, el otro el repliegue práctico. Con ellos el $a d a b$ se convierte en esa "cultura general», en ese "bagaje cultural» más o menos popular ${ }^{82}$. A ellos sumaremos al enciclopedista al-Mas'ūdī, que supone una evolución aún anclada en el adab.

3.2.1. La figura del polígrafo al-Ŷāhiz ( $h a$. 160-255 /776-868), parcialmente envuelta en la leyenda, encierra bajo su paternidad una serie de obras cuyos fragmentos se aproximan a lo que luego hallaremos en las obras de la literatura geográfica. En ese sentido hay que considerar primero su Kitāb at-tarbī'a wa-t-tadwìr 'Tratado sobre la cuadratura del círculo ${ }^{83}$; bajo título apócrifo y forma de risāla, versa sobre la historia universal, la religión y el mundo; describe, por tanto, el marco en el que se desarrollará la nueva religión, englobando las ciencias cosmológicas, matemáticas, física, geografía general (șurrat al-'ard y 'aŷa'ib) y geología, zoología, etnografía, medicina y magia. Es, por tanto, la primera obra que desarrolla de modo sistemático el problema de las diversas interferencias externas al islam. Consecuencia de su carácter mu'tazilī, al-Ŷạhiz concibe el adab como un programa y un espíritu de investigación; esto se concreta en la primacía que concede a la razón ('aql), que deriva en una actitud fundamental: la defensa de la observación directa ('iyān) como medio privilegiado del conocimiento, complementario al razonamiento.

Sus concepciones se aprecian aún más claramente en el Kitāb al-hayawān, 'Tratado sobre los seres vivos' ${ }^{84}$, extensa obra, también de $a d a b^{85}$. En ella prima la geografía humana (pues se analiza la relación entre el hombre y el medio físico), así como una geografía de las estructuras sociales (análisis de circulación de bienes y personas, grupos sociales, religiosos, costumbres, etc.).

${ }^{82}$ A este concepto de una geografía como eje esencial y de esta culture moyenne le dedicó A. Miquel la obra "Comment lire la littérature géographique arabe au Moyen Age?», Cahiers de Civilisation Médiévale, n. 2 (1972 janvier-mars), pp. 97-104. Dada su importancia, reprodujo este texto tal cual como "Advertissement" al tomo 2 de su La géographie humaine du monde musulman jusquiau milieu du 11e. siècle. Géographie arabe et représentation du monde: la terre et l'étranger. París-La Haya, Mouton \& École Pratique des Hautes Études, tome 2, 1975, pp. Ix-xx.

${ }^{83}$ El Kitāb at-tarbī'a wa-t-tadwīr de al-Ŷăhiz fue editado en primer lugar por G. van VLoTEN dentro de Tria opuscula auctore al-Djahiz. Leiden, 1903, pp. 86-157. Luego reeditado por Ch. Pellat, en Damasco, Institut Français de Damas, 1955. Ha sido traducido al castellano por P. BuenDía Pérez, Yaăhiz. Libro de la cuadratura del círculo. Madrid, Gredos (Col. Clásicos Medievales, 9), 1998, 170 pp.

${ }^{84}$ El Kitāb al-hayawān lo fue a su vez por A.M. HĀrūN, Al-Ŷăhiz. Kitāb al-hayawān. Beirut, Dār Iḥyā' al-Turāt al-'Arabī, 1388/1967 (2. ${ }^{a}$ ed.), 7 vols., y por F. Aṭ̂ī [s.l.], 1982, 1292 pp. Ha sido estudiado -entre otros- por M. Asín PALAcios, «El Libro de los Animales de Jāḥiẓ», Isis, vol. xiv, núm. 43 (1930 mayo), pp. 31-70.

${ }^{85}$ En esta obra se ve claramente su fondo árabe e islámico, pero también deja entrever las traducciones del griego, especialmente Aristóteles. En ella, al-Ŷāḥiz revisa la creación y plantea el lugar del hombre en el mundo, asimilándolo a una especie animal entre los ángeles y ŷunūn (genios), y los animales con pelo. 
Finalmente, el Kitāb al-amșār wa-'aŷa' 'ib al-buldān, 'Tratado acerca de las metrópolis y las maravillas de los países' ${ }^{86}$, compuesto en $248 / 862$, es posiblemente el más "geográfico» de los tres tratados. Solo se nos han conservado fragmentos del mismo, que no fue muy extenso. Su propósito es el estudio de las relaciones entre el hombre y su entorno espacial y temporal. Al-Mas'ūdī le reprochó el escribir de geografía sin haber viajado ${ }^{87}$ y al-Muqaddasī el haber escrito un opúsculo escaso en referencias precisas ${ }^{88}$, lo que equivale a afirmar que nos hallamos ante una ciencia de gabinete, especulativa, general y abstracta, puesto que al-Ŷāhiz no aporta una suma de conocimientos técnicos, sino el resultado de una reflexión de conjunto sobre el fenómeno humano, que pretende aportar las claves de los mecanismos fundamentales de las asociaciones del hombre a su medio, natural o social.

3.2.2. Bien diferente es el caso de Ibn Qutayba (213-276/828-889), puesto que su obra está destinada a formar los cuadros de la administración 'abbāasin, teniendo en cuenta dos premisas básicas: eficacia y respeto de la vocación árabe del islam ${ }^{89}$. La geografía la hallamos especialmente en su Kitāb al-anwā', 'Libro sobre los eventos astronómicos', en la que se ofrece al gran público un repertorio fundamental de los conocimientos árabes en la materia. En ella hallamos la austeridad de la nomenclatura técnica, aunque está llena de comentarios y citas de versos y obras. Analiza los amșar, metrópolis, grandes ciudades (en este caso dos: Küfa y Bașra), pero desde un punto de vista jurídico: se hace como lugares en que reside una autoridad revestida directamente por el poder supremo, y en la que se aplican las penas del derecho (hudūd).

3.2.3. En la personalidad polifacética de Abū 1-Ḥasan 'Alī Ibn al-Ḥusayn Ibn 'Alī al-Mas'ūdī (303-355/915-956) se reúnen las cualidades de un viajero/geógrafo experimentado y las del polígrafo. Se sabe que compuso cerca de quince obras, parte de ellas perdidas. Buena parte del material de estas obras ha perdurado en su enorme

${ }^{86}$ El Kitāa al-amșār wa-'aȳà'ib al-buldān lo editó Ch. Pellat, en Al-Mašriq (1966 marzoabril), pp. 169-205.

${ }^{87}$ Al-Mas'ūDī dice: «Refiere al-Ŷăḥiz que el río Mihrān (Indus), del Sind, proviene del Nilo de Egipto, y aduce como prueba la existencia de cocodrilos en el Mihrān. Ignoro dónde ha podido encontrar tal argumento. Ha escrito esto en su Kitāb al-amșār wa-'aŷà'ib al-buldān, que es una buena obra, pero no habiendo navegado el autor, ni viajado lo suficiente como para conocer los reinos, ni las ciudades, ignora que el Mihrān del Sind nace en fuentes bien conocidas, situadas en la región alta del Sind...», ed. ár., trad. fr. del Kitāb murūŷal-dahab por C. BARBier De Meynard; P. de Courteille, Les Prairies d'or. París, Imprimerie Impériale, 1861-1877. Reeditado en París, Geuthner, 1930, t. I, pp. 206-207.

${ }^{88}$ Ed. ár., trad. fr. de los fragmentos de la obra de al-Muqaddasī relativos al Occidente musulmán, por Ch. Pellat, Description de l'Occident Musulman au IVe.-Xe. siècle, Argel, 1950, \$13, 13bis.

${ }^{89}$ No es la búsqueda absoluta, como al-Ŷāhiz, sino el conocimiento técnico y relativo, que encuentra su justificación no en sí, sino en la relación que le une al objeto. En sus obras se tiende a buscar esa "cultura media» y la especialización que caracteriza este tipo de adab no es sino el resultado de la reducción de la cultura a las normas que la tornan aplicable a todas las situaciones. Mientras que al-Ŷăhiz, preocupado por el espíritu, pone la necesidad de la investigación en cuanto a tal, sin olvidar los imperativos del islam, Ibn Qutayba es eminentemente práctico. 
tratado, titulado Kitāb murūŷa at-tanbīh wa-l-išra $\bar{f}{ }^{91}$, última obra que escribiera (compuesta en 345/956), es una especie de resumen final de toda su obra; en él nos podemos hacer una idea bastante clara de su concepto de geografía, que considera como una parte introductoria «espacial» a la historia (estructura que será habitual posteriormente) y sigue la tradición geográfica persa ${ }^{92}$.

Las dos obras citadas no son propiamente geográficas, y en ellas no hallamos exposiciones sobre el imperio islámico, ni sus rutas o postas; no son de geografía regional, en sentido estricto. Por el contrario, presentan un buen resumen de los conocimientos de sus contemporáneos sobre geografía matemática y física. Al-Mas'ūdī es un sintetizador de primer orden, y sus obras transmiten la vastísima cultura que acumuló, y no únicamente de ciencia de gabinete. Saca partido de los anteriores escritos geográficos en árabe, así como de la literatura marítima y de viajes, a la par que ańade experiencias de sus propios viajes ${ }^{33}$. Su principal contribución es el panorama de la geografía humana que presenta; pone el acento en la influencia del medio y de otros factores geográficos sobre el aspecto físico de animales, plantas y seres humanos. En este sentido, sigue conceptos griegos ya desarrollados con anterioridad en la obra de Hipócrates ${ }^{94}$.

${ }^{90}$ Ed. ár., trad. fr. del Kitāb murūŷal-ḍahab por C. Barbier de Meynard; Pavet de Courteille, cit. nota 88, nueva ed. ár. Ch. Pellat, Mas'ūdī. Les Prairies d'or. Edition Barbier de Maynard et Pavet de Courteille, revue et corrigée par Charles Pellat. Beirut, Publications de l'Université Libanaise, 1962-1965, 2 vols.

${ }_{91} B G A$, viII. Ed. ár. M.J. DE Goeje, Bibliotheca Geographorum Arabicorum, vol. viII. Kitâb at-tanbîh wa'l-ischrâf auctore al-Masûdî. Leiden, E.J. Brill, 1894. Reed. Leiden, E.J. Brill, 1967.

${ }_{92}$ Pues se rige por el sistema expositivo de los siete kišwār-s; con el Iraq como el kišswār central, le considera como el mejor del mundo y a Bagdad como la mejor de todas las ciudades.

${ }_{93}$ Presenta las noticias mezcladas, sin selección previa, y a menudo sin sacar las conclusiones que cabría esperar. Se le ha reprochado el haber sido en exceso crédulo, aunque para Blachère y Darmaun esto no es más que aparente. Pero, gracias a haber recogido todo tipo de noticias, algunas inverosímiles, tenemos un ingente mar de datos, muchos de los cuales se habrían perdido de otro modo. Como concluyen Blachère-Darmaun, «es, en cierto modo, una obra colectiva, caótica, en ocasiones exacta, frecuentemente barroca, reunida por un narrador encantador que había leído mucho, visto mucho y entendido aún más», R. Blachère y H. Darmaun, Extraits des principaux géographes arabes du Moyen Âge. París, Librairie C. Klincksieck (Collection Études arabes et islami-

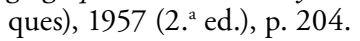

${ }_{94}$ En el Corpus Hippocraticum en general, y más especialmente en la obra de Hipócrates (m.

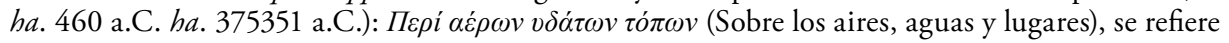
pormenorizadamente la influencia positiva o negativa de los diversos vientos, aguas, lugares y regiones sobre la vida, la salud y el carácter del hombre. 


\section{LA CREACIÓN DE UNA NUEVA GEOGRAFÍA SELLO DE IDENTI- DAD DEL NUEVO IMPERIO 'ABBĀSIIY PROPIA DEL ISLAM $\left(\check{S} I^{\prime} \bar{T}\right)$}

De la larga exposición que precede, es posible extraer una serie de factores que tienen en común buena parte de estos autores y sus obras. Los referidos factores hasta la fecha han sido poco resaltados entre todo el mar de informaciones que rodea a estos autores y sus obras. Los diferentes datos dispersos van a ser agrupados por temas. De este modo, su consideración conjunta fundamentará nuevas conclusiones sobre este grupo de geógrafos y sobre sus $K M M$.

\subsection{EVOLUCIÓN EN CUANTO A LA CONSIDERACIÓN DE LA FILOSOFÍA Y OTROS SABERES DE LAS 'CIENCIAS DE LOS ANTIGUOS'}

4.1.1. En la biografía de al-Sarajsī se le asocia con los jāriŷ̃es y coinciden los biógrafos en dos aspectos: en uno primero en que tanto él, como al-Baljī fueron dos discípulos reconocidos de al-Kindī. Por si fuera poco explícita la acusación de filósofo y lo que esto implicaba en este marco de finales del s. III/Ix, Yāqūt hace dos afirmaciones radicales. Por un lado le acusa de que «invitó a al-Mu'taḍid a la escuela (madhab) de los filósofos y a abandonar el islam», haciendo equiparar el pensamiento filosófico no a una interpretación o corriente cultural, sino a una tendencia religiosa (madhab) establecida dentro del islam, aunque luego llega más lejos incitando al califa a abandonar el islam, situando con ello a al-Sarajsī fuera del mismo.

Por si quedara alguna duda, escribe que al-Sarajsī solicitó morir borracho (tras haber ingerido mucho vino añejo), con el fin de no ser consciente del dolor físico de la ejecución. Esto en un contexto religioso implica una clara defensa de la transgresión, incluso ante la propia muerte. Ahora bien, en un contexto médico y šš $\bar{\imath}$ tendría una diferente explicación: es conocido cómo el gran médico Avicena reconoce beber vino para aliviar sus dolencias, y como estimulante para poder suportar largas veladas de estudio y trabajo. Por otro lado, en este contexto $s ̌ s \imath \bar{\imath}$ inicial, perece habérsele concedido escasa relevancia al consumo del vino, incluso reconociéndolo públicamente, en contraste con la gravedad que se concede a su consumo público en los contextos sunnies occidentales.

Como ya se ha indicado, Ibn Jurradādbih escribió un tratado sobre música y otro sobre astronomía, lo cual indica que había recibido una formación en el ámbito de las "ciencias de los antiguos», aunque no se cite explícitamente la filosofía. Al continuador de su obra, al-Ŷayhānī, al-Muqaddasī le califica como filósofo y astrólogo.

Abū Zayd al-Baljī es conocido como uno de los discípulos del gran al-Kindī. Es un personaje central que merecería un estudio aparte, puesto que es posible aventurar que estuvo relacionado con los principales eventos culturales de la segunda mitad del s. Ix y primera del s. X en Bagdad. Inciden todos sus biógrafos en calificarle de filósofo y discípulo de al-Kindī; así, Yāqūt dice que "profundizó en la filosofía», pero que "no se le puede acusar de las opiniones filosóficas que injustamente se le adjudicaban». Al-Șafadī lo expresa diciendo que "escogía en sus obras el camino de los filósofos, pero se parecía más a los literatos», así, entre las 34 obras que dice 
que escribió enuncia el título de una obra de astronomía, dos de filosofía, un tratado sobre el ajedrez y al menos tres de adab o formación del funcionario-político, concluyendo que «no era conocido por lo que la gente le acusaba a causa de sus conocimientos filosóficos; no encontraron nada en sus libros que pudiera cuestionar la doctrina o la creencia mayoritaria». Al-'Asqalānī acaba precisando esto diciendo que "fue acusado injustamente de ateísmo, pero afirmó que era monoteísta y $m u^{\prime} t a z i l \bar{l}[. .$.$] era de doctrina ši '̄i imāmin, pero que luego la abandonó», añade que$ enseñó lógica (al-mantiq). La aclaración de esta acusación de ateísmo la explica Ibn al-Nadīm, quien afirma que «fue acusado de ilhăd 'ateísmo', por dividir las ciencias según un modelo aristotélico».

Queda claro que su perfil intelectual era fronterizo, y por tener formación y escribir obras ligadas a diversos saberes filosóficos, a sus coetáneos y biógrafos les era complicado situarle dentro de una clasificación ideológica determinada. Esto sí, todos acaban concluyendo que no era ateo y que no hallaron en sus libros nada que pudiera entenderse que cuestionaba «la doctrina o la creencia mayoritaria» del islam que vivió. Al-Safadī lo sintetiza diciendo que «fue una persona que tenía conocimiento de todas las ciencias, de los antiguos y los contemporáneos, y que escogía en sus obras el camino de los filósofos, pero se parecía más a los literatos», y también que «destacó en medicina», lo cual no es extraño, pues fue discípulo de al-Kindī. Como colofón, su dominio y conocimiento de las "ciencias de los antiguos», así como su deseo de integrarlas en la doctrina religiosa, hizo que recibiera severas descalificaciones. De este modo, no queda clara su ubicación religiosa; por ello se le califica como monoteísta y mu'tazilī, luego ši '̄i imāmì̄, que luego abandona.

4.1.2. El rechazo a la filosofía, como ciencia ajena al islam, extranjera, extraña y peligrosa, no es nuevo en el contexto 'abbāsì. En el mismo, la creciente animadversión popular derivó en persecución hacia los filósofos, cuya influencia se deseó eliminar.

El III/IX es el siglo de al-Kindī (ca. 178-261/ ca. 794-874) y de la influencia de los filósofos. Ésta se hizo sentir poderosamente en todos los ámbitos de la cultura. Como ejemplo singular, las Rasā'il de los Ijwān al-Șafā' son una enciclopedia del saber musulmán en la que se islamizan la filosofía y «ciencias de los antiguos» griegos; escritas en este s. III/Ix bagdadí, sus autores no reflejarán sus nombres para preservar su seguridad, siendo atribuidas, de este modo, al colectivo autodenominado como los 'Hermanos de la Pureza' ${ }^{95}$. Son uno de los ejemplos de esa influen-

${ }^{95}$ Sobre este tema hay muchísima bibliografía. Remitimos al estado de la cuestión que hizo Mourad KaCimi en su tesis doctoral titulada Edición critica árabe y estudio de la Risālat al-ŷāmī’a d̄āt al-fawā'id al-nāfi'a, tāŷ Rasā’il Ijwān al-Șafā' (finales del s. IV H. IX e.C, principios del s. V H./XI e.C.), defendida en la Universidad de Alicante el 7 de julio de 2015. Sobre este tema concreto ver M. KaCimI, «Al-Tā’wīl al-bāținī: Asbābuḥu wa-mașādiruhu (Ijwān al-Șafā' namūḍayan)», Al-Tawāṣulīya, vol. 4 (2015), pp. 170-171, 173-175, 178-184, y «El pensamiento baținī en Al-Andalus: Reflexiones a partir de la Rutbat al-hakìm y la Gāyat al-hakìm (s. Iv H./x e.C.)", en Estudios sobre Patrimonio, Cultura y Ciencias Medievales, Granada, ed. Grupo de Investigación HUM-165: Patrimonio, Cultura y Ciencias Medievales, vol. 19 (2017), pp. 731-735. 
cia de la filosofía helenística sobre la religión, más concretamente sobre las escuelas de la $s_{\grave{l}} \mathfrak{a}$, en este momento en plena ebullición intelectual.

En la sede del poder 'abbāsī la opinión pública se fue derivando en contra de los filósofos. En el contexto de finales del s. III/Ix la pugna contra la filosofía de origen griego y los filósofos derivará en persecución en todo el imperio. El crear una religión alejada de los presupuestos extranjeros de la filosofía griega era prioritario, y esta deriva se produjo en el seno doctrinal $\breve{s} s \grave{\imath}$.

\subsection{ReCHAZO GENERAL A LA ASTRONOMÍA Y A LA ASTROLOGÍA}

4.2.1. Es conocido cómo el califa al-Manșūr (136-158/754-775), antes de comenzar la construcción de la nueva capital de Bagdad, consultó a astrónomos y astrólogos tanto acerca del mejor lugar como del mejor momento para efectuar tal fundación ${ }^{96}$. La astrología, por tanto, era ciencia admitida y utilizada en la corte 'abbāsi en el s. II/viII.

Se le atribuye a Ibn Jurradād̂bih un Kitāb al-anwāa, sobre astronomía, no conservado. No sabemos de la postura de Ibn Jurradādbih a este respecto, pero en cambio al-Ŷayhānī, el continuador de su obra (entendido como una autoría, no como tres autores), es calificado por al-Muqaddasī como filósofo y astrólogo, y añade que había solicitado a sus informadores que le enviaran datos sobre la altura de los astros y la posición que toma su sombra, en sus diversas poblaciones (una información de geografía astronómica). Estos datos sitúan claramente a los autores citados del lado de los favorables a la astronomía.

Entre las 34 obras que al-Șafadī enuncia como de autoría de al-Baljī, le atribuye un tratado de astronomía, no conservado.

Por su parte en el $K M M$ de al-Muhallabī se anota para cada lugar su indicación precisa de longitud y latitud, así como su indicación del clima (iqlìm) en que estaba situado. Es evidente que esta obra estaba en el marco conceptual de la geografía astronómica "científica» tolemaica. Con él se cierra este escaso elenco de autores relacionados con la astronomía y/o astrología.

4.2.2. En este sentido, es curioso cómo el filósofo al-Sarajsī (que no hemos hallado

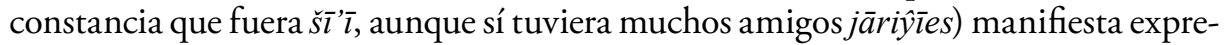
samente su rechazo hacia la astrología y la astronomía, las otras «ciencias de los antiguos» heredadas de indios y griegos, que concitaron la animadversión popular y de determinados grupos religiosos. Consideradas por estos como ciencias al servicio de la superstición y la magia, acabarán convirtiéndose en la diana de las invectivas de

${ }^{6}$ En un principio, la capital elegida fue Kūfa, pero ya al-Saffāh, el primer califa 'abbāsì, había abandonado Kūfa por razones de seguridad para ir a residir a la no lejana Hāšimīya. Será el califa al-Manșūr quien decidirá la construcción ex novo de Bagdād, llamada «la ciudad de la paz» y también «la ciudad redonda». En 145/762 se inició la construcción de la ciudad redonda de Bagdad en la orilla occidental del Tigris, y ésta se prolongó durante cuatro años. 
grupos religiosos radicales. Es éste un tema curioso, porque hay autores que le atribuyen un tratado de astronomía, pero sí que tenemos constancia de que fue autor de obras de filosofía, lógica, música, etc.

Realmente la astronomía sí que rindió importantes servicios a las ciencias de la religión, como instrumento para ayudar a orientar la qibla de las mezquitas, o como medio para fijar el calendario religioso anual, pero el rechazo se dirigía hacia la astronomía utilizada con fines de astrología, una cienciamancia que concitaba múltiples rechazos. Por otro lado, entre las "ciencias de los antiguos", filosofía y astrología concitaron amplio rechazo entre las masas populares ${ }^{97}$.

En cuanto a este aspecto, el perfil biográfico que nos ha llegado de Abū Zayd al-Baljī es interesante. Yāqūt nos informa que "atacó los secretos de la astronomía y la astrología», pero "otras veces se entregaba a las ciencias de la astronomía y la astrología», y pone en boca de al-Wazīrī que «era un buen creyente y por eso negaba la ciencia de la astrología y sus efectos, afirmaba lo contrario [que ella]», con lo que se nos dice que conocía los secretos de la astronomía, pero rechazaba su utilización en forma de astrología, con fines adivinatorios (pues esto suponía adelantarse en el conocimiento de los designios divinos, tema que -lógicamente- ponía muy nerviosos a los hombres de religión); otros autores lo resumen diciendo que «se afirma que fue médico, y astrónomo, aunque rechazaba la astrología». La línea de separación entre astronomía y astrología es la fina línea del utilitarismo de los conocimientos de la astronomía por parte de la astrología, para su uso con fines considerados ilícitos. Debido a esta fina línea de separación, generalmente se producía el rechazo de ambas, de la disciplina astronómica y de su utilización práctica como astrología, motivo por el que al-Ṣafadī afirma que «estuvo contra la ciencia de la astrología y la astronomía».

Está claro que esta animadversión de al-Baljī hacia ambas ciencias será uno de los vectores ideológicos compartidos por los autores de su escuela, continuadores de su producción geográfica y cartográfica.

\subsection{Rechazo a LA GeOgrafía DE ORIGEN GRIEGo}

4.3.1. Será al-Mas'ūdī (303-355/915-956) quien en las dos obras citadas haga un buen resumen de los conocimientos de sus contemporáneos sobre geografía matemática y física, para lo que sigue conceptos ya expresados con anterioridad por los griegos, tales como Hipócrates. En este aspecto al-Mas'ūdī es el gran sintetizador de las ciencias de los antiguos indios y griegos, no tiene reparos en presentar e integrar

${ }_{97}$ Esto es patente en el trasfondo detrás de los Ijwān al-Șafā', obligados a ocultar su identidad para no ser perseguidos. Surgen de entornos persas imbuidos y cercanos a la filosofía grecohelenística, pero para evitar su persecución por parte de determinadas élites religiosas, primero, y luego por parte del poder $a b b \bar{a} s \bar{i}$, deciden ocultar la identidad de la autoría de sus Rasā'il. 
esos saberes helenísticos con los otros escritos geográficos en árabe, así como con la literatura marítima y de viajes, y les da al final un enfoque persa muy personal.

Entre los autores de $K M M$, solo al-Muhallabī utiliza la división en climas (aqālìm) de origen griego, el resto de autores al iqlìm le dan un sentido de «región» definida por un territorio y sus habitantes, no por unas coordinadas de longitud establecidas en el pasado.

4.3.2. El rechazo hacia la geografía de origen grecohelénico se manifiesta especialmente en la «escuela de al-Baljī»: buscan nuevas soluciones a la hora de encarar la representación del mundo conocido, tanto a la hora de realizar una nueva geografía política entendida como șürat al-ard como al crear una nueva cartografía regional y mundial. Es éste un tema muy amplio, bien conocido ${ }^{98}$, del cual solo vamos a reseńar este aspecto principal.

\subsection{OBTENCIÓN DE INFORMACIONES GEOGRÁFICAS POR NUEVOS MEDIOS 4.4.1. Información obtenida por medio de corresponsales e informadores}

Entre los autores del primer grupo, Ibn Jurradādbih había ocupado cargos como jefe de Correos e Inteligencia (șăhib al-barìd wa-l-jabar) en la provincia del Ŷibāl y en Bagdad, motivo por el que había estado en una posición de privilegio para llegar a obtener informaciones relevantes sobre itinerarios, distancias y otras referencias geográficas de relevancia.

Curiosamente, su obra -que no ha perdurado completa- parece haber sido inserta en la obra colectiva de al-Ŷayhānī, con la cual se confunde en numerosas ocasiones. Vemos cómo envía cartas a diversas regiones solicitando información sobre las características geográficas de las mismas y a la par envía a corresponsales, con idéntico fin, allí donde no tiene a quién escribir; con los datos recabados escribirá un tratado rutero Kitāb al-masālik, y -según al-Muqaddasī- «esto era para él el medio para llegar a conquistar estos países y conocer sus recursos», o sea, que se le asigna una finalidad de utilidad política, militar y administrativa a la composición de esta obra.

Los dos $K M M$ citados cabría considerarlos como dos ruteros relacionados con fines administrativos similares. En Occidente el equivalente sería el $K M M$ de al-Warrāq, el cual, por haber sido un encargo del califa al-Ḥakam II para tener una relación precisa acerca de los caminos y reinos del Magreb -que él conocía bien personalmente-, sería posible encuadrarlo en este tipo de tratados que buscan el acopio de información para el servicio de los gobernantes.

En la portuaria Almería, tanto al-Bakrī como al-'Ud dīi no habrían necesitado enviar corresponsales a remotas regiones para que les trajeran información para componer sus dos obras. Solo habrían tenido que preguntar en el puerto a los navegantes que, en continuo trasiego, llegaban de todos los lugares del mundo conocido.

98 Ver F. Franco-SÁnchez, «El occidente musulmán», passim. 
A pesar de la centralidad marítima en el Mediterráneo de Sicilia, tenemos constancia de que al-Šarīf al-Idrīsī para componer su Nuzhat al-Muštāq habría enviado a corresponsales para que recabaran información desde muchas partes del mundo. Está claro que buena parte de esta información (la correspondiente a los itinerarios y a la cartografía) habría sido reaprovechada para elaborar su otra obra, el Kitāb uns al-muhaŷ.

\subsubsection{El viaje personal como medio de obtención de una información}

Fue el famoso al-Ŷăhiz (ha. 160-255/776-868) quien, por su carácter mu'tazilī, concibe el adab como un programa y un espíritu de investigación. Su racionalismo le otorga una primacía a la razón ('aql), que deriva en una actitud fundamental: la defensa de la observación directa ('iyān) como medio privilegiado del conocimiento, un «ver para creer» que se convierte en base empírica para justificar un modo diferente de fundamentar el razonamiento. Pero al-Mas'ūdī le reprochó el haber escrito de geografía sin haber viajado, lo que indica que sus ideas geográficas son ciencia de gabinete, especulativa y general.

Por el contrario, en al-Mas'ūdī (303 355/915-956) se reúnen las cualidades de un viajero/geógrafo experimentado y las del polígrafo, siendo sus aportaciones geográficas resultado tanto del resumen de conocimientos de su época como de sus viajes y observación personal.

André Miquel ha hablado largamente y en diversas publicaciones de la importancia del 'iyān, la «observación personal» mediante el viaje directo del escritor a los países y regiones que luego describe. Esto nos ahorra más consideraciones. En el 'iyān ve A. Miquel uno de los fundamentos que convertirían a esta geografía en el resultado del trabajo y de la experimentación personal, en una disciplina renovada y original. Para él se trata de una géographie 'impériale', basada en éxitos políticos y militares, que han configurado un «conjunto económica y culturalmente coherente que explica la posibilidad de viajes y, por consecuencia, la renovación, por estos viajes, de la ciencia de la tierra»" ${ }^{9}$.

Sobre este aspecto reflexiona en múltiples partes de su obra, pero puede quedar resumido en este párrafo:

Es, pues, este 'iyān el que va a definir la nueva geografía de los masālik, y ésta tan seguramente que se puede definir el fenómeno en algunas ecuaciones fundamentales: geografía administrativa + 'iyān = Ya'qūbī, șūrat al-arḍ + 'iyān = Ișțajrī, o todavía, bajo la forma de condición necesaria, si no suficiente, masālik = 'iyān. Todos los autores lo dirán con sus propias palabras: para ser geógrafo, hace falta, en primer lugar, tomar el bastón del viajero ${ }^{100}$.

99 A. Miquel, La géographie humaine, t. I, pp. 270-271, 276-280.

100 Ibidem, p. 278. 
Sirva como apunte esencial, ante lo que huelgan otras consideraciones sobre tema tan bien tratado por André Miquel. El viaje para acumular experiencias e información se apunta entre las novedades que ofrece el Kitāb al-buldān de al-Ya'qūbī, o las obras de al-Baljī (hizo un viaje de ocho años), de al-Iștajrì (viajó por el Oriente conocido), de Ibn Ḥawqal (31 años de su vida viajando) o de al-Muqaddasī (viajando continuamente desde los 20 años).

Ibn Hawqal es el modelo del geógrafo/viajero. La información obtenida tanto en persona como por medio de informadores es garantía de verosimilitud y actualidad, convirtiéndose en el modelo de esta nueva geografía de la observación, que se comienza a propugnar a partir de al-Ya'qūbī y al-Baljī.

El tunecino al-Muhallabī al-'Azīzī es otro š̉̆ ’’ que también viajó para acopiar datos para su $K M M$, aunque solo por el Próximo Oriente.

Esto ha sido visto como reflejo del pundonor científico, pero creemos que también, dado el perfil militantemente $\breve{s}^{\prime} ’ \bar{l}$ de todos ellos, no se puede obviar que también fueron informadores privilegiados de los gobernantes šl $\grave{\imath} \bar{\imath} e s$ del momento (especialmente del poder $f a \bar{t} t i m \bar{\imath})$.

El $K M M$ del cairuaní sunn̄̄ al-Warrāq, básicamente un informe exhaustivo sobre el Magreb, fue escrito por quien había crecido y vivido en la región y por ello la conocía bien.

Todos tienen en común que fueron grandes viajeros y que obtuvieron personalmente muchos de los datos que reflejan, puesto que pasaron por esas rutas y conocieron esas poblaciones que ubican y describen.

\subsection{Elogio a la figura de 'Alī y sus suCesores}

Hay unánime consideración acerca de que las creencias šs'ìes de al-Ya'qubī en su Kitāb al-buldān se evidencian por su clara hostilidad hacia los omeyas y por su atracción por la figura de 'Alī. Se ha dicho que utiliza fuentes šš̀'ies procedentes del sexto imām (Ŷa'far al-Șādiq).

Al-Muqaddasī no deja de criticar en terreno teológico los excesos de los

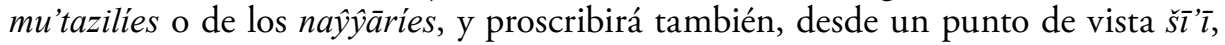
los excesos en la devoción hacia 'Alī.

El resto de autores mencionados, en su gran mayoría šš'ies, no llegan tan lejos como los citados, evitando los loores a las personalidades de la šśa con una buscada ambigüedad.

\subsection{CRíticas a LA DINASTÍA OMEYA ORIENTAL Y A LOS COETÁNEOS DE AL-ANDALUS}

Uno de los aspectos relacionados con la mentalidad šsı $\bar{\imath}$ de buena parte de los autores citados es que, llegado el caso, no dejan de criticar a los omeyas orientales o a los coetáneos omeyas de al-Andalus.

Brockelmann califica a al-Iștajrī de autor objetivo, salvo cuando habla del mālikismo del Magreb, del jāriŷismo ibādī o de los omeyas de al-Andalus. Ibn Ḥawqal 
no critica explícitamente a los omeyas andalusíes, pero describe al-Andalus como un país rico, con un ejército escaso y poco valiente y su informe es en general tendencioso (si tenemos en cuenta los votos que, en el capítulo sobre el Magreb, expresa por el éxito de las empresas de los fătimies).

De igual modo, al-Muqaddasī no deja de criticar la actitud histórica de los omeyas hacia los šš'ies. En cuanto al sunnismo, hay rechazo también del afecto excesivo hacia el omeya Mu'āwiya, del exceso de apego a los hadices y de la intransigencia general de los mälikies. En otro lugar elogia las cualidades "profanas» de los omeyas de al-Andalus, esto es, los compara con gobernantes no musulmanes.

En los pocos fragmentos que se nos han conservado del $K M M$ del magrebí al-Muhallabī no dejamos de encontrar firmes reparos contra la dinastía omeya de Damasco, lo cual es lógico, si tenemos en cuenta que la propia obra está dedicada al califa fạtimī al-'Azīz.

\section{CONCLUSIONES}

Los puntos de referencia que hemos enumerado en el epígrafe anterior son punto de partida y fundamento argumental para una serie de conclusiones que se desarrollan seguidamente.

\subsection{UNA ESTRUCTURA EXPOSITIVA COMÚN, ÚtIL DURANTE CUATRO SIGLOS PARA UNA VARIADA PRODUCCIÓN DE $K M M$}

En el trabajo anterior que dedicamos al tema ya se vio que entre las obras que llevan el título de Kitāb al-masālik wa-l-mamālik hallamos una mayoría que son de geografía, pero, sobre todo, desde las primeras, del s. III/IX, a la última, del s. $\mathrm{X} / \mathrm{XVI}$, hay una notable variedad en cuanto a sus autores y a sus contenidos ${ }^{101}$.

Por otro lado, en este estudio, dedicado únicamente a los $K M M$ de contenido geográfico, en la propia diferenciación en epígrafes ya ha quedado evidente que existen tres grupos o familias de obras: un primer grupo, el más antiguo, que reuniría a los tratados cuya finalidad era la de acopiar el máximo de información, con fines similares a los que ya Estrabón definió como el objeto de la geografía: «La mayor parte de la geografía satisface las necesidades de los estados», «la geografía en su conjunto tiene un vínculo directo con las actividades de los dirigentes»; el cometido de la geografía era, por tanto, proporcionar la información que requerían los dirigentes políticos para conquistar nuevos territorios o para mantener el poder en las tierras que regían:

101 Ver F. FranCO-SÁNCHEZ, "Al-Masālik wa-l-mamālik». 
La descripción que ofrece la geografía es de importancia para los hombres que deben saber si esto o aquello es de tal manera u otra, conocido o desconocido. Así podrán gobernar sus asuntos de forma más satisfactoria si conocen las dimensiones de un territorio, cuáles son sus accidentes y las características del cielo o del suelo ${ }^{102}$.

Idéntica finalidad hallamos en este tipo de obras de $K M M$, siendo estos administradores ligados al poder 'abbāsì los principales impulsores de las mismas, por motivos de praxis político-administrativa.

Un segundo grupo de $K M M$ lo constituyeron los autores que quisieron elaborar una nueva geografía, renovadora y renovada bajo nuevos supuestos, conocidos como la «escuela de al-Baljī» y también como del «Atlas del Islam». Éstos fueron viajeros/geógrafos orientales, militantemente šlı̀'es, a quienes les movía la necesidad de cambiar el paradigma de la representación del mundo, tanto por escrito, como cartográficamente.

Un último grupo son los autores ya occidentales y sunnīes que utilizaron esta estructura expositiva para crear nuevas obras, ya con un carácter más mixto entre geografía e historia. En este último grupo se han incluido dos obras que se salen del marco prefijado, como son las escritas por al-Muhallabī al-'Azīzī así como por al-Šarīf al-Idrīsī.

Estos tres grupos esenciales vienen a ilustrar cómo la estructura expositiva común que tienen todas estas obras de $K M M$ ha sido útil durante cuatro siglos (desde el s. III/IX al VI/XII), y en contextos bien diferentes, como modo de transmisión de unos conocimientos de carácter geográfico. La estructura básica de exposición del rutero itinerario, enriquecida con informaciones sobre poblaciones, así como con datos administrativos, económicos, etnológicos, etc., ha garantizado que estas obras de $K M M$ se haya percibido que tienen elementos comunes entre sí, a pesar de sus muchas diferencias entre unas y otras a lo largo del tiempo.

Entendemos que el elemento común esencial es esta estructura expositiva y preferimos no hablar del "género $K M M$ » porque, por lo antedicho entendemos que habría tres géneros o tipos diferenciados de obras, a los que habría que sumar las cuatro últimas obras enunciadas en el cuadro-apéndice (\$12-15) como epígonos tardíos, corolario heterogéneo para esta familia de obras etiquetadas como $K M M$.

\subsection{Los KMM, UNA NUEVA GEOGRAFÍA AL SERVICIO DE LA CAUSA Š̃ $’ \grave{I}$}

En la exposición del punto $2 .^{\circ}$ se ha perseguido reflejar con detalle lo que las fuentes nos dicen acerca de la adscripción religioso-cultural de cada uno de los autores. En el cuadro-apéndice del final se indica también, pero de modo resumido,

102 Estrabón, Geografía, Libro I, I.16, cfr. con la traducción española de J. García Blanco; J.L. García Ramón, Estrabón. Geografía. Libros III. Madrid, Gredos (Col. Biblioteca Clásica Gredos, 159), 1991, 559 pp. Cfr. G. AujaC, Strabon et la science de son temps. Les sciences du monde. París, Les Belles Lettres, 1966, 326 pp. 
cómo la mayor parte de ellos son šì īes, desde un primer momento, hasta al-Bakrī y resto de autores occidentales. Son autores cuya adscripción religiosa fue la de su época, evolucionando en algunos casos desde el jāriŷismo o el racionalismo mu'tazilī a posturas ideológicas más plenamente identificadas con el fatimismo u otros grupos de los 'alies. Se ha puesto especial interés en delimitar este marco ideológico de cada autor como modo de definir el marco esencial conceptual en que se concibieron y fueron redactadas estas obras.

Planteando que la ideología de sus autores no debe ser disociada de sus obras, hemos recogido muchas de las apreciaciones que André Miquel hiciera en su momento, para que al exponerse de modo sistemático quede más en evidencia -si cabe- el šsis ismo como el sustrato cultural en que se elaboraron la mayor parte de estas obras.

Este 'alismo militante ha sido condicionante y ha impregnado tales obras; bien, pero si esto es así, la pregunta siguiente es ¿en qué se aprecia que esta geografía es marcadamente 'alì? Dicho de otro modo ¿cuáles son los signos diferenciales de este carácter $s_{\breve{l}}^{\imath} \imath$ de la nueva geografía? Desde el inicio de esta investigación ésta es una de las cuestiones esenciales.

La respuesta a la que hemos llegado está encadenada a otras dos preguntas:

1. ${ }^{a}$ Claro, pero entonces ¿cómo sería una geografía claramente šlı $\imath$ ? . He buscado desde hace años la respuesta a esa pregunta, sin hallarla. Tampoco he encontrado bibliografía al respecto, ni tan siquiera tangencial. O nadie se ha planteado esta pregunta antes o quizás la respuesta tenga que discurrir por otros derroteros. Al final la respuesta estaba ante los ojos: no ha sido percibida como šl $\mathfrak{\imath}$ porque en todas las historias de la geografía las peculiaridades de estas obras se han visto como procedentes de la civilización y personalidad persa. El mundo cultural persa se ha presentado como precedente, como elemento diferenciador e idiosincrático que envolvió esta nueva geografía šs $s \bar{l}$.

2. ${ }^{a}$ Bien, entonces ¿̨por qué en el Occidente musulmán coetáneo y posterior éstos $K M M$ no fueron percibidos como šsı'ies? Porque son obras cuya estructura expositiva de rutero se ve complementada con la exposición de datos de geografía humana y económica, de geografía económica y física, y más tarde también con narraciones históricas. En ningún caso se recogen de modo evidente apreciaciones ni defensa de posturas religiosas 'alīes, y tenemos que leer con mucho detalle para encontrar los caracteres antes apuntados respecto a determinados juicios de valor que identifican como š̉' '̀es a algunos de sus autores. Esto ha hecho que su difusión por todo el mundo cultural árabe islámico haya sido general, y en Occidente incluso hayan sido un modelo que importantes autores han querido adaptar y completar con los datos que han conseguido acumular (en especial sobre los territorios del Occidente islámico y Europa). 


\subsection{UNA NUEVA GEOGRAFÍA AL SERVICIO DE UNA RELIGIÓN RENOVADA}

El marco intelectual en que surge esta nueva geografía queda delimitado por el oriente 'abbāsī centrado en el Bagdad de la segunda mitad del s. III/IX y el siglo IV/X. En el anterior punto $4 .^{\circ}$ hemos definido algunas de las circunstancias culturales que concurrieron y condicionaron el surgimiento de esta nueva geografía, pero no apuntamos unas conclusiones a esta exposición.

De este modo, se ha mostrado cómo a partir de mediados del s. III/IX va creciendo la condena popular y social contra la filosofía y otros saberes de las «ciencias de los antiguos» (como se ha desarrollado en $\$ 4.1$.). De entre éstas, al rechazo hacia la filosofía se le unirá una especial desaprobación de la astronomía y la astrología (entendida ésta como una aplicación práctica de la primera) (\$ 4.2.). Se ha referido en el $\$ 3$ cómo en el inicio de la geografía árabe se citan las tablas astronómicas procedentes de la India. E igualmente cómo durante el gobierno de los califas abasíes al-Manșūr (136-158/754-775) y de al-Ma'mūn (197-218/813-833) tiene lugar una progresiva traducción del saber geográfico griego al árabe, de modo que diversas obras de Aristóteles, Eratóstenes, Marino de Tiro o Ptolomeo serán vertidas al árabe y dadas a conocer en el entorno cultural de la capital 'abbāsī. En paralelo, en algunos tratados de adab del mu'tazilì al-Ŷăhị ( $h a$. 160-255/776-868) hallamos que se ha sintetizado buena parte del saber helenístico referido a astronomía, matemáticas, física, geografía general y geología, zoología, etnografía, medicina y magia (\$3.2.). Esto es, las ciencias grecohelenísticas configuraron la base cultural del período omeya y del 'abbāsì en los siglos II / VIII y III / IX.

A lo largo del s. III/IX se hicieron diversos intentos para la elaboración de esa nueva ciencia: desde los integradores y eclécticos, representados por las Rasā'il de los Ijwān al-Șafă' ${ }^{103}$, a otros que rechazaban esta aportación griega. Esta objeción se fue haciendo firme convicción entre ciertos círculos intelectuales de la šs'a, pues creían necesario que esa nueva ciencia estuviera alejada de la filosofía, y de las "ciencias de los antiguos», tal y como habían sido transmitidas hasta ese momento.

Ello implicó la desaprobación de la astronomía india y sus tablas astronómicas, de la astronomía y geografía tolemaica griega y, en general, de un tipo de geografía astronómica que pudiera parecer que estaba relacionada con el cálculo de longitud y latitud con fines cartográficos, o con la finalidad de establecer tablas astronómicas de lugares y regiones. Junto con ellas, el rechazo se extenderá a la geografía griega, y no solo a Ptolomeo, sino a todo lo que el pasado clásico grecohelenístico había legado en el ámbito de las «ciencias de los antiguos» (\$ 4.3.).

103 Sobre la Risāla dedicada a la geografía ver el estudio de G. de Callatä̈, «Kishwār-s, planètes et rois du monde: le substrat iranien de la géographie arabe, à travers l'exemple des Ikhwān al-Safä’”, en B. Broeckaert, S. Van den Branden y J.J. Pérennès (ed.), Perspectives on Islamic Culture, Cahiers du MIDEO 6, Lovaina, Peeters, 2013, pp. 53-71. Es éste un acercamiento superficial a la materia, siendo necesario un estudio más profundo de esta risāla desde el punto de vista de la historia de la geografía árabe. 
Esto conllevó una importante consecuencia: el descrédito de la astronomía o de las tablas astronómicas indicadoras de la longitud y latitud de los lugares implicó que se hubo de establecer un modo diferente de obtención de datos geográficos. De ahí que, por un lado, surgiera la necesidad de enviar corresponsales a buscar la información ( $\$$ 4.4.1.), mientras que, por otro, el 'iyān, la búsqueda personal, la comprobación in situ, se presenta como esencial para poder escribir la más atinada y fiel descripción de lugares, itinerarios y grupos humanos (\$ 4.4.2.).

En suma, estas premisas de carácter ideológico-cultural acabarán siendo condicionantes para la nueva geografía. Buena parte de sus obras, etiquetadas como $K M M-\mathrm{o}$ con títulos diferentes, pero emparentados con este espíritu- huyendo de la geografía del mundo grecohelenístico y a falta de otros elementos referenciales, se derivaron por el camino idiosincrático de lo persa. La organización del mundo según el antiguo concepto de los kišwars, la redefinición del iqlīm «clima» griego como «región", la utilización de medidas de longitud y parámetros comparativos de carácter persa, etc., servirán para estos fines de elaborar un nuevo tipo de geografía, diferente a lo conocido, sin seguir los parámetros de la geografía griega o la india. No hay otros modelos u otros caminos diferentes, de modo que las antiguas ideas persas serán las que acaben dotando de ropaje descriptivo y de marco conceptual

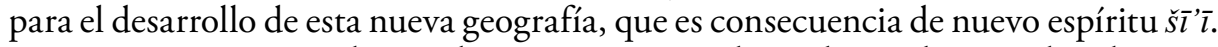

En esta misma línea, algunos autores no dejan de escribir tímidos elogios a la figura de 'Alī y sus sucesores ( $\$ 4.5)$, y bastantes más no se ahorran críticas a los omeyas del pasado o a los omeyas andalusíes del presente (\$ 4.6.).

\subsection{El COMERCiO Y LA GEOGRAFÍA COMO EXCUSA PARA EL Misionero (DẢ’}

André Miquel, al inicio del capítulo dedicado a «Lavènement d’une véritable géographie humaine: les masālik wa l-mamālik et l'étude de la terre des hommes", reconoce el ámbito poco definido que supone esta etiqueta: «La expresión de masālik wa l-mamālik con la que R. Blachère designa estas obras esenciales no es sino una convención, cómoda e insuficiente a la vez $»^{104}$. Hablando de la época en que se escribieron estas obras, se mueve en una cierta ambigüedad y, así, bajo el subepígrafe de «El siglo de los masālik wa l-mamālik», escribe que es un

siglo agitado, en todos los casos «ismailí» por retomar la palabra de Massignon, sobre un terreno que se ha vuelto propicio para las tensiones económicas y sociales y por las crisis dinásticas, étnicas o religiosas, el movimiento šš $\bar{\imath}$ se amplifica y va a dar todo su sentido a la gran confrontación de la segunda mitad del siglo, la que opone a los dos califatos rivales de los abasíes y de los fatimíes: confrontación presente, como se verá, hasta en las obras de nuestros autores.

104 A. Miquel, La géographie humaine, t. I, dedica todo el cap. vin a los tratados de KMM (pp. 267-330). Cita de pp. 267-268. 
Siglo inquieto: la bella construcción del imperio musulmán, la mamlakat al-Islām, tan viva en las consciencias, pues ella proporciona la trama, hace poco exclusiva, de los masālik, es contradicha por los hechos de la política: el Egipto fātimí, la España [sic] omeya (en la que un tercer califato ha sido proclamado en 316/929), el Jurāsān sāmāní, sin hablar de los múltiples principados locales, ni, en la misma Bagdad, del advenimiento de un poder pretoriano definitivamente consagrado en 334/945, por el protectorado būyz; todos estos hechos confirman el hundimiento temporal del califato abasí: el islam políticamente unido no es más que un recuerdo. Por su parte, los masālik viven sobre un sueńo o, por lo menos, aun conociendo la realidad, quieren vivir como si el sueño no hubiera desaparecido, y ellos continúan presentando, siguiendo en esto la ficción califal, un islam soberbiamente construido alrededor de un Bagdad del cual ellos saben, por lo tanto, de su irremediable decadencia ${ }^{105}$.

Recogemos las palabras literales de André Miquel para que la interpretación personal no las transmita de modo inadecuado. Él reconoce por un lado que el s. IV/X es un «siglo agitado, [...] 'ismailí'» mientras que, por otro lado, entiende que estas obras transmiten la imagen del imperio islámico congelada en la época gloriosa imperial 'abbāsī. Recuerda de este modo a lo que en al-Andalus fueron los "nostálgicos del califato» ${ }^{106}$, o a un al-'Udrī, cuya obra es un recuerdo notarial de un pasado extinto (la escribe en pleno siglo de las taifas, pero su $K M M$ recoge la imagen administrativa del al-Andalus califal).

Pero no incide más en el asunto, sino que comienza un análisis de las obras y de los autores en el cual se desarrollan otros aspectos. En este sentido, como se ha visto en el epígrafe anterior, no deja de anotar el carácter persa, šs' $\bar{l}$, ismà' $\bar{l} l \bar{l}$, etc., de los diversos autores, pero no llega más lejos en sus apreciaciones al respecto.

Esta descripción del marco cronológico y cultural de A. Miquel nos es de utilidad para poner el acento en un aspecto que se ha ido sazonando en forma de datos dispersos en las diversas referencias realizadas en la biografía de cada autor: su pertenencia a la šśa tiene una carácter militante y activo, lo cual nos comentan sus biógrafos, y también hemos visto que se puede reconocer en diversas pistas que hallamos en sus obras.

El grupo de los geógrafos más antiguos, los que elaboran una geografía administrativa, manifiestan su šš ísmo del modo ya indicado. No son viajeros, de modo que sus concepciones están en el rechazo a la filosofía, la astrología, las «ciencias de los antiguos» griegos, etc.

105 A. Miquel, La géographie humaine, t. I, pp. 268-269.

106 «En este grupo, no incluimos a los poetas de la corte de Almanzor aunque siguiesen componiendo como Ibn Darrāŷ al-Qaștallī, Șā’id de Bagdad o Ubāda Ibn Mā' al-Samā', supervivientes del desastre cordobés, peregrinos por las cortes de taifas, poetas hasta su muerte, sino al grupo formado por Ibn Šuhayd (992-1035), Ibn Ḥazm (994-1063), Ibn Ḥayyān (987-1067), Ibn Zaydūn (1003-1070), Ibn Burd 'el joven' y otras figuras secundarias», M.J. Rubiera, Literatura hispanoárabe. Madrid, Mapfre, 1992, p. 77. 
Este carácter del viajero está en las personalidades de al-Baljī y al-Iștajrī, pero son en especial las figuras de Ibn Hawqal y al-Muqaddasī las que se adaptan perfectamente al perfil del comerciante que, con la disculpa de hacer acopio de datos para una geografía mundial elaborada bajo los presupuestos del rigor y el 'iyān, encuentran el motivo perfecto para la encuesta, quizás seguida del adoctrinamiento, labo-

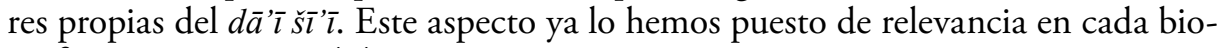
grafía, así como en $\$ 4.4 .2$.

Hay que apuntar que estos misioneros, junto con su coetáneo al-Muhallabī, ejercieron de informadores para el nuevo imperio fạtîmin de El Cairo, pero, sobre todo, ejercieron de propagandistas del mismo (sin ahorrarse algunas críticas menores, como ya hemos apuntado que hacen Ibn Hawqal y al-Muqaddasī).

\section{5. ¿UNA GEOGRAFÍA SOLO DEL MUNDO ISLÁMICO?}

André Miquel califica estos $K M M$ como una "geografía del islam», y otros autores hablan del "Atlas del Islam» para referirse a la cartografía que se encuentra asociada a la «escuela de al-Baljī». Creemos que, sin ser inexacta, esta caracterización es incorrecta.

Si revisamos estos $K M M$ vemos cómo de la familia de compendios administrativos poco podemos concluir, al conformarla varias obras incompletas, algunas de las cuales no conservadas. Las obras de al-Ya'qūbī y al-Ŷayhānī parecen haber tenido un carácter global, mientras que las de Qudāma Ibn Ŷa’far e Ibn Jurradādbih no parecen haber ido más allá de ser meras geografías regionales.

Es al-Baljī el epónimo de un grupo de geógrafos que solo describen en sus obras el mundo conocido, esto es el mundo islámico, con excepción de los mapamundis. En sus textos y cartografía únicamente hablan del mundo islámico conocido, minusvalorando, cuando no directamente olvidando, los territorios más allá del mismo.

Esta tendencia la rompe al-Muhallabī, cuya geografía es más que una geografía exclusivamente del mundo islámico, puesto que se puso como objetivo elaborar una nueva imagen del mundo.

Entre los occidentales, solo el $K M M$ de al-Warrāq es una obra regional dedicada al Magreb, mientras que los tratados de al-Bakrī, al-'Ud dn̄î y finalmente al-Idrīsī buscan la descripción de todo el mundo conocido, más allá de las fronteras del islam, buscando convertirse en geografías de carácter global.

Solo la «escuela de al-Baljī», por tanto, participa de este carácter de geografía únicamente de los territorios del islam. La realidad es que para un musulmán era asunto peligroso y complejo el viaje más allá de las fronteras del islam, convirtiéndose en comprometido el acopio personal de datos. Pero podrían haber utilizado cartografía tolemaica para elaborar sus mapas, o haber consultado otros textos árabes o griegos más antiguos para tomar las informaciones necesarias sobre Europa, África o Asia. La realidad es que creemos que la ausencia de la descripción de estas partes del mundo en sus obras se debe al consciente rechazo de utilizar otras obras escritas, de hacer una geografía de gabinete en base a textos precedentes, y más si 
procedían de la denostada tradición grecohelenística o india. En ello no podemos dejar de ver un cierto fanatismo, puesto que prefiere hurtarse esta información al lector interesado que incluirla sin haber sido comprobada fehacientemente.

También hay otra posible interpretación para ello: el mundo que no es islámico no merece la pena ser conocido. Pero hemos visto cómo en algunos juicios que hallamos en sus obras hay crítica, incluso a algunos gobiernos o grupos de šììies. En consecuencia, no encontramos en ellas un grado tan alto de intransigencia como este juicio indicaría.

Recepción: julio 2018, aceptación: noviembre 2018 


\section{BIBLIOGRAFÍA}

Anagnostakis, Christopher, The Arabic Version of Ptolemy's Planisphaerium. New Haven, CONN., Yale University Press, 1984.

Arendonk, C. VAN, «Ibn Ḥawḳal, Abū l-Ḳāsm (Muhammad)». EI'1 , vol. III (1913), p. 83.

Asín Palacios, Miguel, «El Libro de los Animales de Jāḥiẓ». Isis, vol. Xiv, núm. 43 (1930 mayo), pp. 31-70.

'Aț̣̂̄' AllāH, J. Aḥmad, Bayt al-Hikma fī 'aṣr al-'Abbāsīyīn. El Cairo, Dār al-Fikr al-'Arabī, 1989.

'Ațītū MaḥmŪD, Ḥ. 'Abbās y ḤAlLĀQ, Ḥassān, Al-'ulūm 'inda l-'arab. Beirut, Dār al-Nahụa al-'Arabīya, 1990.

Aujac, Germaine, Strabon et la science de son temps. Les sciences du monde. París, Les Belles Lettres, 1966.

AL-BAKRī, Abū 'Ubayd, Kitāb al-masālik wa-l-mamālik. Ed. ár. Adrien P. van Leeuwen y André Ferré, Kitāb al-masālik wa-l-mamālik li-Abī 'Ubayd al-Bakrī. Qarțāŷ (Túnez), Dār al-'Arabīya li1-Kitāb / Bayt al-Ḥikma, 1992, 2 vols. Reproducción, Dār al-Garb al-Islāmī, 1992, 2 vols.

Blachère, Régis, Henri Darmaun, Extraits des principaux géographes arabes du Moyen Âge. París, Librairie C. Klincksieck (Collection Études arabes et islamiques), $1957^{2}$.

Bosworth, C.E., «Ebn Kordādbeh (or Korradād̂dbeh), Abu'l-Qāsem 'obayd-Allāh b. 'Abd-Allāh». Encyclopadia Iranica. Londres, 1982, vol. viII, pp. 37-38. http://www.iranicaonline.org/ articles/ebn-kordadbeh.

Brockelmann, Carl, Geschichte der Arabischen Litteratur (GAL). Leiden, E.J. Brill, 1937-1942.

Callatä̈, Godefroid de, «Kishwār-s, planètes et rois du monde: le substrat iranien de la géographie arabe, à travers l'exemple des Ikhwān al-Safä'», en B. BroecKaert, S. VAN DEN Branden y J.J. Pérennès (eds.), Perspectives on Islamic Culture, Cahiers du MIDEO 6, Lovaina, Peeters, 2013, pp. 53-71.

Canard, Marius, "L'impérialisme des fātimides et leur propagande». Annales de l'Institut d'Études Orientales de la Faculté des Lettres d'Alger, n. vi, 1942-1947, pp. 156-193.

Carmona González, Alfonso, "Las corrientes doctrinales del Occidente musulmán vistas por geógrafos orientales del siglo X», en Actas del II Coloquio Hispano-Marroqui de Ciencias Históricas "Cultura, Ciencia y Sociedad", Granada, 6-11 noviembre 1989, Madrid, ICMA / Al-Andalus'92, 1992, pp. 107-114.

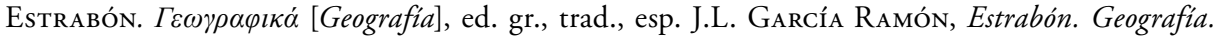
Libros III. Madrid, Gredos (Col. Biblioteca Clásica Gredos, 159), 1991.

Franco-SÁnchez, Francisco, «El occidente musulmán en los mapas del Mediterráneo de la "escuela de al-Baljî" (s. Iv H./x J.C.)», en Ana I. Planet y Fernando Ramos (eds.), Relaciones hispano-marroquies: una vecindad en construcción, Madrid, Ediciones del Oriente y del Mediterráneo, 2005, pp. 35-62.

Franco-SÁnchez, Francisco, «El tratado de Teodomiro en su contexto histórico y paleográfico». eHumanista/IVITRA, núm. 5 (2014), $\$ 4$, pp. 325-327. http://www.ehumanista.ucsb.edu/ ivitra/volumes/5.

Franco-SÁnchez, Francisco, «Al-Masālik wa-l-mamālik: Precisiones acerca del título de estas obras de la literatura geográfica árabe medieval y conclusiones acerca de su estructura expositiva». Philologia Hispalensis, vol. 31/2 (2017), pp. 37-66. 
[EI $I^{1}$ Houtsma, M.T. et al. (eds.), The Encyclopedia of Islam: A Dictionary of the Geography, Ethnography and Biography of the Muhammadan Peoples. Leiden/Londres, E.J. Brill/Luzac, 1913-1938, 4 tomos y 5 suplementos (reimpesión: Leiden/New Yorl/Köln, E.J. Brill, 1993, 8 vols. + 1 Suppl.).

[EI²] Bearman, P.J., Th. Bianquis, C.E. Bosworth, E. Donzel, W.P. Heinrichs et al. (eds.), Encyclopédie de l'Islam, nouvelle èdition. Leiden, E.J. Brill, 1960-2005, 12 vols. Ed. inglesa: The Encyclopaedia of Islam. 2nd edition. Leiden, E.J. Brill, 1960-2005, 12 vols.

Goeje, Michael Jan de (ed.), Bibliotheca Geographorum Arabicorum. Leiden, E.J. Brill, 1870-94. Reedición, Leiden, E.J. Brill, 1967.

Al-HamDĀNī, Lisān al-Yaman Abū Muḥammad al-Ḥasan, Șifa Ŷazīrat al-'Arab. Ed. ár. D.H. Müller, Al-Hamdānī. Șifa Ŷazìrat al-'Arab. Leiden, 1884-1891.

IbN ḤAwQAL, Abū l-Qāsim Muḥammad, Kitāb șūrat al-arḍ, o Kitāb al-masālik wa-l-mamālik. Ed. ár. M.J. de Goeje, Bibliotheca Geographorum Arabicorum. Pars Secunda. Viae et Regna. Descriptio Ditionis Moslemicae, auctore Abu'l-Kásim Ibn Haukal, Leiden, E.J. Brill (BGA, II), 1873. Ed. ár. J.H. Kramers, Opvs Geographicvm auctore Ibn Hawkal (Abū l-Kāsim Ibn Hawkal alNașībī). Secundum textum et imagenes Codicis Constantinopolitani conservati in Bibliotheca antiqui Palatii n. 3346 cui titulus est "Liber Imaginis Terrae». Leiden, E.J. Brill, 1938. Trad. fr. J.H. Kramers por G. Wiet, Ibn Hawqal. Configuration de la Terre (Kitāb Șūrat al-Arḍ). Beirut-París, Maisonneuve et Larose / Comission Internationale pour la Traduction des Chefs-Oeuvre, 1964, 2 vols.

Ibn Ḥ̂ŶAR AL-'AsQALĀNī, Abū l-Faḍl Aḥmad, Lisān al-mīzān. Ed. 'Abd al-Fațțāḥ Abū Gudda. Beirut-Damasco, Dār al-Baššā'ir, 2002.

IBN 'IQ̣ĀR̄̄, Abū l-'Abbās Aḥmad, Al-Bayān al-mugrib fī ijtișār ajbār mulūk al-Andalus wa-l-Magrib. Ed. ár. Reinhardt P. Dozy, Histoire de l'Afrique et de l'Espagne intitulée al-Bayano'l-mogrib par Ibn Adhari (de Maroc), des fragments de la Chronique d'Arîb (de Cordue). Leiden, E.J. Brill, 1848-1851, 2 vols. Ed. ár. G.S. Colin; É. Lévi -Provençal, Histoire de l’Afrique du Nord et

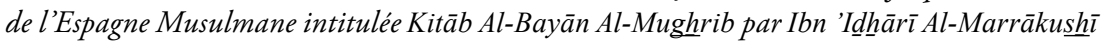
et fragments de la Chronique de 'Arīb. Tome Premier. Histoire de l'Afrique du Nord de la Conquête au XIe. Siècle. Leiden, E.J. Brill, vol. I, 1948.

IbN JURRADĀd̄BIH, Abū l-Qāsim 'Ubayd Allāh, Kitāb al-masālik wa-l-mamālik. Ed. ár. M.J. de Goeje, Kitâb al-Masâlik wa'l-Mamâlik (Liber Viarum et Regnorum) auctori Abu'l Kâsim Obaidalla ibn Abdallah Ibn Khordâdhbeh et excerpta e Kitâb al-Kharâdj auctori Kodâma ibn Dja'far, quae cum versione gallica edidit, indicibus et Glosario instruixit M.J. de Goeje. Leiden, E.J. Brill (BGA vi), 1889.

Al-IDRīsī, Abū 'Abd Allāh Muḥammad, aš-Šarīf al-Idrīsī Uns al-muhây wa-rawḍ al-furây. Ed. ár. Fuat Sezgin, Al-Idrīsī (d. ca. 560/1165). Uns al-muhaj wa-rawd al-furaj. The Entertainment of Hearts, and Meadows of Contemplation. Frankfurt am Main, ed. Institute for the History of Arabic-Islamic Science (Series C - 7), 1984.

Al-IDrīsī, Abū 'Abd Allāh Muhammad, Al-Idrīsī. Los caminos de al-Andalus en el siglo XII según Uns al-Muhây wa-rawd al-furây. Trad. esp., estudio, Jassīm Abid Mizal [Alubudi]. Madrid, CSIC, 1989.

Al-IșFAhāNī, 'Imâd al-Dīn, Al-Bustān al-Ŷāmi' li-Ŷami' tawārīj ahl al-zamān. Ed. ár. 'Umar 'Abd alSalām Tadmurī. Beirut, al-Maktabat al-’Așrīya, 2002.

Al-JațīB AL-BAGDĀDī, Tārīj Bagdād wa-dِduyūlu-hu. Ed. ár. Mușțafà 'Abd al-Qādir 'Aț̣̂̄a. Beirut, Dār al-Kutub al-'Ilmīya, 1417/1996-7. 
KaCıMI, Mourad, Edición crítica árabe y estudio de la Risālat al-ŷāmı̄’a d̄āt al-fawā'id al-nāfi'a, tāŷ Rasā'il Ijwān al-Ṣafā' (finales del s. IV H. IX e.C, principios del s. V H. /XI e.C.). Tesis doctoral defendida en la Universidad de Alicante el 7 de julio de 2015.

KACıMI, Mourad, "Al-Tā’wīl al-bāținī: Asbābuḥu wa-mașādiruhu (Ijwān al-Ṣafā’ namūḍayan)». AlTawāṣulīya, vol. 4 (2015), pp. 169-198.

KACıMI, Mourad, «El pensamiento bațin̄̄ en Al-Andalus: Reflexiones a partir de la Rutbat al-hakīm y la Gāyat al-hakìm (s. Iv H./x e.C.)». Estudios sobre Patrimonio, Cultura y Ciencias Medievales, Granada, ed. Grupo de Investigación HUM-165: Patrimonio, Cultura y Ciencias Medievales, vol. 19 (2017), pp. 731-735.

Kunitzsch, P., «Ibn Qutayba». Dictionary of Scientific Biography. Nueva York, Charles Scribner's Sons, vol. 11, 1981.

LÉvi-ProvenÇal, Évariste, «Abū ’Ubayd al-Bakrī». $E I^{2}$, vol. I (1960), pp. 159-161.

Lirola Delgado, Jorge, «Al-Bakrī, Abū 'Ubayd». Biblioteca de al-Andalus [BA], dirección y edición Jorge Lirola Delgado. Almería, Fundación Ibn Tufayl de Estudios Árabes, 2004-2012, vol. 1, pp. 154-160.

LÖFGREN, Oscar, «Al-Hamdān̄̄». EI $I^{2}$, vol. III (1971), pp. 126-128.

Maqbul Ahmad, Sayyid, «Djughrāafiyā». $E I^{2}$, vol. II (1965), pp. 590-602.

AL-MAS'ŪDī, Abū l-Ḥasan 'Alī, Kitāb murūŷy al-dֵahab wa-ma'ādin al-ŷawhar. Ed. ár., trad. fr. C. Barbier de Meynard y Pavet de Courteille, Les Prairies d'or. París, Imprimerie Impériale, 1861-1877, 9 vols. Reeditado en París, Geuthner, 1930, 9 vols. Ed. ár. Charles Pellat, Mas'ūdī. Les Prairies d'or. Edition Barbier de Maynard et Pavet de Courteille, revue et corrigée par Charles Pellat. Beirut, Publications de l'Université Libanaise, 1962-1965, 2 vols.

Micheau, Françoise, «Les institutions scientifiques dans le Proche Orient médiéval». Histoire des sciences arabes. 3. Technologie, alchimie et sciences de la vie, Sous la direction de Roshdi Rashed, París, Éditions du Seuil, vol. 3 (1997), pp. 233-254.

Miquel, André, «Comment lire la littérature géographique arabe au Moyen Age?». Cahiers de Civilisation Médiévale, vol. 2 (1972 janvier-mars), pp. 97-104.

Miquel, André, La géographie humaine du monde musulman jusqu'au milieu du 11e. siècle. Géographie et géographie humaine dans la littérature arabe des origines à 1050. París-La Haya, ed. Mouton \& École Pratique des Hautes Études, tomo 1 (1967), tomo 2 (1975), tomo 3 (1980), tomo 4 (1988).

Morelon, Régis, «Tābit b. Qurra and Arab Astronomy in the 9 th. Century». Arabic Sciences and Philosophy. A Historical Journal, vol. 4, núm. 1 (1994), pp. 111-140.

Mu’NIs, Ḥusayn, «Al-Ŷugrāfīya wa-l-ŷugrāfīyūn fī-l-Andalus min al-bidāya ilà 1-Ḥiŷārī». Revista del Instituto de Estudios Islámicos en Madrid, vol. viI-viII (1959-1960), pp. 199-359 [parte árabe]; resumen 213-228.

Mu’NIs, Husayn, «Las traducciones del texto y los mapas de la Geografía de Ptolomeo», en La Traducción y la critica Literaria. Actas de las Jornadas de Hispanismo Arabe, Madrid, ICMA, 1990, pp. 303-306.

Al-Muqaddasī, Šams ad-Dīn Abū 'Abd Allāh Muhammad, Kitāb aḥsan at-taqāsīm fī ma'rifat alaqā̄ìm. Ed.ár. M.J. de Goeje, Bibliotheca Geographorum Arabicorum. Pars Tertia. Descriptio Imperii Moslemici auctore Al-Mokaddasi. Leiden, E.J. Brill, 1877. Segunda ed. ár., Leiden, E.J. Brill, 1906. 
Mžıк, Hans von, «Ptolemaeus und die Karten des arabischen Geographen. Vortrag gehalten in der Fachsitzung der KK geographischen Gesellshchaft in Wien». Mitteilungen der KK, vol LVIII (1915), pp. 152-176.

MžıK, Hans von, "Osteuropa nach der arabischen Bearbeitung der Geografikà Huphêgêsis des Klaudios Ptolemaios von Moḥammed Ibn Mūsa al Khuwārizmī». Wiener Zeitung Fûr die Kunde des Morgenlandes, vol. XLIII (1936), pp. 161-193.

Nallino, Carlo Alfonso, Al-Huwārizmī e ilsuo rifacimento della Geografia di Tolomeo. Roma, Accademia dei Lincei (Memoria della Reale Accademia dei Lincei, serie v, vol. II, 1), 1894, pp. 4-53.

Nef, Annliese, «Al-Idrīsī: un complément d'enquête biographique», en Henri Bresc y Emmanuelle Tixier du Mesnil (dirs.), Géographes et voyageurs au Moyen Âge, París, Presses Universitaires de Paris Ouest, 2010, pp. 63-64.

O’Leary, D. Lacy, How Greek Science Passed to the Arabs. Londres, 1949. Reimpr. Londres-Boston, Henley, 1979.

Pellat, Charles, Description de l'Occident Musulman au IVe.-Xe. Siècle. Argel, 1950.

Pellat, Charles. «Al-Mas'ūdī». $E I^{2}$, vol. vi (1991), pp. 784-789.

Pocklington, R., "Al-Warrāq, Muḥammad». Biblioteca de al-Andalus [BA], dirección y edición Jorge Lirola Delgado, Almería, Fundación Ibn Tufayl de Estudios Árabes, 2004-2012, vol. 7, pp. 614-615.

Rosenthal, Franz, Ahmad b. aț-Tayyib as-Sarahsī. A Scholar and a Littérateur of the Ninth Century. New Haven, CONN., American Oriental Society, 1943.

Rosenthal, Franz, The Classical Heritage in Islam. Berkeley, California University Press, 1975.

Rubiera, M.J., Literatura hispanoárabe. Madrid, Mapfre, 1992.

Rubinacci, Roberto, "Intorno al cosidetto Piccolo Idrîsî», en Bianca Scarcia Amoretti y Lucia Rostagno (eds.), Yâd-nâma: in memoria di Alessandro Bausani, vol. II: Storia della Scienza-Linguistica-Letteratura, Roma, Bardi Editori / Università di Roma «La Sapienza» "Studi Orientali», vol. x), vol. II, 1991, pp. 88-96.

AL-ṢAfAḍ̄ī, Șalaḥ al-Dīn Jalīl, Al-Wāfī bi-l-wafāyāt. Ed. ár. Aḥmad al-Arnā'ūṭ y Muṣțāà Turkī. Beirut, Dār Iḥyà al-Turāta 2000.

Salama-CARr, Myriam, La traduction à l'époque abbaside: l'école de Hunayn Ibn Ishāq et son importance pour la traduction. París, Didier Érudition. Coll. «Traductologie», n. 6, 1990.

Saliba, George, "Arabic Science and the Greek Legacy», en Josep Casulleras y Julio Samsó (eds.), From Baghdad to Barcelona. De Bagdad a Barcelona. Estudios sobre Historia de las Ciencias Exactas en el Mundo Islámico en honor del prof. Juan Vernet, Barcelona, Universitat de Barcelona/CSIC, 1996, pp. 19-37.

SAmsó, Julio, Las ciencias de los antiguos en al-Andalus. Madrid, Mapfre, 1992.

SARton, George, Introduction to the History of Science. Baltimore, Carnegie Institution of Washington, $1927-1948$.

Tibbets, Gerald R., «The Balkhī School of Geographers», en J.B. Harley y David Woodward (eds.), The History of Cartography. Volume Two. Book One. Cartography in the Traditional Islamic and South Asian Societies, Chicago-Londres, The University of Chicago Press. Vol. II/1, pp. 108-136.

AL-'Uḍ̂̄, Abū l-'Abbās Aḥmad, Kitāb tarșī' al-ajbār wa-tanwī' al-ātāār wa-l-bustān fī garā' ib al-buldān wa-l-masālik ilà ŷamī' al-mamālik. Ed. ár. 'Abd al-'Azīz AL-Ahwān̄i, Ahmad Ibn 'Umar Ibn 


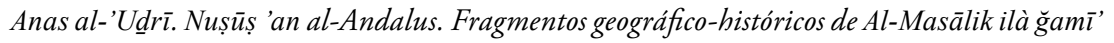
al-Mamālik. Madrid, Instituto Egipcio de Estudios Islámicos de Madrid, 1965.

Vaulx d'Arcy, Guillaume de, Les Épîtres des Frères en Pureté (Rasā'il Ihwwān aṣ-șaāā) une pensée de la totalité. Établissement de la paternité historique et commentaire philosophique de l'ouvrage. Tesis doctoral defendida el 19 noviembre de 2016 en la Université Paris-Sorbonne (École Doctorale v).

Vernet, Juan, La cultura hispano árabe en Oriente y Occidente. Barcelona, Ariel, 1978.

Vernet, Juan, Estudios sobre Historia de la Ciencia Medieval. Barcelona-Bellaterra, Universidades Central y Autónoma de Barcelona, 1979, pp. 21-60.

AL-Ỵ̣̂̄̄ıẓ, Abū 'Uțmān 'Amr, Kitāb al-ḥayawān. Ed. ár. A.M. Hārūn. Beirut, Dār Iḥyā' al-Turāṭ al'Arabī, 1388/1967 (2. ${ }^{a}$ ed.), 7 vols. Ed. ár. F. Ațwī. [s.l.], 1982.

AL-Ŷāḥız, Abū 'Uțmān 'Amr, Kitāb al-tarbī'a wa-l-tadwīr. Ed. ár. G. van Vloten, Tria opuscula auctore al-Djahiz. Leiden, 1903. Ed. ár. Charles Pellat. Damasco, Institut Français de Damas, 1955. Trad. esp. P. Buendía Pérez, Ŷăhiz. Libro de la cuadratura del círculo. Madrid, Gredos, Col. Clásicos Medievales, 9, 1998.

YĀQūT al-Ḥamāwī, Iršād al-arīb ilà ma'rifat al-adīb o Iršād al-albā' ilà ma'rifat al-udabā'. Ed. ár. de Iṇsān 'Abbās, Mu'ŷam al-'udabā'. Beirut, Dār al-Garb al-Islāmī, 1993, 7 vols. 


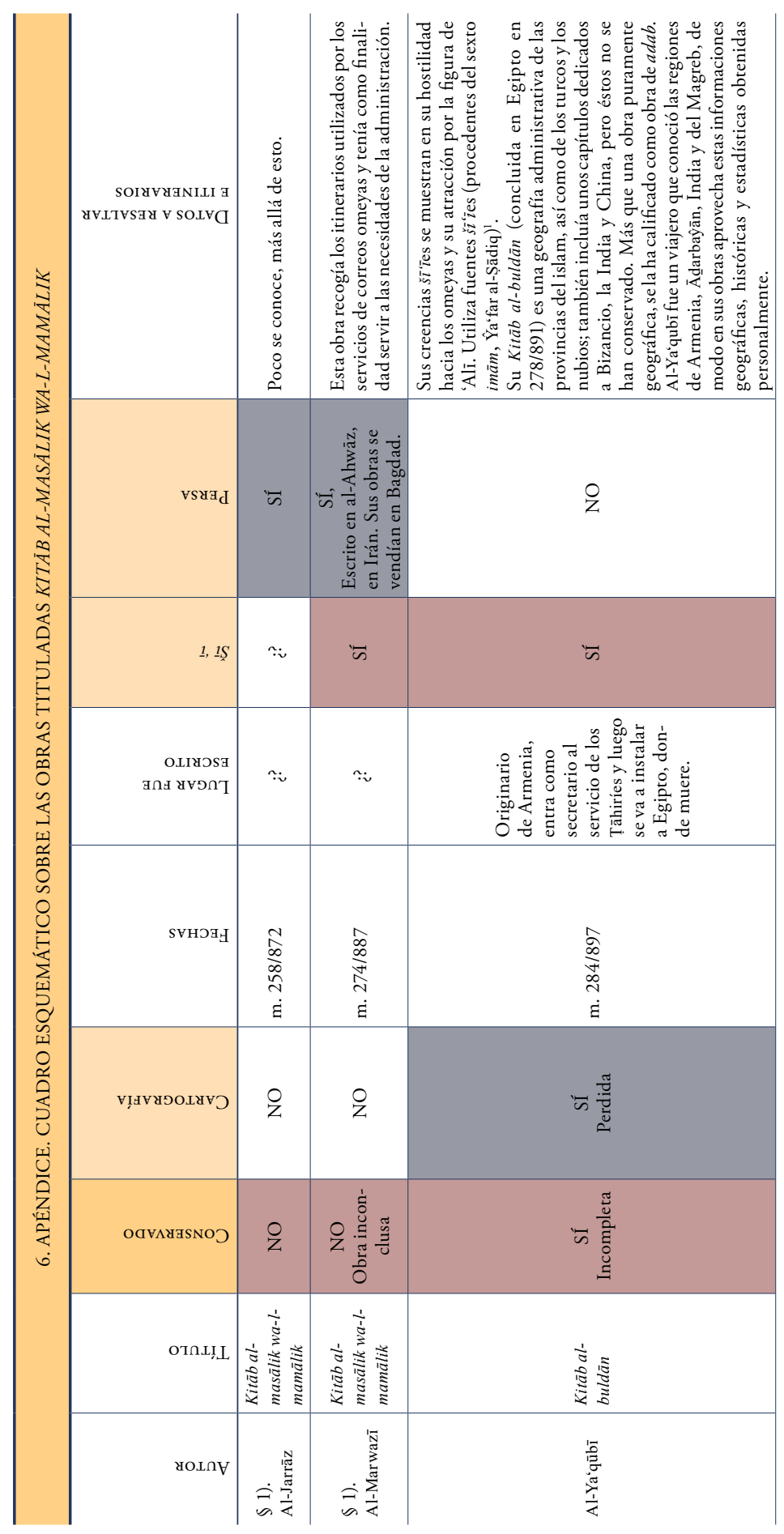




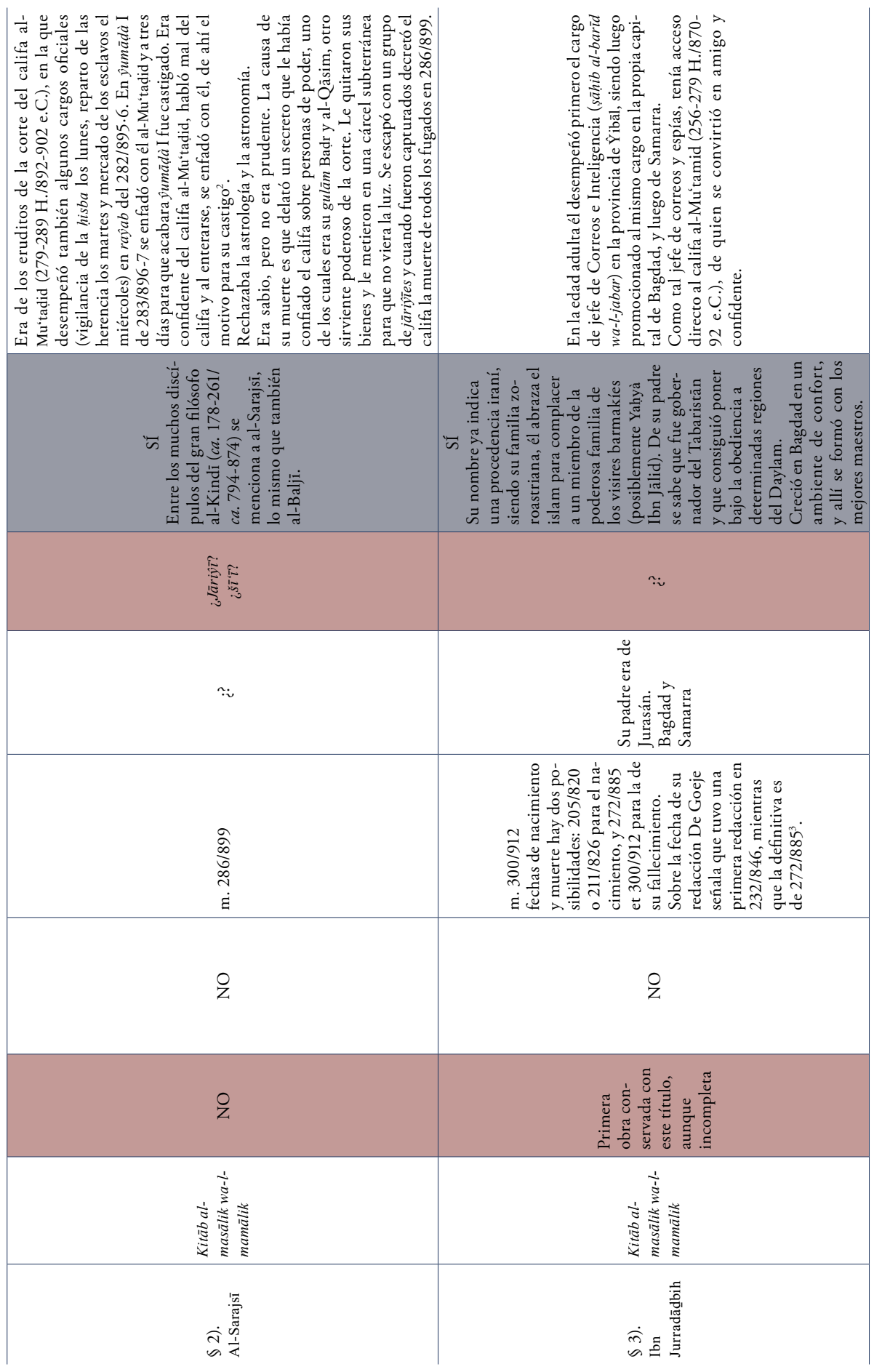




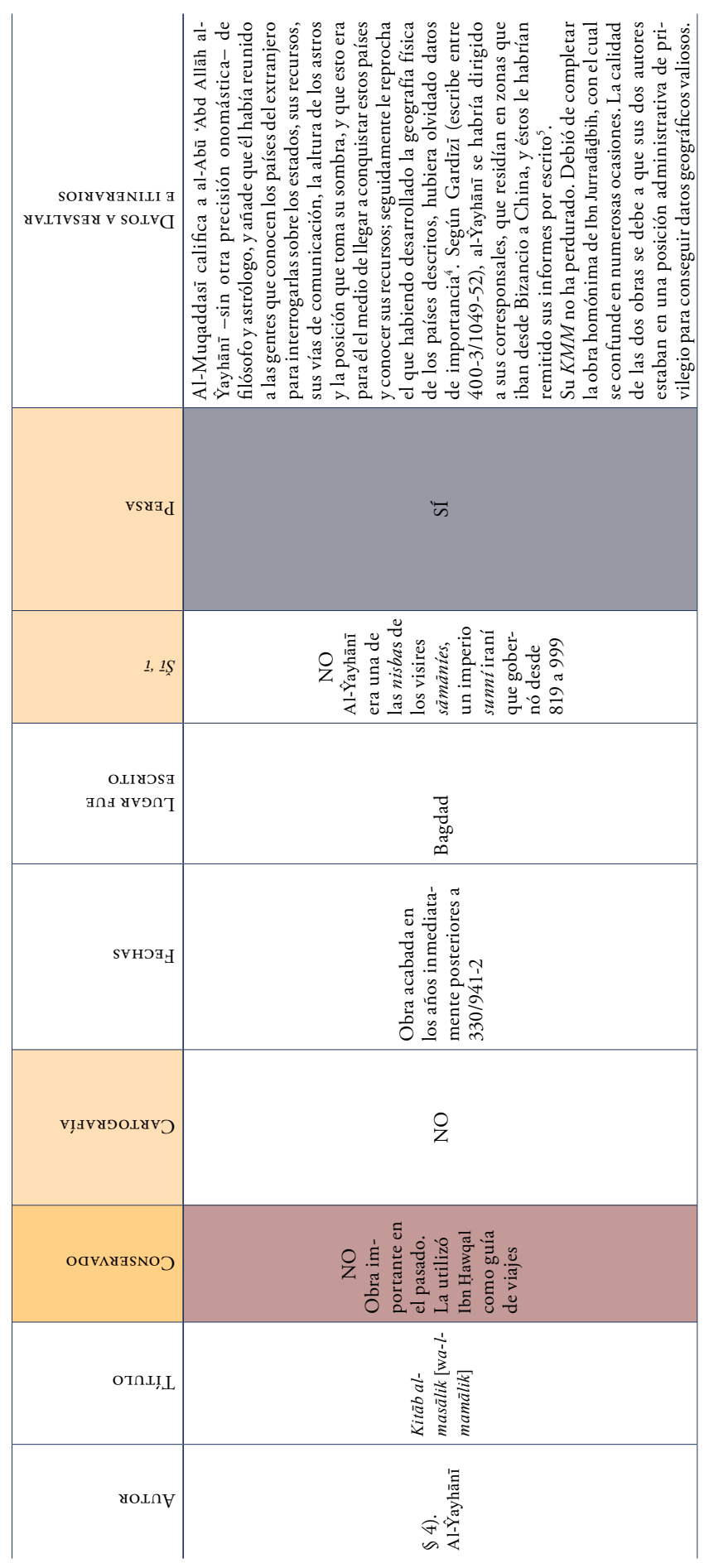




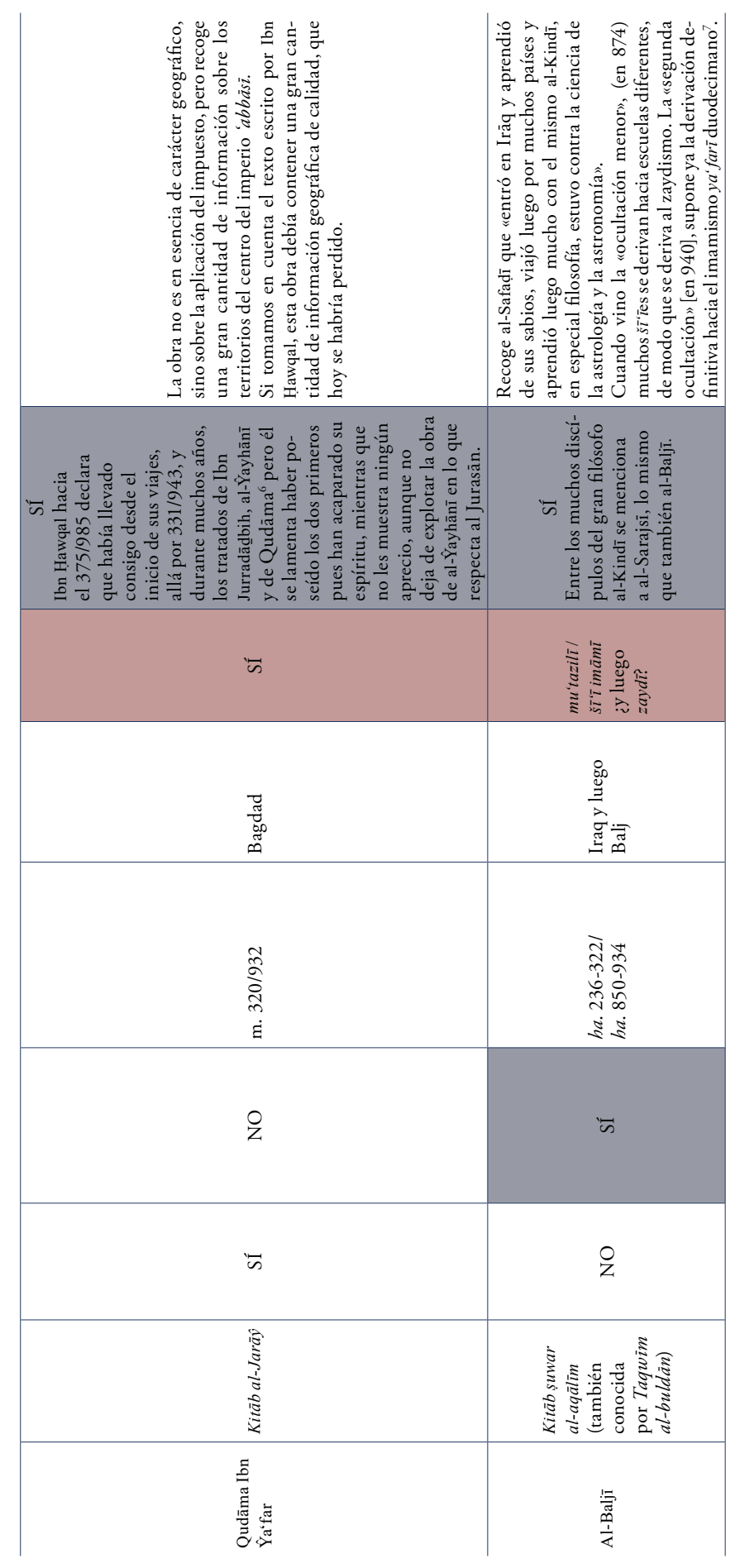


SOIYVYGNILI A EVITVSGY V SOLVC

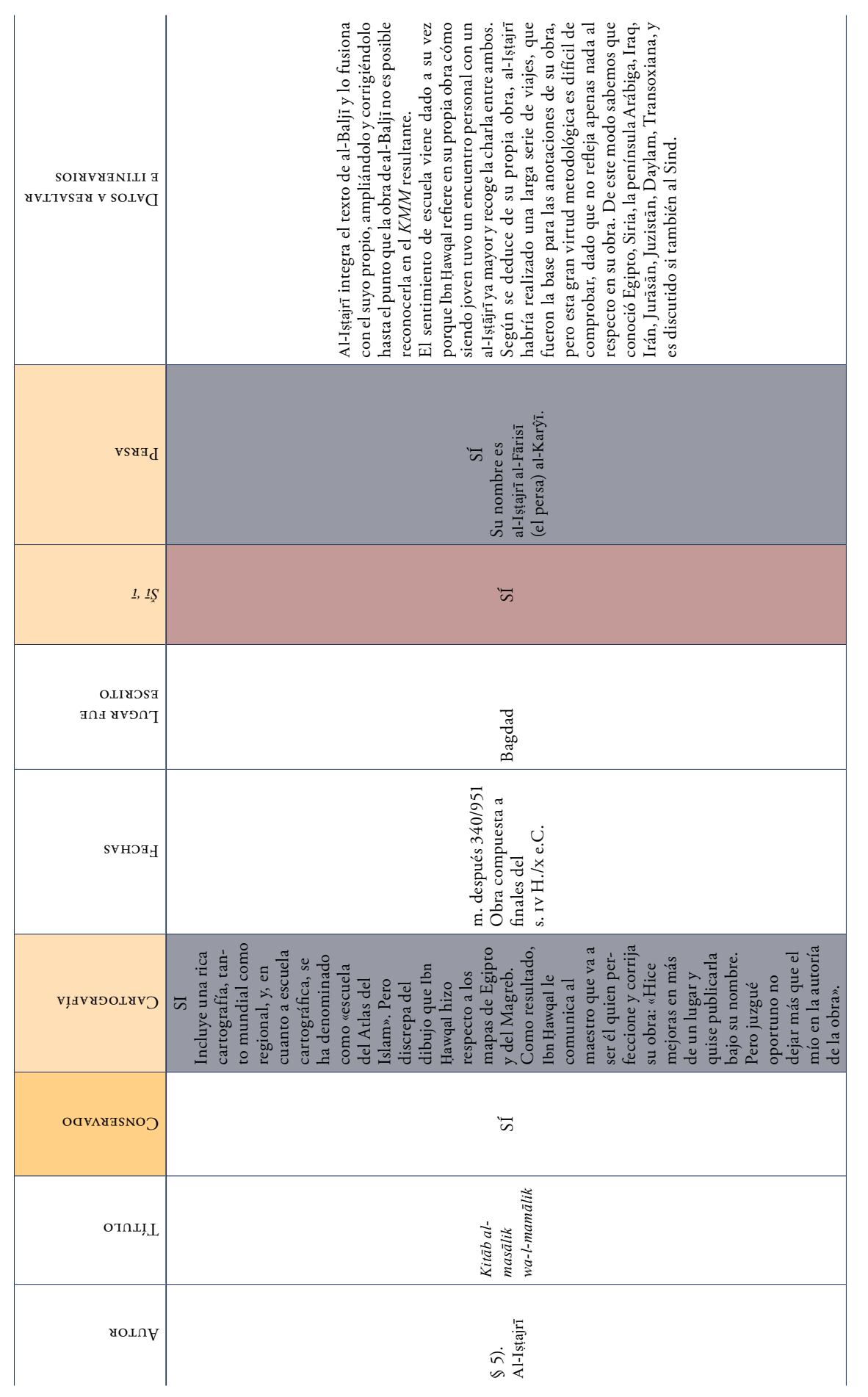



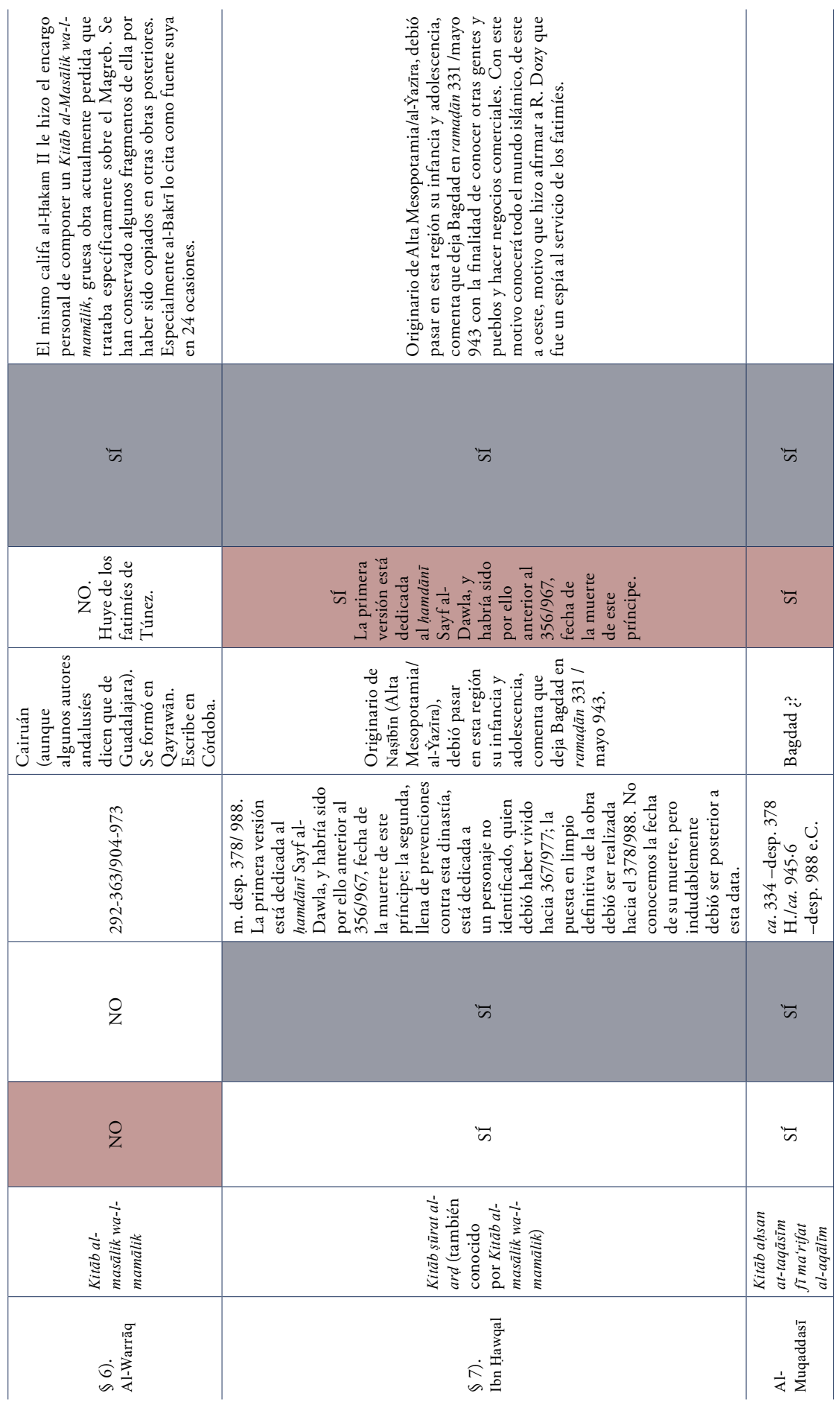


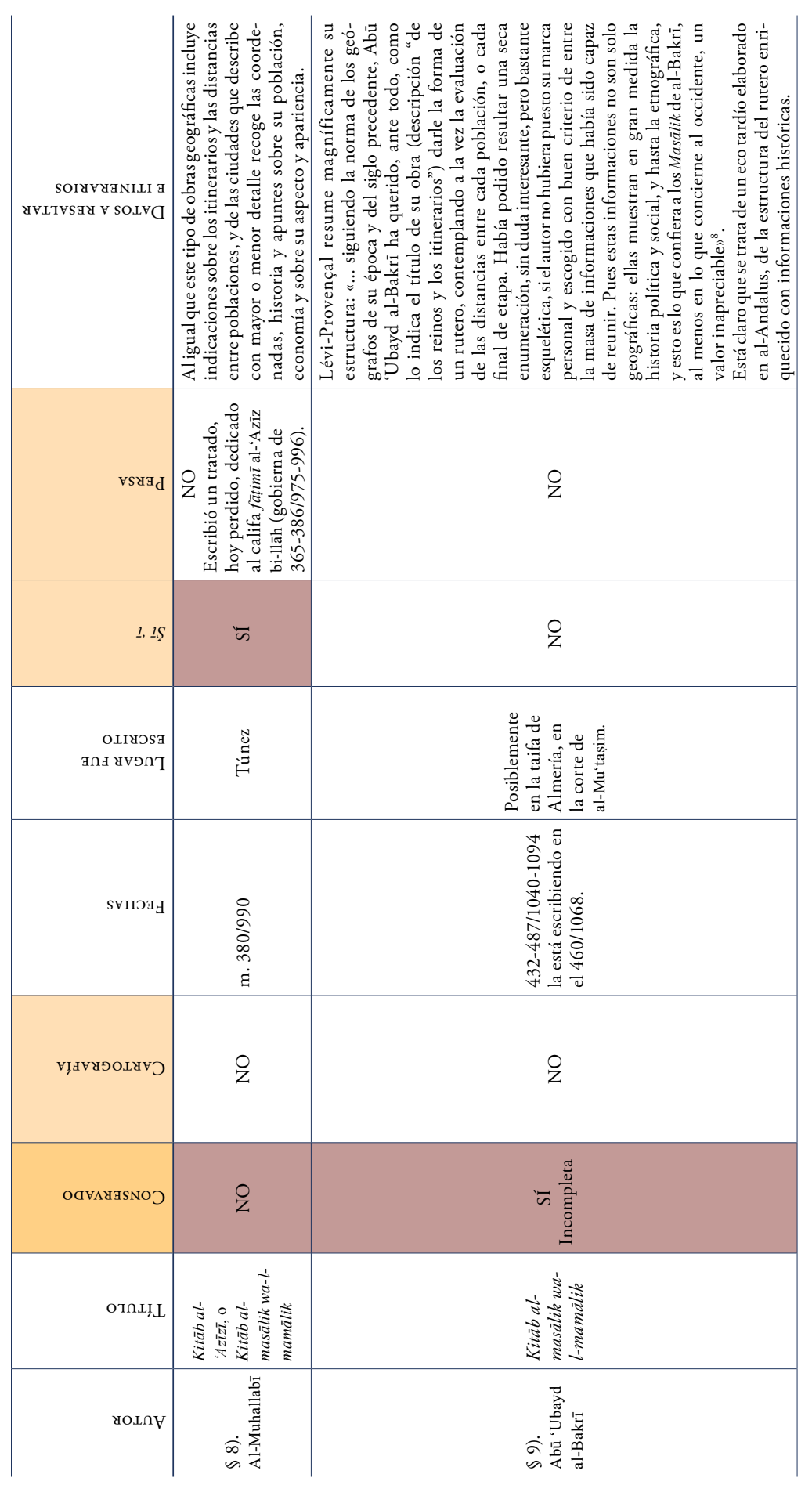




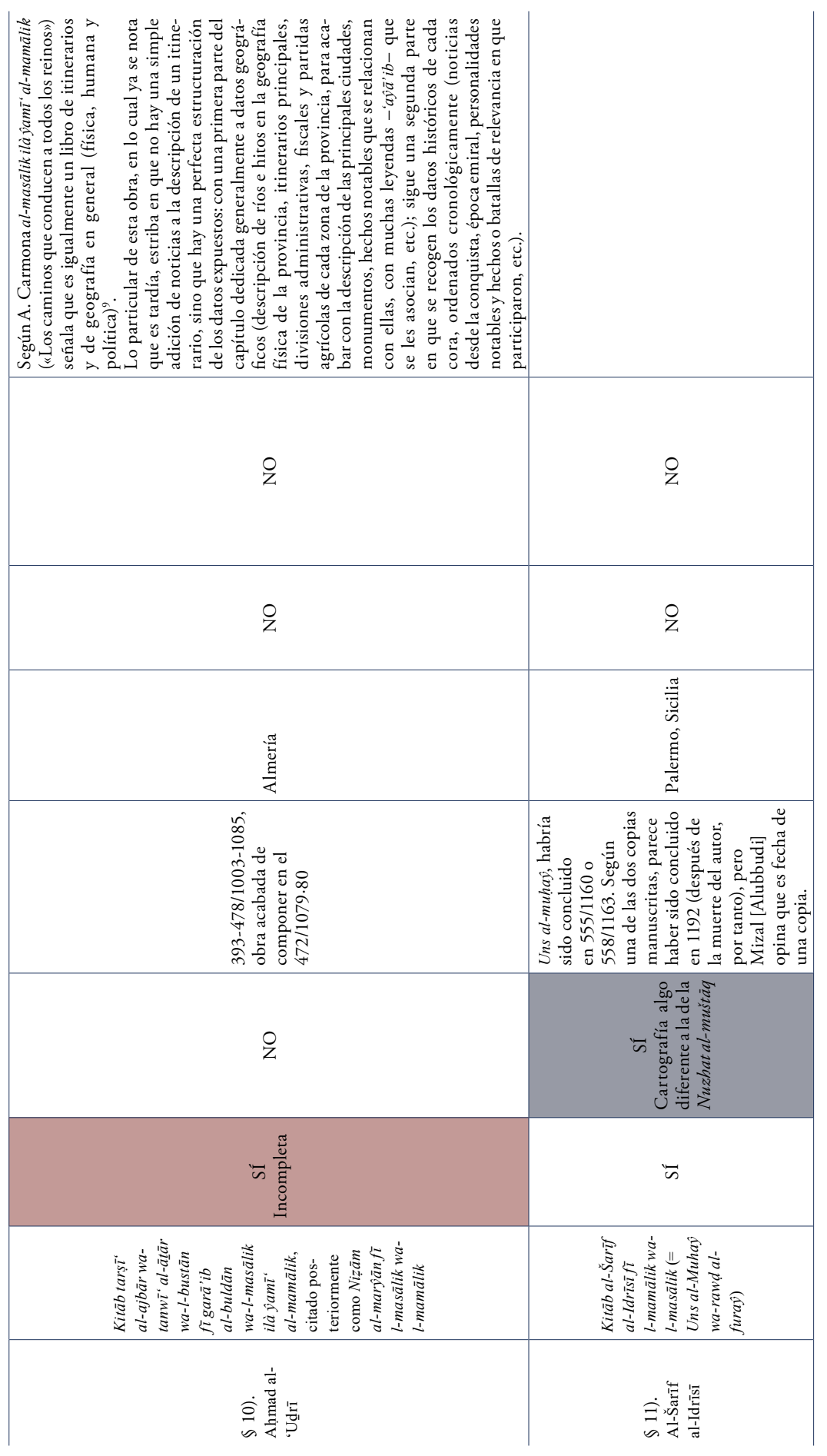




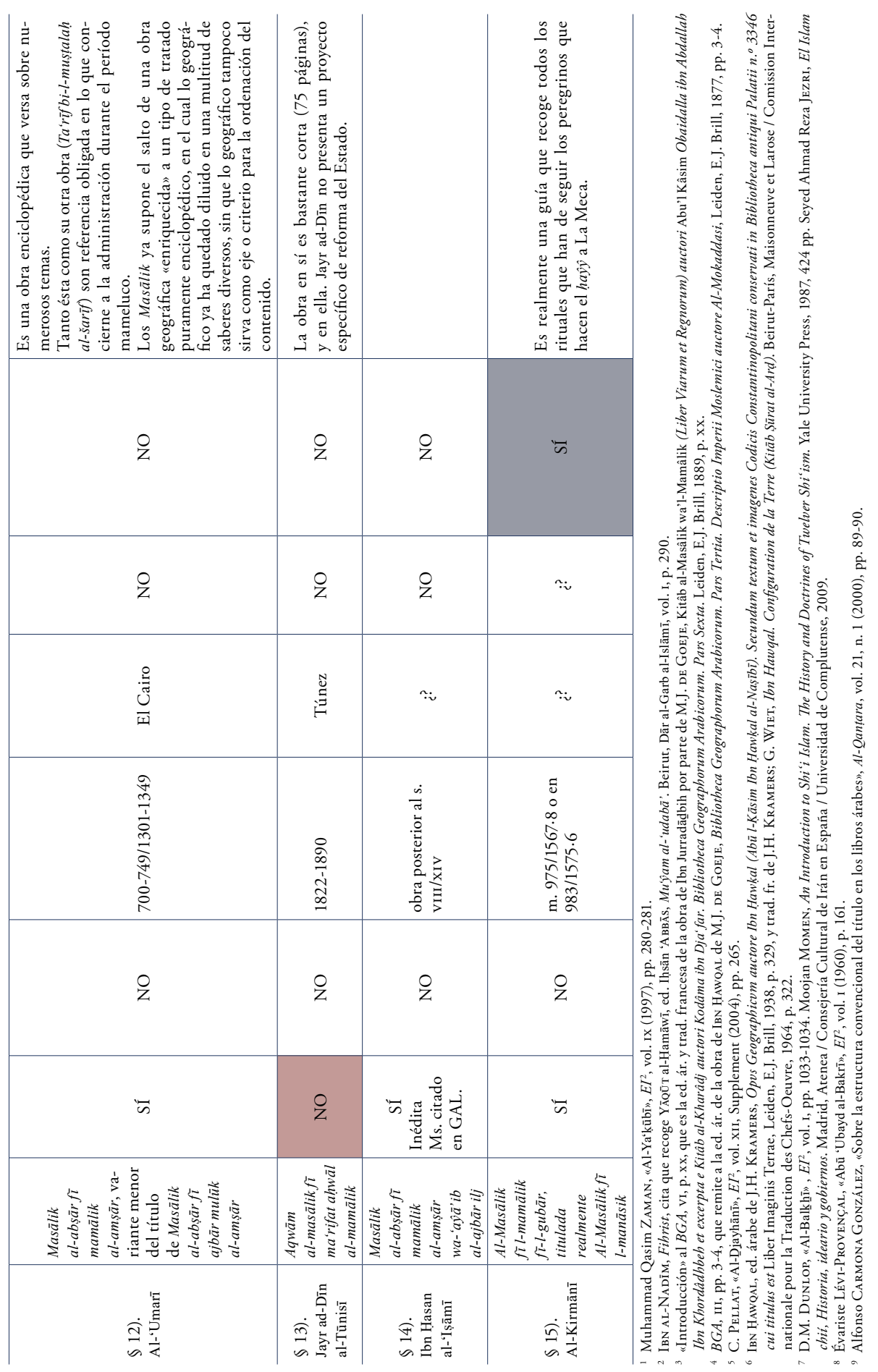

